\title{
European College of Veterinary Internal Medicine- Companion Animals
}

Oral Research Communications of the 20th ECVIM-CA Congress

Toulouse, France, 9 to 11 September 2010

Number Day

Time First Author

Presenting

Title

Last Name

Author

Last Name

ESVCP* - European Society of Veterinary Clinical Pathology

N.B. ABSTRACTS PUBLISHED ELSEWHERE

1 Thursday 9

September 2010

8:30 Hohneck

Spodsberg

Hohneck

Spodsberg

2 Thursday 9

September 2010

8:45 Dondi

Giunti

3 Thursday 9

September 2010

$4 \quad$ Thursday 9

September 2010

5 Thursday 9

September 2010

6 Thursday 9

September 2010

7 Thursday 9

September 2010

$8 \quad$ Thursday 9

September 2010

9 Thursday 9

September 2010

10 Thursday 9

September 2010

11 Thursday 9

September 2010
9:00 Liebenberg Liebenberg

9:15 Jaquith

Brown

9:30 Nielsen

Nielsen

9:45 Gaal

Gaal

10:35 Smets

10:50 Giori

Giori

11:05 Martin

Martin

11:20 Riond

11:35 Weber

Weber
THROMBOELASTOGRAPHIC MEASUREMENT OF ENDOGENOUS FIBRINOLYTIC POTENTIAL IN CANINE CITRATED WHOLE BLOOD FROM CLINICALLY HEALTHY DOGS

HEMOLYSIS AND HYPERCOAGULABLE STATE IN STANDARDBRED HORSES DURING A SHORT TERM HIGH SPEED COMPETITION

HYPERCOAGULABILITY IN UNCOMPLICATED CANINE BABESIOSIS CAUSED BY BABESIA ROSSI

EFFECTS OF DECREASED PLATELET CONCENTRATION ON CANINE THROMBOELASTOGRAPHY

PROLONGED APTT AND BREED SPECIFIC VARIATION IN HAEMOSTATIC ANALYTES IN HEALTHY ADULT BERNESE MOUNTAIN DOGS

BLOOD REDOX MARKERS IN DOGS WITH HYPERCREATININAEMIA

EFFECT OF SAMPLING METHOD AND STORAGE CONDITIONS ON ALBUMIN, RETINOL-BINDING PROTEIN AND N-ACETYL- $\beta$-D-GLUCOSAMINIDASE CONCENTRATIONS IN CANINE URINE SAMPLES

HIGH RESOLUTION GEL ELECTROPHORESIS ON URINE SAMPLES FOR QUALITATIVE ANALYSIS OF PROTEINURIA IN DOGS

DETERMINATION OF REFERENCE VALUES FOR PLASMA LEPTIN IN HEALTHY HORSES

EVALUATION OF THE HEMOCUE WBC POINT-OF-CARE DEVICE FOR USE IN CATS, DOGS, HORSES AND CATTLE

VALIDATION OF THE FULLY AUTOMATED HEMATOLOGY ANALYZER CELLTAC ALPHA WITH CANINE AND FELINE PATIENT SAMPLES 
12 Thursday $9 \quad$ 11:50 Lilliehook Lilliehook September 2010
FAILURE OF THE ADVIA 2120, SYSMEX XT-2000iV AND CELL-DYN 3500 TO DETECT CANINE BASOPHILS

\begin{tabular}{|c|c|c|c|}
\hline 13 & $\begin{array}{l}\text { Thursday } 9 \\
\text { September } 2010\end{array}$ & $9: 15$ & Kessler \\
\hline 14 & $\begin{array}{l}\text { Thursday } 9 \\
\text { September } 2010\end{array}$ & $9: 30$ & Peter \\
\hline
\end{tabular}

15 Thursday 9 September 2010

9:45 Hadzijusufovic Hadzijusufovic

16

Friday 10

September 2010

17

Friday 10

September 2010

18

Friday 10

September 2010

19

Friday 10

September 2010

$\begin{array}{ll}20 & \text { Friday } 10 \\ & \text { September } 2010\end{array}$

9:30 de Fornel-

Fornel-

Thibaud

$21 \quad$ Friday 10

September 2010

$22 \quad$ Friday 10

September 2010

23 Friday 10

September 2010
9:45 Kessler Kessler

10:35 Rivera Rivera

10:50 Benchekroun Benchekroun
ESVONC $^{\dagger}$ - European Society of Veterinary Oncology Thibaud

\section{N.B. ABSTRACTS PUBLISHED ELSEWHERE}

WORKPLACE CONTAMINATION WITH CYTOTOXIC DRUGS IN A VETERINARY HOSPITAL

POLO-LIKE KINASE-1 (PLK-1) AS A NOVEL DRUG TARGET IN CANINE AND HUMAN NEOPLASTIC MAST CELLS

NI-1: A NOVEL CANINE MAST CELL LINE WITH A UNIQUE KIT MUTATION AND RESISTANCE AGAINST MASATINIB

THE CYTOTOXIC EFFECT OF MASITINIB (MASIVET®) ON A CANINE LEUKEMIA CELL LINE DOES NOT RESULT FROM INHIBITION OF THE ABC-TRANSPORTERS P-GP AND MRP-1

THE USE OF TEMOZOLOMIDE AND DOXORUBICIN IN DOGS WITH MULTICENTRIC LYMPHOMA RESISTANT TO MULTIPLE STANDARD CHEMOTHERAPY PROTOCOLS

CANINE LYMPHOMA: MORPHOMETRIC ANALISYS OF CYTOLOGICAL SAMPLES

BONE MARROW EXAMINATIONS IN BERNESE MOUNTAIN DOGS WITH DISSEMINATED HISTIOCYTIC SARCOMA

USE OF INTERSTITIAL BRACHYTHERAPY (IRIDIUM192) FOR TREATMENT OF FIBROSARCOMAS IN CATS: 252 CASES (2000-2004)

PALLIATIVE RADIATION THERAPY IN 100 DOGS WITH APPENDICULAR OSTEOSARCOMA

IDENTIFICATION OF A RARE DOG LEUKOCYTE ANTIGEN CLASS II HAPLOTYPE AS A PROTECTIVE FACTOR AGAINST CANINE MAMMARY TUMORS

DIAGNOSTIC UTILITY OF HEART RATE AND BODY TEMPERATURE IN DOGS WITH PITUITARY MACROADENOMAS, INTRA AXIAL FOREBRAIN TUMORS OR PITUITARY MICROADENOMAS

ESFM - European Society of Feline Medicine

$\begin{array}{llrlr}24 & \begin{array}{l}\text { Thursday } 9 \\ \text { September } 2010\end{array} & \text { 13:30 } & \text { Adams } & \text { Adams } \\ 25 & \begin{array}{l}\text { Thursday } 9 \\ \text { September } 2010\end{array} & \text { 13:45 } & \text { Biermann } & \text { Biermann } \\ 26 & \begin{array}{l}\text { Thursday } 9 \\ \text { September } 2010\end{array} & \text { 14:00 Bennett } & \text { Bennett } \\ & & & \\ 27 & \begin{array}{l}\text { Thursday } 9 \\ \text { September } 2010\end{array} & 14: 15 \text { Korman } & \text { Korman }\end{array}$
ANTI-INSULIN ANTIBODIES IN INSULIN-TREATED AND UNTREATED DIABETIC CATS
HAEMATOLOGIC AND CARDIOVASCULAR EFFECTS OF FOUR INTRAMUSCULAR SEDATIVE DRUG COM- BINATIONS IN CATS
PREVALENCE OF BARTONELLA SPECIES, HEMOPLAS- MAS AND TOXOPLASMA GONDII IN CATS FROM SCOTLAND.

RETROSPECTIVE STUDY OF 178 CASES OF FELINE ANAEMIA 
Thursday 9

September 2010

29

Thursday 9

September 2010

30

Thursday 9

September 2010

31 Thursday 9

September 2010
14:30 Kuehner

Kuehner

15:00 Osto

15:15 Freiche
Osto

Freiche
Riviere

HISTORIC, CLINICAL, AND LABORATORY FEATURES IN CATS WITH FELINE INFECTIOUS PERITONITIS - A RETROSPECTIVE STUDY OF 186 CONFIRMED CASES $(2000-2007)$

THE KITTEN STRAW-COLORED ABDOMINAL FLUID: FIP OR PANLEUKOPENIA? ABOUT 31 CASES

SUBACUTE ENDOTOXEMIA ALTERS LIPID AND LIPOPROTEIN METABOLISM IN CATS

A PSYLLIUM-ENRICHED DRY EXTRUDED DIET IMPROVES RECURRENT FELINE CONSTIPATION

ESVNU - European Society of Veterinary Nephrology and Urology

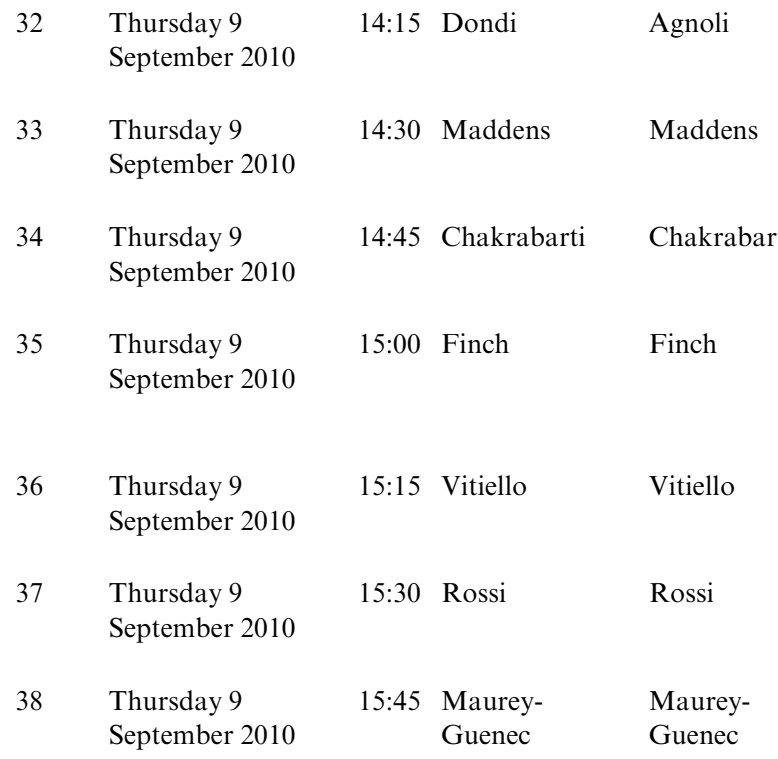

IRON PROFILE EVALUATION IN CHRONIC KIDNEY DISEASE: A RETROSPECTIVE STUDY OF 46 DOGS

PROTEINURIA, KIDNEY BIOPSY FINDINGS AND URINARY BIOMARKERS IN DOGS WITH PYOMETRA

RENAL ENDOTHELIN-1 EXPRESSION IN FELINE CHRONIC KIDNEY DISEASE

PREDICTION FORMULAE FOR FAT FREE MASS (FFM) AND ESTIMATED GLOMERULAR FILTRATION RATE (eGFR) IN CATS.

URINARY PARAMETERS: EVALUATION OF NEW KITS IN LIQUID CHEMISTRY IN DOGS AND CATS

ANALYTICAL VARIABILITY OF URINE PROTEIN-TOCREATININE RATIO DETERMINATION IN DOGS

MICROBIOLOGIC FINDINGS AND ANTIBIOTIC RESISTANCE TRENDS IN CANINE POPULATION-ACQUIRED FIRST URINARY TRACT INFECTIONS AT NATIONAL VETERINARY SCHOOL OF ALFORT: 543 CASES (20022007)

$39 \begin{aligned} & \text { Thursday } 9 \\ & \text { September } 2010\end{aligned}$

16:00 Dorsch Dorsch
$40 \quad$ Thursday 9
September 2010

16:15 Nickel

Nickel

$117 b$

Friday 10

September 2010

9:00 Klosterman Emily

$41 \quad$ Friday 10

September 2010

14:15 Rowlands Rowlands

$42 \quad$ Friday 10

September 2010

14:30 Höglund

Höglund

$43 \quad$ Friday 10

September 2010

14:45 Pelligand Pelligand

URINARY CONCENTRATIONS OF FIBRONECTIN AND TFF2 IN CATS WITH BACTERIAL URINARY TRACT INFECTION AND UROLITHIASIS

ASSESSMENT OF NORMAL AND ABNORMAL ANATOMY OF THE URETERO-VESICAL JUNCTION IN BRIARD DOGS BY ENFORCED DIURESIS B-FLOW SONOGRAPHY

CASE-CONTROL STUDY OF NEPHROTIC SYNDROME IN DOGS: 78 CASES

THE EFFECT OF BORIC ACID ON BACTERIAL CULTURE OF CAT AND DOG URINE SUBMITTED TO THE LABORATORY BY RAPID SERVICE POSTAL DELIVERY

ROUTINE CLINICAL EXAMINATION AFFECTS URINARY DENSITY AND $\mathrm{pH}$ IN HEALTHY DOGS OF DIFFERENT BREEDS

EFFECT OF ROBENACOXIB AND KETOPROFEN ON EXOGENOUS SERUM CREATININE CLEARANCE IN CONSCIOUS HEALTHY CATS 
VBPS - Veterinary Blood Pressure Society

$\begin{array}{llrlr}44 & \begin{array}{l}\text { Thursday } 9 \\ \text { September } 2010\end{array} & \text { 13:30 Höglund } & \text { Höglund } \\ 45 & \begin{array}{l}\text { Thursday } 9 \\ \text { September } 2010\end{array} & \text { 13:45 Wiberg } & \text { Wiberg } \\ 46 & \begin{array}{l}\text { Thursday } 9 \\ \text { September } 2010\end{array} & \text { 14:00 } & \text { Merveille } & \text { Merveille }\end{array}$

ESVIM/ISCAID - European Society of Veterinary Internal Medicine

$\begin{array}{llrll}47 & \begin{array}{l}\text { Friday 10 } \\ \text { September 2010 }\end{array} & 8: 30 & \text { Mylonakis } & \text { Mylonakis } \\ 48 & \begin{array}{l}\text { Friday 10 } \\ \text { September 2010 }\end{array} & 8: 45 & \text { Garden } & \text { Garden } \\ 49 \quad & \begin{array}{l}\text { Friday 10 } \\ \text { September 2010 }\end{array} & 9: 15 & \text { Nienhoff } & \text { Nienhoff } \\ & & & & \\ 50 & \begin{array}{l}\text { Friday 10 } \\ \text { September 2010 }\end{array} & 9: 30 & \text { Grellet } & \text { Grellet } \\ & \begin{array}{l}\text { Friday 10 } \\ \text { September 2010 }\end{array} & 9: 45 & \text { McClure } & \text { McClure }\end{array}$

$52 \quad$ Friday 10

September 2010

53 Friday 10

September 2010

Friday 10
September 2010

55

Friday 10

September 2010

56

Friday 10

September 2010

Friday 10

September 2010

58

Saturday 11

September 2010
BLOOD PRESSURE AND HEART RATE RESPONSES DURING DIFFERENT CLINICAL SITUATIONS IN HEALTHY DOGS OF FOUR BREEDS

INDIRECT BLOOD PRESSURE MEASUREMENT IN HEALTHY DOGS - COMPARISON OF THREE METHODS AND ASSESSMENT OF BREED AND STRESS LEVEL EFFECT ON SYSTOLIC ARTERIAL PRESSURE

EFFECT OF STRESS ON BLOOD PRESSURE MEASURED BY DOPPLER ULTRASONOGRAPHY AND HIGH DEFINITION OSCILLOMETRY IN A LARGE POPULATION OF WORKING DOGS

SERUM ACUTE PHASE PROTEINS IN NATURALLYOCCURRING CANINE MONOCYTIC EHRLICHIOSIS (EHRLICHIA CANIS)

OF MICE, MEN AND DOGS? A POPULATION OF CANINE CD4 + CD25HIGH FOXP3 + T CELLS EXHIBITS SUPPRESSIVE PROPERTIES IN VITRO

PREVALENCE OF METHICILLIN-RESISTANT STAPHYLOCOCCUS ISOLATES IN DOGS ATTENDING A GERMAN VETERINARY TEACHING HOSPITAL

EVALUATION OF CANINE CALPROTECTIN IN FECES FROM A LARGE GROUP OF PUPPIES

SERIAL C-REACTIVE PROTEIN CONCENTRATIONS AS A PREDICTOR OF OUTCOME IN PUPPIES INFECTED WITH PARVOVIRUS

10:35 Vanherberghen Vanherberghen

CYTOKINE EXPRESSION BY ASPERGILLUS FUMIGATUS STIMULATED PERIPHERAL BLOOD MONONUCLEAR CELLS FROM DOGS WITH SINO-NASAL ASPERGILLOSIS

CLINICAL, CLINICOPATHOLOGICAL AND RADIOGRAPHIC FEATURES AND OUTCOME OF ANGIOSTRONGYLOSIS IN DOGS FROM IRELAND

TOLL- AND NOD- LIKE RECEPTOR EXPRESSION IN CANINE SINO-NASAL ASPERGILLOSIS AND IDIOPATHIC LYMPHOPLASMACYTIC RHINITIS

PLASMA D-DIMERS AND SERUM FRUCTOSAMIN CONCENTRATIONS IN BEAGLES EXPERIMENTALLY INFECTED WITH ANGIOSTRONGYLUS VASORUM

EVALUATION OF THE EFFECT OF HAEMATOCRIT AND ACCURACY OF TWO POINT OF CARE GLUCOMETERS IN DOGS

NEXT GENERATION SEQUENCING AND TRANSCRIPTOME SUBTRACTION FOR VIRAL IDENTIFICATION IN CANINE TISSUE

EFFECT OF TRAINING ON CLINICAL AND BIOLOGICAL VALUES IN MILITARY DOGS 
59

Saturday 11

September 2010

60

Saturday 11

September 2010

61

Saturday 11

September 2010

62 Saturday 11

September 2010

63

Saturday 11

September 2010
8:45 Merveille Merveille

9:00 Krafft

9:15 Krafft

9:30 Heikkilä

Heikkilä

9:45 Heikkilä

PREVALENCE OF THE MUTATION RESPONSIBLE FOR PRIMARY CILIARY DYSKINESIA IN A LARGE POPULATION OF EUROPEAN AND AMERICAN OLD ENGLISH SHEEPDOGS

ENDOTHELIN-1 AS A SERUM BIOMARKER IN IDIOPATHIC PULMONARY FIBROSIS IN DOGS

IS TRANSFORMING GROWTH FACTOR- BETA 1 INVOLVED IN THE PATHOGENESIS OF IDIOPATHIC PULMONARY FIBROSIS IN DOGS?

PROCOLLAGEN TYPE III AMINO TERMINAL PROPEPTIDE CONCENTRATIONS IN DOGS WITH IDIOPATHIC PULMONARY FIBROSIS, CHRONIC BRONCHITIS AND EOSINOPHILIC BRONCHOPNEUMOPATHY

ARTERIAL BLOOD GAS ANALYSIS IN DOGS WITH IDIOPATHIC PULMONARY FIBROSIS

SONOGRAPHIC WHOLE BODY PARAMETERS OF PORTOSYSTEMIC SHUNTS IN 38 DOGS \& CATS

RETROSPECTIVE COMPARISON OF PREDNISONE AND URSODEOXYCHOLIC ACID FOR THE TREATMENT OF FELINE LYMPHOCYTIC CHOLANGITIS

AUTOANTIBODIES IN DOBERMAN HEPATITIS

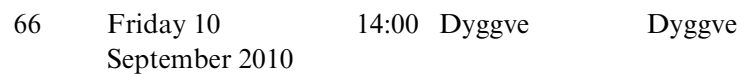

AUTOANTIBODIESIN DOBERMAN HEPATITIS

ESVC - European Society of Veterinary Cardiology

67

Friday 10

September 2010

68

Friday 10

September 2010

69

Friday 10

September 2010

$70 \quad$ Friday 10

September 2010

$71 \quad$ Friday 10

September 2010

$72 \quad$ Friday 10

September 2010

73

Friday 10

September 2010
13:30 Günther

Günther

13:45 Hezzell

Hezzell

14:00 Green

Green

14:15 Oyama

Oyama

14:30 Zois

Zois

14:45 Tidholm

Tidholm

15:35 Hezzell

Hezzell
INFLUENCE OF SAMPLE PREPARATION IN MEASUREMENT OF N-TERMINAL PRO-BRAIN NATIURETIC PEPTIDE (NT-PROBNP) IN CATS

THE EFFECT OF PROTEASE INHIBITION ON TEMPORAL STABILITY OF NT-proBNP IN FELINE PLASMA AT ROOM TEMPERATURE.

CHANGES IN PLASMA NT-PrOBRAIN NATRIURETIC PEPTIDE CONCENTRATION IN DOGS TREATED FOR CONGENITAL HEART DISEASE

NOVEL CIRCULATING BIOMARKERS IN DOGS AND CATS WITH HEART DISEASE

SERUM CYTOKINE CONCENTRATIONS IN DOGS WITH DIFFERENT DEGREE OF MYXOMATOUS MITRAL VALVE DISEASE

COMPARISONS OF THREE-DIMENSIONAL AND TWODIMENSIONAL ECHOCARDIOGRAPHIC METHODS IN ESTIMATING LEFT ATRIAL SIZE IN DOGS WITH AND WITHOUT MYXOMATOUS MITRAL VALVE DISEASE

RELATIONSHIPS BETWEEN SYSTOLIC BLOOD PRESSURE MEASUREMENT, ECHOCARDIOGRAPHIC VARIABLES AND OUTCOME IN DOGS WITH MITRAL VALVE DISEASE 
Friday 10

September 2010

76

Friday 10

September 2010

September 2010

Saturday 11

September 2010

Saturday 11

Saturday 11

Saturday 11

Saturday 11

September 2010

Saturday 11

September 2010

Saturday 11

September 2010

Saturday 11

Saturday 11

September 2010

Saturday 11

September 2010
16:05 Copeland

16:35 Margiocco

16:50 Misbach

16:20 Hoepfner

16:35 Atencia

16:50 Porciello

Porciello
Copeland

Payne

Margiocco

Misbach

Palermo

Dennis

Green

Rishniw

Ferasin

López-Alvarez

Wendt

Oliveira

Savarino

Hoepfner

Atencia
USE OF A SCORING SYSTEM FOR DILATED CARDIOMYOPATHY TO IDENTIFY BREED-SPECIFIC REFERENCE RANGES FOR ECHOCARDIOGRAPHY IN GREAT DANES

TRANSMITRAL FLOW VELOCITY PATTERNS AND SURVIVAL IN FELINE HYPERTROPHIC CARDIOMYOPATHY

PHARMACOKINETICS OF ORAL PIMOBENDAN IN HEALTHY CATS: A SINGLE DOSE STUDY

ECHOCARDIOGRAPHIC AND TISSUE DOPPLER IMAGING ALTERATIONS ASSOCIATED WITH SPONTANEOUS CANINE SYSTEMIC ARTERIAL HYPERTENSION

CARDIOMYOPATHY IN BOXER DOGS FROM THE UK: A COMPARISON BETWEEN THE ARRHYTHMIC AND THE MYOCARDIAL DYSFUNCTION FORM

EFFECT OF HIGH DOSE ASPIRIN ON SERUM THROMBOXANE B2 IN CATS WITH MYOCARDIAL DISEASE

CARDIAC HEALTH SCREENING IN 221 IRISH WOLFHOUND DOGS: THE NORTH AMERICAN EXPERIENCE

SLEEPING RESPIRATORY RATES IN DOGS AND CATS WITHOUT OBSERVABLE CARDIAC DISEASE

LACK OF ASSOCIATION BETWEEN CANINE BODY SIZE AND HEART RATE IN VETERINARY CLINICAL SETTINGS

APPLICATION OF ALLOMETRIC SCALING TO DETERMINE THE REFERENCE VALUES FOR THE M-MODE MEASUREMENTS IN DOBERMANNS

REPEATABILITY AND INTEROBSERVER VARIABILITY OF PULMONARY TRANSIT TIME (PTT, N-PTT) IN DOGS USING THE ECHOCARDIOGRAPHIC CONTRAST MEDIA SONOVUE®

RETROSPECTIVE REVIEW OF CONGENITAL HEART DEFECTS IN 976 DOGS

ECHOCARDIOGRAPHIC CHARACTERIZATION OF LEFT VENTRICULAR FALSE TENDONS IN A CAT POPULATION: A RETROSPECTIVE STUDY

LONGTERM OUTCOME OF DOGS WITH PULMONIC STENOSIS WITH AND WITHOUT BALLOON VALVULOPLASTY

THORACOSCOPIC PARTIAL PERICARDECTOMY FOR MANAGEMENT OF PERICARDIAL EFFUSION IN DOGS : 12 CASES

TRANSTHORACIC ULTRASOUND-GUIDED INTERVENTIONAL CARDIAC PROCEDURES IN THE DOG: A PRELIMINARY STUDY 
ESVE - European Society of Veterinary Endocrinology

\begin{tabular}{|c|c|c|c|c|}
\hline 91 & $\begin{array}{l}\text { Saturday } 11 \\
\text { September } 2010\end{array}$ & $13: 30$ & Gilor & Gilor \\
\hline 92 & $\begin{array}{l}\text { Saturday } 11 \\
\text { September } 2010\end{array}$ & $13: 45$ & Forcada & Forcada \\
\hline 93 & $\begin{array}{l}\text { Saturday } 11 \\
\text { September } 2010\end{array}$ & 14:00 & Zini & Zini \\
\hline 94 & $\begin{array}{l}\text { Saturday } 11 \\
\text { September } 2010\end{array}$ & $14: 15$ & Hafner & Hafner \\
\hline 95 & $\begin{array}{l}\text { Saturday } 11 \\
\text { September } 2010\end{array}$ & $14: 30$ & Fall & Fall \\
\hline 96 & $\begin{array}{l}\text { Saturday } 11 \\
\text { September } 2010\end{array}$ & $14: 45$ & Niessen & Niessen \\
\hline 98 & $\begin{array}{l}\text { Saturday } 11 \\
\text { September } 2010\end{array}$ & $15: 50$ & Smets & Smets \\
\hline 99 & $\begin{array}{l}\text { Saturday } 11 \\
\text { September } 2010\end{array}$ & $16: 05$ & Fracassi & Fracassi \\
\hline 100 & $\begin{array}{l}\text { Saturday } 11 \\
\text { September } 2010\end{array}$ & $16: 20$ & Galeandro & Galeandr \\
\hline
\end{tabular}

$\begin{array}{llrll}101 & \begin{array}{l}\text { Saturday 11 } \\ \text { September 2010 }\end{array} & \text { 16:35 } & \text { Braun } & \text { Braun } \\ 102 & \begin{array}{l}\text { Saturday 11 } \\ \text { September } 2010\end{array} & \text { 16:50 Fanini } & \text { Fanini }\end{array}$

ESCG - European Society of Comparative Gastroenterology

\begin{tabular}{|c|c|c|c|c|}
\hline 103 & $\begin{array}{l}\text { Saturday } 11 \\
\text { September } 2010\end{array}$ & $13: 30$ & Jergens & Suchodolski \\
\hline 104 & $\begin{array}{l}\text { Saturday } 11 \\
\text { September } 2010\end{array}$ & $13: 45$ & Burgener & Schnyder \\
\hline 105 & $\begin{array}{l}\text { Saturday } 11 \\
\text { September } 2010\end{array}$ & $14: 00$ & Belshaw & Belshaw \\
\hline 106 & $\begin{array}{l}\text { Saturday } 11 \\
\text { September } 2010\end{array}$ & $14: 15$ & Grützner & Grützner \\
\hline 107 & $\begin{array}{l}\text { Saturday } 11 \\
\text { September } 2010\end{array}$ & $14: 30$ & Grellet & Grellet \\
\hline
\end{tabular}
GLP-1 MIMETIC EXENATIDE POTENTIATES INSULIN
SECRETION IN HEALTHY CATS
A MISSENSE MUTATION IN THE CODING SEQUENCE OF MC4R (MC4R:C.92 C > T) IS ASSOCIATED WITH DIABETES MELLITUS IN DSH CATS
EARLY PREDICTORS OF CLINICAL REMISSION IN CATS WITH DIABETES MELLITUS

CONTINUOUS GLUCOSE MONITORING SYSTEM IN DIABETIC CATS: ASSESSMENT OF DIFFERENT SENSOR SITES.

REMISSION OF DICESTRUS DIABETES IN ELKHOUNDS IS PREDICTED BY GLUCOSE CONCENTRATIONS AT DIAGNOSIS AND BY TIME TO SURGERY FROM ONSET OF CLINICAL SIGNS
DIABETES MELLITUS AND EUTHANASIA: HOW OFTEN AND WHY?
GLOMERULAR AND TUBULAR MARKERS OF RENAL FUNCTION IN DIABETIC DOGS: COMPARISON TO HEALTHY DOGS AND FOLLOW-UP
USE OF INSULIN GLARGINE IN DOGS WITH DIABETES MELLITUS
EVALUATION OF FIVE IMMUNOASSAYS FOR MEA- SUREMENT OF URINARY CORTICOID CONCEN- TRATIONS IN DOGS IN COMPARISON WITH GAS CHROMATOGRAPHY-MASS SPECTROMETRY RE- SULTS

COMPARISON OF TWO DOSE RANGES OF TRILOSTANE FOR THE TREATMENT OF PITUITARY-DEPENDENT HYPERADRENOCORTICISM IN DOGS

EVALUATION OF SERUM FREE-THYROXINE CONCENTRATIONS DETERMINED BY CHEMILUMINESCENT ASSAY IN DOGS

INTERPLAY OF COMMENSAL BACTERIA, HOST GENE EXPRESSION, AND CLINICAL DISEASE ACTIVITY IN THE PATHOGENESIS OF CANINE INFLAMMATORY BOWEL DISEASE

DYSREGULATION OF TLR2 AND 4 IN DOGS WITH CHRONIC ENTEROPATHIES

SERUM THYMIDINE KINASE ACTIVITY IN CANINE INFLAMMATORY BOWEL DISEASE AND GASTROINTESTINAL LYMPHOMA

SEQUENCING OF THE INTRON REGION OF THE HAS 2 GENE IN COBALAMIN DEFICIENT CHINESE SHAR PEIS AND HEALTHY CONTROLS.

PREVALENCE OF TRITRICHOMONAS FOETUS IN PUPPIES FROM FRENCH BREEDING KENNELS 


$\begin{array}{llrlr}108 & \begin{array}{l}\text { Saturday 11 } \\ \text { September 2010 }\end{array} & \text { 14:45 } & \text { Unterer } & \text { Unterer } \\ 109 & \begin{array}{l}\text { Saturday 11 } \\ \text { September 2010 }\end{array} & \text { 15:35 } & \text { Mandigers } & \text { Mandigers } \\ 110 \quad & \begin{array}{l}\text { Saturday 11 } \\ \text { September 2010 }\end{array} & \text { 15:50 Lee } & \text { Lee } \\ 111 & \begin{array}{l}\text { Saturday 11 } \\ \text { September 2010 }\end{array} & \text { 16:05 } & \text { Ruhnke } & \text { Ruhnke } \\ & & & \end{array}$
TREATMENT OF HAEMORRHAGIC GASTROENTERITIS IN DOGS WITH AMOXICILLIN/CLAVULANIC ACID - A CLINICAL TREATMENT STUDY
A RANDOMISED POSITIVE-CONTROLLED FIELD TRIAL OF A HYDROLYSED PROTEIN DIET IN DOGS WITH CHRONIC ENTEROPATHY
CAPSULE ENDOSCOPY OF DOGS FOR SMALL BOWEL DIAGNOSTIC IMAGING
EVALUATION OF AN ADAPTER-MODIFIED USSING CHAMBER FOR ASSESSMENT OF ENDOSCOPICALLY OBTAINED COLONIC BIOPSIES FROM CATS AND DOGS

ESVCN - European Society of Clinical Nutrition

\begin{tabular}{|c|c|c|c|c|}
\hline 112 & $\begin{array}{l}\text { Saturday } 11 \\
\text { September } 2010\end{array}$ & $13: 30$ & Hahn & Hahn \\
\hline 113 & $\begin{array}{l}\text { Saturday } 11 \\
\text { September } 2010\end{array}$ & $13: 45$ & Leray & Leray \\
\hline 114 & $\begin{array}{l}\text { Saturday } 11 \\
\text { September } 2010\end{array}$ & $14: 00$ & German & German \\
\hline 115 & $\begin{array}{l}\text { Saturday } 11 \\
\text { September } 2010\end{array}$ & $14: 15$ & Jewell & Jewell \\
\hline 116 & $\begin{array}{l}\text { Saturday } 11 \\
\text { September } 2010\end{array}$ & $14: 30$ & Jewell & Jewell \\
\hline 117 & $\begin{array}{l}\text { Saturday } 11 \\
\text { September } 2010\end{array}$ & $14: 45$ & Houston & Houston \\
\hline
\end{tabular}
EFFECTIVENESS OF BCS FOR ESTIMATION OF IDEAL BODY WEIGHT AND ENERGY REQUIREMENTS IN OVERWEIGHT AND OBESE CATS COMPARED TO DXA
EFFECT OF DIRLOPATIDE ON FOOD INTAKE AND PLASMA SATIETY FACTORS IN OBESE DOGS
QUALITY OF LIFE IS REDUCED IN OBESE DOGS, BUT IMPROVES AFTER SUCCESSFUL WEIGHT LOSS
EFFECTS OF ADDED DIETARY ANTIOXIDANTS AND FATTY ACIDS ON CHANGES IN NEUTROPHIL BAC- TERIAL KILLING PERCENT AND NEUTROPHIL- RELATED GENE EXPRESSION IN DOGS
PROTEIN CONCENTRATIONS CONSISTENT WITH CON- TROLLED PROTEIN RENAL FOODS MAINTAIN LEAN BODY MASS AND HEALTH INDICES IN SENIOR DOGS
EFFICACY OF A DIET DESIGNED WITH A RELATIVE SUPER SATURATION $>1$ TO DISSOLVE STRUVITE STONES IN THE FELINE BLADDER.

*ESVCP Abstracts will be published in the December 2010 issue of Veterinary Clinical Pathology. DOI: 10.1111/j.1939-165X.2010.00273.x

${ }^{\dagger}$ ESVONC Abstracts will be published elsewhere. 
024 - ESFM - ADAMS

ANTI-INSULIN ANTIBODIES IN INSULIN-TREATED AND UNTREATED DIABETIC CATS. Jamie Adams, Brian Catchpole. Royal Veterinary College, NORTH MYMMS, United Kingdom

Treatment of diabetes mellitus in cats generally involves administration of exogenous insulin. The licensed insulin preparations in the UK are either of porcine (Caninsulin ${ }^{\mathbb{R}}$, Intervet ScheringPlough Animal Health, Milton Keynes, UK) or bovine origin (Insuvet ${ }^{\mathbb{R}}$ Lente \& Insuvet ${ }^{\mathbb{R}}$ PZI, Pfizer Animal Health, Sandwich, UK). Since both differ from feline insulin, treatment with either could stimulate an immune response. The aim of this study was to assess the prevalence of anti-insulin antibodies (AIA) in insulintreated diabetic cats, and to examine any difference in immunogenicity between insulin preparations. Newly diagnosed, untreated diabetic cats were also assessed for presence of insulin autoantibodies. Additionally, anti-protamine antibodies were investigated in cats treated with protamine zinc insulin.

Serum samples were collected from 150 insulin-treated diabetic cats (comprising 50 cats treated with Caninsulin, 50 cats treated with Insuvet Lente and 50 cats treated with Insuvet PZI) and 25 newly-diagnosed untreated diabetic cats. Serum samples from 50 non-diabetic cats were used as controls. Antibodies against porcine/ bovine insulin and protamine were determined by enzyme-linked immunosorbent assay (ELISA).

There was a significant difference $(\mathrm{p}<0.001)$ in AIA between the insulin-treated diabetic and control group. Serological reactivity was similar regardless of whether porcine or bovine insulin was used as the antigen in the ELISA. In total, 32 out of $150(21 \%)$ insulintreated diabetic cats demonstrated AIA. There was no significant difference in AIA prevalence between the treatment groups, with 16 of 50 cats receiving Caninsulin, 9 of 50 cats receiving Insuvet Lente, and 7 of 50 cats receiving Insuvet PZI demonstrating AIA. There was no significant difference between the control group and the newly-diagnosed untreated diabetic cat group, with only one AIA positive diabetic cat. There was no significant difference in antibody reactivity to protamine, comparing non-diabetic and diabetic cats and comparing the different treatment groups.

This study demonstrates a low prevalence of AIA amongst insulin-treated diabetic cats. Treatment using porcine insulin did not give a significantly higher prevalence of AIA than treatment with bovine insulin. Presence of insulin autoantibodies in newly diagnosed diabetic cats was not demonstrated. Treatment with protamine zinc insulin did not seem to stimulate anti-protamine antibodies, and in fact some control cats demonstrated antibodies against this protein, possibly as the result of exposure in the diet. The clinical significance of AIA remains unclear and further work is needed to investigate any role in diabetes management.

\section{5 - ESFM - BIERMANN}

HAEMATOLOGIC AND CARDIOVASCULAR EFFECTS OF FOUR INTRAMUSCULAR SEDATIVE DRUG COMBINATIONS IN CATS. Kirsten Biermann, Stephan Hungerbühler, Reinhard Mischke, Sabine Kästner. University of Veterinary Medicine Hannover, HANNOVER, Germany

In veterinary practice, cats may be more difficult to handle than dogs due to their species-specific behaviour. Therefore, certain diagnostic procedures may necessitate sedation. The aim of this study was to compare the effects of different combinations of butorphanol, midazolam, ketamine and dexmedetomidine on echocardiographic and haematologic parameters as well as recovery in cats.

Six healthy cats received each of the following treatments intramuscularly in a randomised, cross-over design with at least 8 day intervals: midazolam $0.4 \mathrm{mg} / \mathrm{kg}$ with butorphanol $0.4 \mathrm{mg} / \mathrm{kg}(\mathrm{MB})$ combined with ketamine $3 \mathrm{mg} / \mathrm{kg}$ (MBK) or dexmedetomidine $5 \mu \mathrm{g}$ / $\mathrm{kg}$ (MBD) or ketamine $3 \mathrm{mg} / \mathrm{kg}$ with dexmedetomidine $5 \mu \mathrm{g} / \mathrm{kg}$ (KD) alone. At 2, 4, 6, 8 and 10 minutes after injection sedation was scored on a numeric scale $(0-5)$ and the area under the curve (AUC) was calculated. Echocardiography and systolic arterial blood pressure (SAP) measurement (Doppler) were performed at baseline and 10 minutes after treatment. Recovery was videotaped and scored by one anaesthetist blinded to treatments using a numerical rating scale (0-14). Data are presented as mean $\pm \mathrm{SD}$ and were analysed by ANOVA for repeated measures and paired t-tests. Alpha was set at $5 \%$

Lowest sedation score was obtained by MB $(12.33 \pm 5.13)$, highest by KD $(39.00 \pm 4.00)$. Quality of recovery was best with KD $(0.67 \pm 0.8)$, worst with $\mathrm{MB}(7.33 \pm 2.3)$. Treatments decreased SAP by $17 \%, 25 \%, 13 \%, 5 \%$ in MB, MBK, MBD and KD, respectively. Heart rate decreased $(\mathrm{p}<0.05)$ after MBD $(44 \%)$ and KD $(34 \%)$. All treatments decreased stroke volume by $24 \%, 21 \%, 24 \%, 36 \%$ in MB, MBK, MBD and KD, and cardiac output by $23 \%, 34 \%, 54 \%$, $53 \%$, respectively. Packed cell volume was decreased $(\mathrm{p}<0.05)$ by $20 \%, 31 \%, 29 \%$ in MBK, MBD and KD, respectively. Glucose concentration was increased after MBD $(31 \%)$ and KD $(52 \%)$ and lactate concentration was decreased $(\mathrm{p}<0.05)$ after MBK $(58 \%)$, $\operatorname{MBD}(72 \%)$ and $\mathrm{KD}(65 \%)$.

Midazolam with butorphanol failed to produce adequate sedation and caused dysphoric behaviour making echocardiography more difficult. Both protocols with dexmedetomidine led to excellent sedation and recovery but more cardiovascular depression and haematologic changes.

\section{6- ESFM - BENNETT}

PREVALENCE OF BARTONELLA SPECIES, HEMOPLASMAS AND TOXOPLASMA GONDII IN CATS FROM SCOTLAND. A.D. Bennett ${ }^{1}$, D. Gunn-Moore ${ }^{2}$, M. Brewer ${ }^{2}$, A. Alberico ${ }^{2}$, M.R. Lappin ${ }^{2}{ }^{1}$ Colorado State University, FORT COLLINS, CO. ${ }^{2}$ Division of Veterinary Clinical Studies, University of Edinburgh, ROSLIN, United Kingdom

While Ctenocephalides felis infestations are common in the United Kingdom (UK), little is known about the prevalence rates for Bartonella spp. and haemotropic Mycoplasma spp., in Scotland. In addition, few studies of the Toxoplasma gondii seroprevalence have been published from this region. The purpose of this study is to determine the prevalence of Bartonella spp., haemoplasmas, and Toxoplasma gondii in client-owned and shelter cats in Scotland.

Blood, serum, and samples of the oral mucosa and nail beds were collected with institutional approval from cats that presented to the Hospital for Small Animals at the Royal (Dick) School of Veterinary Studies, University of Edinburgh, between June and August 2009. Samples were stored at $-20^{\circ} \mathrm{C}$ until being shipped on ice packs to Colorado State University. Total DNA was extracted from blood samples and swabs and assessed for total DNA by spectrophotometry and in conventional PCR assays that amplify the DNA of Bartonella spp., Mycoplasma haemofelis (Mhf), 'Candidatus M haemominutum' (Mhm), 'Candidatus M. turicensis' (Mtc), and GAPDH. In the haemoplasma PCR, both Mhf and Mtc give the same amplicon size which is sequenced to determine the infective species. Serology was used to detect antibodies against $\mathrm{T}$. gondii and Bartonella spp.. PCR results were reported only for cats with adequate total DNA or GAPDH.

Bartonella spp. antibodies were detected in 8 of 52 serum samples $(15.3 \%)$. Bartonella henselae DNA was amplified from 3 of 52 blood samples $(5.8 \%)$; each of these cats were also seropositive for Bartonella spp. IgG. Nail bed swabs $(\mathrm{n}=71)$ were negative for Bartonella spp. and haemoplasma DNA and oral mucosal swabs (n $=71$ ) were negative for Bartonella spp. DNA. Haemoplasma DNA was amplified from the blood of 12 of 63 blood samples $(19.0 \%)$. From blood, an amplicon consistent with $\mathrm{Mhf} / \mathrm{Mtc}$ DNA was detected in 4 cats, an amplicon consistent with Mhm DNA was detected in 6 cats, and both amplicons were detected in 2 cats. From oral swab samples, an amplicon consistent with Mhf/Mtc was detected in 1 cat and 4 cats had an amplicon consistent with $\mathrm{Mhf} / \mathrm{Mtc}$ One of the amplicons consistent with Mhf/Mtc has been sequenced to date and was shown to be Mhf. Of the 5 cats positive for haemoplasma DNA on oral swabs, blood results were available for 4 cats; 2 cats were also positive in blood. Toxoplasma gondii IgG alone (5 cats), IgM alone (4 cats), or both antibodies (1 cat) were detected in 10 of 53 samples $(18.7 \%)$

The results from this study indicate that Bartonella spp., haemoplasmas, and T. gondii infections are common in cats in this area of Scotland with prevalence rates for T. gondii and haemoplasmas being similar to other studies in the UK. The results emphasize the importance of the use of flea control products which may aid in blocking the spread of Bartonella spp. among cats. 
027- ESFM - KORMAN

RETROSPECTIVE STUDY OF 178 CASES OF FELINE ANAEMIA. Rachel Korman, Natasha Hetzel, Andrea Harvey, Séverine Tasker. University of Bristol, BRISTOL, United Kingdom

The aim of this study was to review historical and clinical factors, diagnosis and prognosis of anaemic cats that presented over a 7 year period.

One hundred and seventy-eight cats with a packed cell volume (PCV) or haematocrit (HCT) $<25 \%$ and complete medical records were identified. Signalment, history, physical examination, haematology, infectious disease status (feline leukaemia virus [FeLV], feline immunodeficiency virus [FIV], haemoplasma spp.), diagnosis and survival data were reviewed.

Age ranged from 0.25 to 15 years (median 5). Most cats (122 $[68.5 \%])$ were non-pedigree whilst $56(31.5 \%)$ were pedigree $(5.6 \%$ Persian and $5.6 \%$ Siamese). One hundred and five cats (58.9\%) were male and $73(41.1 \%)$ were female. Common historical findings were lethargy $(117$ cats; $65.7 \%)$, inappetance $(85 ; 47.8 \%)$ and weakness $(51 ; 28.7 \%)$. Pica was uncommon $(7 ; 3.9 \%)$. Common physical examination abnormalities were pallor $(85 ; 47.8 \%$ of cats), heart murmur $(52 ; 29.2 \%)$, jaundice $(30 ; 16.9 \%)$, pyrexia $(22 ; 12.4 \%)$ and abdominal pain $(11 ; 6.2 \%)$.

$\mathrm{PCV} / \mathrm{HCT}$ values had a mean \pm standard deviation (SD) of $16.7 \pm$ $5.9 \%$. Anaemia was very severe $(\mathrm{PCV} / \mathrm{HCT}<10.9 \%)$ in 35 $(19.7 \%)$ cats, severe (PCV/HCT $11-13.9 \%)$ in $22(12.4 \%)$, moderate (PCV/HCT $14-19.9 \%)$ in $55(30.9 \%)$ and mild (PCV/HCT 20 $24.9 \%$ ) in $66(37.1 \%)$. Cats were classified according to final diagnosis; infectious conditions were most common (45 cats; $25.3 \%$ ) followed by neoplasia $(40 ; 22.5 \%)$, vascular $(18 ; 10.1 \%)$, trauma $(18 ; 10.1 \%)$, metabolic $(17 ; 9.6 \%)$, inflammatory $(16 ; 9 \%)$, immunemediated $(16 ; 9 \%)$, anomalous $(5 ; 2.8 \%)$ and miscellaneous $(3$; $1.7 \%$ ) causes. Amongst the infectious group, feline infectious peritonitis was most common $(21 / 45$ cats; $46.8 \%)$ followed by miscellaneous infections $(10 ; 22.2 \%)$ and FeLV $(6 ; 13.3 \%)$. In the neoplastic group, myeloproliferative disease was most common (12/ 40 cats; $30 \%$ ) followed by unclassified neoplasia $(10 ; 25 \%)$ and lymphoma $(9 ; 22.5 \%)$. Anaemia severity was significantly different (Chi-squared, $\mathrm{P}=0.03$ ) between cats when classified according to diagnosis with the immune-mediated group having more severe anaemia. One hundred and seven cats $(60.1 \%)$ survived to discharge, $60(33.7 \%)$ were euthanased and $11(6.2 \%)$ died in hospital. The proportion of cats that survived to discharge was not significantly different (Chi-squared, $\mathrm{P}=0.54$ ) when grouped according to degree of anaemia [very severe; $18 / 35(51.4 \%)$, severe $12 / 22$ $(54.5 \%)$, moderate $36 / 55(65.5 \%)$ and mild $41 / 66(62.1 \%)]$, however was significantly different (Chi-squared, $\mathrm{P}=0.03$ ) between cats when classified according to diagnosis, with the immune-mediated group being more likely to survive to discharge.

In conclusion, anaemia arose most commonly due to infectious and neoplastic disease. The degree of anaemia did not affect initial outcome but cats with immune-mediated disease were most likely to have more severe anaemia and survive to discharge.

\section{8- ESFM - KUEHNER \\ HISTORIC, CLINICAL, AND LABORATORY FEATURES IN CATS WITH FELINE INFECTIOUS PERITONITIS - A RET- ROSPECTIVE STUDY OF 186 CONFIRMED CASES (2000- 2007). Kirsten Kuehner ${ }^{1}$, Friederike Riemer ${ }^{2}$, Katrin Hartmann ${ }^{2}$ ${ }^{1}$ Ludwig Maximilian University, MUNICH, Germany, ${ }^{2}$ Clinic of Small Animal Medicine, Ludwig Maximilian University,} MUNICH, Germany

Feline infectious peritonitis (FIP), an immune-mediated disease triggered by a mutated form of the ubiquitously occurring feline coronavirus $(\mathrm{FCoV})$, is one of the leading infectious causes of death among cats. As the proportion of cats presenting with "classical"manifestation of FIP is thought to have decreased in the past decades, the purpose of this study was to investigate historic, clinical, and laboratory features of FIP in a large number of recent, naturally occurring cases of FIP. The medical records of cats presented to the Clinic of Small Animal Medicine of the Ludwig Maximilian University of Munich, Germany, between January 2000 and March 2007 were evaluated retrospectively. Of these, 186 with FIP confirmed via histopathology $(n=162)$ or immunostaining of FCoV antigen in macrophages $(n=24)$ were included in the study. Signalment, history, clinical signs and laboratory parameters were analysed using SPSS 17.0 statistical software. Age, sex, and breed distribution of cats with FIP were compared with the clinic population between 2000 and 2007. A p-value $<0.05$ was considered statistically significant. As in previous studies, males were significantly more likely to be diagnosed with FIP $(\mathrm{p}<0.001)$. The age of infected cats ranged from 2 months to 19 years (median: 1 year) and young age was significantly associated with disease ( $\mathrm{p}<$ $0.001)$. Domestic cross-breed cats were commonly affected (155 $186)$ and among purebred cats, only Devon Rex cats were at an increased risk of disease $(p=0.010)$. Deaths from FIP were observed more frequently in fall and winter $(60 \%)$. In contrast to past studies, the majority of cats $(71 \%)$ lived in single- or two-cat households at the time of diagnosis and $25 \%$ had outdoor access. Similar to previous investigations, effusion was evident in $74 \%$ of cats with FIP. Lymphopenia and elevated serum protein was documented in only $50 \%$ and $15 \%$ of cats respectively, while hypoalbuminemia $(63 \%)$ and an albumin globulin ratio $<0.6(65 \%)$ was observed more commonly. Hyperbilirubinemia occurred significantly less frequently in cats with non-effusive FIP (45\%) compared to cats with effusive FIP $(68 \%)(p=0.018)$. Interestingly, at necropsy CNS involvement did not differ significantly between cats with and without effusion ( $17 \%$ and $20 \%$ respectively). This study indicates that history and clinical signs classically associated with FIP are not evident in a considerable percentage of confirmed cases. Non-effusive FIP was common. Although considered rare, nearly one-fifth of cats showed both effusion and granulomatous lesions.

\section{9- ESFM - RIVIERE}

\section{THE KITTEN STRAW-COLORED ABDOMINAL FLUID: FIP} OR PANLEUKOPENIA? ABOUT 31 CASES. Delphine Riviere, Corine Boucraut-Baralon. SCANELIS, COLOMIERS, France

Feline parvovirus (FPV) and feline coronavirus (FCoV) are two viruses responsible for feline panleukopenia and feline infectious peritonitis (FIP) respectively. The aim of this study was to demonstrate that feline panleukopenia has to be taken into account in the differential diagnosis of straw-colored abdominal fluids in kitten.

All the straw-colored abdominal fluids from kittens less than 12 months of age received at Scanelis Laboratory from September 2008 to December 2009 were submitted for quantitative real-time PCR testing for feline coronavirus and parvovirus. All the tested cats were clinically suspicious of FIP at the time of the analysis.

Thirty-one abdominal fluids were selected. The cats were aged from 2 to 10 months. Clinical signs were variable but all cats were dull and most of them presented digestive troubles (dysorexia, weight of loss, vomiting and diarrhoea or hemorrhagic diarrhoea). Additional clinical features included pyrexia or ataxia.

High parvovirus loads were detected by real-time PCR in 8 abdominal fluids ( $26 \%$ ), with 106 to 108 copies of target sequence per $\mathrm{mL}$ of fluid. For these same samples, the coronavirus loads were very low for 2 cats and below the limit of detection ( 37 copies of target sequence per analysis, limit of detection $95 \%$ ) for 6 cats. Eighteen abdominal fluids $(58 \%)$ were positive with high FCoV loads and FPV negative; 4 samples $(13 \%)$ were positive with high coronavirus loads and low parvovirus loads. One cat presented high FPV and FCoV loads ( 105 copies of target sequence $/ \mathrm{mL}$ for both viruses).

The association between a straw-colored, clear abdominal fluid and a particular epidemiological context (multi-cat environment, pedigree, adoption...) makes the hypothesis of an effusive FIP very likely. However, feline panleukopenia is able to mimic the clinical picture of FIP by the presence of a straw-colored abdominal fluid.

Furthermore, this study illustrates the interest of real-time PCR, which offers advantages over conventional PCR, especially the pathogen quantification. Indeed, a positive FCoV result, without any quantification, even if the clinical suspicion is very strong, is not synonymous with FIP. The RT-PCR detection of a very low coronavirus load in an abdominal fluid is not significant and makes the hypothesis of FIP very unlikely.

Feline panleukopenia virus is more frequent than it seems to be and has re-emerged as a major cause of mortality in cats in shelters. In our prospective study, $26 \%$ of color-strawed abdominal fluids observed in kittens were secondary to the FPV. All cats with an unknown vaccination history or an incomplete vaccine status are at risk and suspect. The real diagnosis is all the more important as the 
risk of contamination, treatments, prophylaxis and prognoses are different between FIP and panleukopenia.

\section{0- ESFM - OSTO}

SUBACUTE ENDOTOXEMIA ALTERS LIPID AND LIPOPROTEIN METABOLISM IN CATS. Melania Osto ${ }^{1}$, Eric Zini ${ }^{2}$, Marco Franchini ${ }^{3}$, Karin Kaufmann ${ }^{2}$, Michaela Hafner ${ }^{2}$, Mathias Ackermann $^{3}$, Claudia Reusch ${ }^{2}$, Thomas Lutz ${ }^{4}{ }^{1}$ Institute of Veterinary Physiology, ZURICH, Switzerland, ${ }^{2}$ Clin. Small Anim. Intern. Med., ZURICH, Switzerland, ${ }^{3}$ Inst. Virol., ZURICH, Switzerland, ${ }^{4}$ Inst. Vet. Physiol., ZURICH, Switzerland

In humans, infection and inflammation lead to changes in lipid and lipoprotein profile comparable to those observed in obesity and type 2 diabetes. Hypertriglyceridemia, low levels of high-density lipoprotein (HDL) cholesterol and increased small, dense low-density lipoprotein (LDL) are typical features of dyslipidemia and contribute to insulin resistance in the human metabolic syndrome. Obese cats and humans present with similar lipid and lipoprotein profiles. We hypothesized that subacute lipopolysaccharide (LPS)induced inflammation might be sufficient to induce similar changes in lipid metabolism in cats

Healthy cats were infused IV with increasing doses (10-1000 ng/ $\mathrm{kg} / \mathrm{h})$ of LPS $(\mathrm{n}=5)$ or saline $(\mathrm{n}=5)$ for 10 days. Fasting plasma cortisol, triglycerides (TG) and non-esterified fatty acids (NEFA) were measured daily. On day 10 , total lipoprotein and its fractions were quantified, and levels of $\alpha 1$-acid glycoprotein (AGP), serum amyloid A (SAA) and $\beta$-hydroxybutyrate (BHB) were measured. Samples from subcutaneous and omental fat were collected and processed for gene, protein and activity levels of hormone-sensitive lipase (HSL) and for the lipid droplet-associated protein perilipin. Results were compared with non parametric tests.

In response to LPS, plasma TG and cortisol sharply increased on day 1 and then rapidly decreased to baseline levels. Fasting NEFA and BHB levels were similar to controls. On day 10, LPS-infused cats had increased circulating levels of AGP and SAA, and lower plasma concentration of phospholipids, total and esterified cholesterol compared to controls; HDL and HDL-cholesterol (free and esterified) were also reduced. Following LPS, HSL activity and protein expression were increased in adipose tissues. The size of adipocytes and mRNA expression of perilipin were reduced in visceral and subcutaneous fat.

PS-infusion in cats induced low-grade inflammation and activated lipolysis in adipose tissue. This was accompanied by changes in the lipid and lipoprotein profile which partly resemble those associated with insulin resistance in the human metabolic syndrome. The acute-phase response to a subacute endotoxemia was sufficient to produce dyslipidemia in cats.

031- ESFM - FREICHE

A PSYLLIUM-ENRICHED DRY EXTRUDED DIET IMPROVES RECURRENT FELINE CONSTIPATION. Valérie Freiche $^{1}$, Geraldine Deswarte ${ }^{2}$, Yannick Soulard ${ }^{2}$, Vincent Biourge $^{2}$. ${ }^{1}$ Clinique Vétérinaire Alliance, BORDEAUX, France, ${ }^{2}$ Royal Canin, AIMARGUES, France

The dietary management of constipation in cats is either based on high fiber diets (total dietary fiber $>20 \%$ as fed basis) or on highly digestible diets supplemented with various soluble fiber. High levels of insoluble fibers, such as cellulose might not be as efficient in chronic feline constipation and could even worsen the clinical signs. Soluble fiber supplementation on highly digestible diets is not convenient especially on dry diets. The objective of this study was thus to assess the efficacy of a moderate fiber, psyllium-enriched, dry extruded feline diet on recurrent feline constipation.

Fourteen neutered cats ( 8 females and 7 males) and 1 intact male, age $43 \pm 36$ months were presented to a referral gastroenterology consultation for recurrent constipation ( $>1$ episode and clinical signs $>2$ wks). Causes of constipation were variable (pelvic fracture malunion, pelvic canal stenosis, idiopathic megacolon) and refractory to usual medical and dietary management by the referring veterinarian. One cat had a rectal prolapse associated to the constipation. Following clinical examination and in more severe cases complete cell counts, biochemistry and colonic lavage, owners were instructed to feed a moderate fiber, psyllium-enriched, dry extruded diet (Protein $31 \%$, Fat $15 \%$, Carbohydrate $27.7 \%$, Total dietary fiber $11.5 \%$, Minerals $7.8 \% ; 4042 \mathrm{Kcal} \mathrm{ME} / \mathrm{kg}$ as fed, Fibre response, Feline Veterinary Diet, Royal Canin, Aimargues, France). Fecal score (1 liquid diarrhea - 5 dry hard feces), frequency and ease of defecation as observed by the owner and body weight were re-evaluated 1 and 2 months after the dietary change. Owners were also asked to give a general satisfaction score on a scale from 1-10 on the efficacy of the diet on the constipation signs. Results are expressed as a mean $\pm \mathrm{SD}$. The protocol has been reviewed and accepted by Royal Canin ethical committee.

At the time of examination, 10/15 cats were bright and alert, and able to pass small dry feces. The 5 remaining cases were more severe, undertook fluids and electrolytes therapy as well as colonic lavages. All cats ate their prescribed diet readily. After 1month on the diet, 14/ 15 cats did defecate normally and show no clinical signs. Improvement was visible within 7 days on the diet in 10/15 cats. After 2 months on the diet, no recurrence of constipation was observed in all 15 cases. Mean fecal score was 3,5 $\pm 0,7$ Body weight increased from $3,94 \pm 0,73$ to $4,12 \pm 0,71 \mathrm{~kg}$. No other medication or laxatives were used over the 2 months. Overall owner satisfaction was $8.5 \pm 1.0 / 10$.

Despite its moderate level of fiber, the psyllium-enriched, dry extruded diet used in this pilot study appears efficient in the management of recurrent feline constipation and might be a better therapeutic strategy to recurrent colonic lavages.

\section{2- ESVNU - AGNOLI}

IRON PROFILE EVALUATION IN CHRONIC KIDNEY DISEASE: A RETROSPECTIVE STUDY OF 46 DOGS. Francesco Dondi ${ }^{1}$, Robert Mihai Lukacs ${ }^{2}$, Chiara Agnoli ${ }^{3}$, Massimo Giunti ${ }^{2}$, Luisa Conti $^{2}$, Gloria Isani ${ }^{2}$, Emilio Carpené ${ }^{2}$. ${ }^{1}$ Alma Mater Sturiorum - University of Bologna, OZZANO DELL'EMILIA, BOLOGNA, Italy, ${ }^{2}$ Dipartimento Clinico Veterinario - Alma Mater Studiorum - University of Bologna, OZZANO DELL'EMILIA, BOLOGNA, Italy, ${ }^{3}$ Clinica Veterinaria "M.E. Miller", CAVRIAGO, REGGIO EMILIA, Italy

The evaluation of iron metabolism in course of chronic kidney disease (CKD) is justified by the still growing number of studies in humans. Similar reports in veterinary patients are rare or completely missing. The aim of this study was the evaluation of the Iron Status in canine patients affected by CKD, and the assessment of a potential correlation between iron homeostasis, progression of the $\mathrm{CKD}$, and presence of an acute phase response (APR).

The medical records of dogs, referred for a nephrological evaluation from January 2007 to December 2009, were analyzed. Fortysix dogs with CKD were selected and compared with healthy dogs $(\mathrm{n}=28)$. Considering a cut-off hematocrit value $(\mathrm{HCT})$ of $35 \%$, CKD dogs were afterwards divided in 2 groups defined as "anemic"and "non-anemic". Based on the International Renal Interest Society (IRIS) guidelines, CKD dogs were further divided in stage II, III and IV. Iron Status was assessed by the evaluation of Total Iron, Ferritin, Total Iron Binding Capacity (TIBC), TIBC-saturation $\%$, and haematological parameters together with an acute phase proteins profile comprehensive of C-reactive Protein (CRP), Haptoglobin (Hp), and Albumin (Alb). CRP, Hp and Ferritin were measured using immunoturbidimetric methods. The Urinary Protein to Creatinine ratio (UPC) was also evaluated.

Iron deficiency in the CKD dogs was defined by the presence of at least one of the following: hypoferremia, hypoferritinemia, increased TIBC, and decreased TIBC-saturation. Thus a prevalence of iron deficiency of $43 \%(20 / 46)$ was achieved. The concomitant presence of the 4 cited abnormalities was detected in the $2 \%$ of dogs (1/46). Considering hypoferritinemia as a more specific estimation of iron deficiency, the prevalence gets to $11 \%(5 / 46)$. These findings suggest that iron abnormalities are common in CKD patients. A concurrent APR was detected in 36/46 dogs, potentially affecting the Iron Status. Indeed, Ferritin concentrations were higher in the CKD dogs than in healthy ones, while Total Iron and TIBC-saturation \% were lower. In our population, "anemic"dogs presented lower Total Iron and negative APP concentrations compared to the "nonanemic"ones, with UPC not different between groups. No significant differences in the iron profile were detected between IRIS stages.

Further studies in a wider population of dogs with CKD, evaluating the prognostic role of iron profile and its potential impact on treatment strategies, are warranted. 
033- ESVNU - MADDENS

PROTEINURIA, KIDNEY BIOPSY FINDINGS AND URINARY BIOMARKERS IN DOGS WITH PYOMETRA. Bert Maddens, Reidun Heiene ${ }^{2}$, Sylvie Daminet ${ }^{1}$, Pascale Smets ${ }^{1}$, Marika Svensson ${ }^{3}$, Jaco van der Lugt ${ }^{4}$, Evelyne Meyer ${ }^{1} .{ }^{1}$ Ghent University, MERELBEKE, Belgium, ${ }^{2}$ School of Veterinary Science, OSLO, Norway, ${ }^{3}$ Blue Star Animal Hospital, GÖTEBORG, Sweden, ${ }^{4}$ Faculty of Veterinary Medicine, UTRECHT, The Netherlands

Renal dysfunction in dogs with pyometra $(\mathrm{P})$ has been described to have an immune-mediated origin and a mild, transient character. However, some P dogs develop permanent substantial proteinuria This study aims to determine the proportion of proteinuric dogs, to evaluate the related renal histomorphology and to characterize the kidney injury in P dogs by use of UPC, kidney biopsy findings and urinary glomerular and tubular biomarkers.

Forty-seven $\mathrm{P}$ dogs without concurrent diseases were included, as well as 10 clinically healthy bitches $(\mathrm{H})$ of comparable age. Analyses of blood, urine and uterine swabs showed that the P dogs were similar to $\mathrm{P}$ dogs of previously published studies. Ten $\mathrm{P}$ dogs with dipstick urine protein $2+$ or $3+$ were prospectively included for kidney biopsy during ovariohysterectomy (10/47). Validated immunoassays were used to quantify the urinary biomarkers for glomerular function, immunoglobulin $\mathrm{G}(\mathrm{uIgG})$, C-reactive protein (uCRP), albumin (uAlb) and thromboxane $\mathrm{B}_{2}\left(\mathrm{uTXB}_{2}\right)$; and for tubular function, retinol-binding protein (uRBP) and N-acetyl- $\mathrm{B}$-Dglucosaminidase (uNAG)

UPC was significantly higher in the group of $47 \mathrm{P}$ dogs (median, range: $0.48,0.05-8.69)$ than in the group of $\mathrm{H}$ bitches $(0.08,0.02$ $0.16)(\mathrm{p}<0.01)$. Twelve $\mathrm{P}$ dogs had UPC $>1.0$, of which 7 had UPC $>2.0$. Light microscopic, immunofluorescence and electron microscopic examination of the kidney biopsies revealed glomerulosclerosis in $6 / 10 \mathrm{P}$ dogs, all 6 had UPC $>1.0$, with lesions resembling focal segmental glomerulosclerosis in $4 / 10$. Tubular atrophy was reported in 5/10 P dogs, as well as interstitial fibrosis (4/ $10)$ and interstitial inflammation $(7 / 10)$. Three $P$ dogs had no histological abnormalities $(3 / 10)$; all 3 had UPC $<0.5$. Dogs with the highest UPCs had the most severe histological lesions. Concentrations of all urinary biomarkers were significantly increased in the group of $47 \mathrm{P}$ dogs compared to the $\mathrm{H}$ dogs $(\mathrm{p}<0.01)$. Furthermore, all biopsied $\mathrm{P}$ dogs with concentrations of urinary biomarkers above the respective $75^{\text {th }}$ percentiles had histological changes.

In conclusion, no evidence for immune-mediated glomerulonephritis was found in this study. Although the majority of the P dogs had UPC $<0.5$, approximately $15 \%$ of the P dogs had UPC $>2.0$, which was related to glomerular abnormalities and might provide indication for monitoring. Finally, kidney biopsies in $\mathrm{P}$ dogs with UPC $>1.0$ or high concentrations of urinary biomarkers revealed glomerulosclerosis and tubulointerstitial nephritis.

\section{4- ESVNU - CHAKRABARTI}

\section{RENAL ENDOTHELIN-1 EXPRESSION IN FELINE}

CHRONIC KIDNEY DISEASE. Shubhro Chakrabarti, Harriet Syme, Cathy Brown, Jonathan Elliott. LONDON, United Kingdom

Chronic Kidney Disease (CKD) is common in geriatric cats with most cases demonstrating lesions of idiopathic tubulointerstitial fibrosis upon histopathological examination. Renal mRNA expression of the profibrotic mediator, Endothelin-1 (ET-1), is increased in cats with CKD and the corresponding protein expression is localised mainly to the tubules. The aim of this study was to identify histopathological correlates of renal tubular ET1 expression in cats with CKD.

Formalin-fixed renal tissues were obtained at post-mortem examination from cats which attended two first opinion practices between 1996 and 2008. The diagnosis of CKD was based on concurrent findings of azotaemia (plasma creatinine concentration greater than $177 \mu \mathrm{mol} / \mathrm{l}$ ) and urine specific gravity less than 1.035 , with persistence of azotaemia or compatible history and clinical signs. Only cases which had plasma creatinine concentration measured within 60 days of death, were included in the study. All cases with a history of hyperthyroidism were excluded. Sections of kidney tissue were stained using a validated immunohistochemical tech- nique and scored for the intensity of tubular ET-1 staining. The same tissues were scored by a renal pathologist for the severity of interstitial fibrosis, interstitial inflammation and glomerulosclerosis all assessed on a scale of $0-3$. For glomerular scores, 25 glomeruli were scored individually with the mean glomerulosclerosis score, mean glomerular volume, number of glomeruli per unit area and obsolescence index recorded. Both assessors were masked to clinical data. Associations between tubular ET-1 scores and histopathological variables were evaluated using the Spearman's rank correlation coefficient.

Thirty-six cases met the criteria for inclusion in the study. The tubular ET-1 intensity score was not associated with plasma creatinine concentration at final blood sample $(\mathrm{p}=0.90, \mathrm{n}=36)$, mean glomerular score $(\mathrm{p}=0.43, \mathrm{n}=36)$, mean glomerular volume $(\mathrm{p}=$ $0.10, \mathrm{n}=33)$, number of glomeruli per unit area $(\mathrm{p}=0.27, \mathrm{n}=17)$ or obsolescence index $(\mathrm{p}=0.29, \mathrm{n}=33)$, but was moderately correlated with interstitial fibrosis $(\mathrm{r}=0.37, \mathrm{p}=0.03, \mathrm{n}=36)$ and interstitial inflammation scores $(r=0.41, p=0.01, n=36)$.

The results of this study suggest renal tubular ET-1 expression is associated with tubulointerstitial inflammation and fibrosis but not glomerular pathology. ET-1 may, therefore, serve as a novel therapeutic target in cats with CKD.

\section{5- ESVNU - FINCH}

PREDICTION FORMULAE FOR FAT FREE MASS (FFM) AND ESTIMATED GLOMERULAR FILTRATION RATE (eGFR) IN CATS. Natalie Finch, David Brodbelt, Harriet Syme, Jonathan Elliott. Royal Veterinary College, LONDON, United Kingdom

In human patients estimated Glomerular Filtration Rate (eGFR) is determined using prediction equations which include serum creatinine and variables such as age, gender and race. These variables may influence kidney function however they are also predictors of muscle mass. The aim of the present study was to explore if signalment, plasma variables and variables which predict Fat Free Mass (FFM) explained variation in GFR over and above that of plasma creatinine concentration [creat $]_{\mathrm{p}}$ alone.

Fifty-five cats were recruited into the study for development of the FFM and eGFR prediction formulae. GFR was measured using a corrected slope-intercept iohexol clearance method. FFM was determined using an Oxygen-18 $\left({ }^{18} \mathrm{O}\right)$ dilution technique. Variables including signalment, zoometric measurements, bodyweight (BW), body condition score (BCS) and plasma variables were entered into a multivariable linear regression model to predict FFM. These variables with the addition of the FFM prediction formula were subsequently entered into a multivariable regression model containing the reciprocal of creatinine $[\mathrm{creat}]_{\mathrm{p}}^{-1}$ to predict eGFR. [creat $]_{\mathrm{p}}^{-1}$ was selected as it displayed a more linear relationship to GFR than $[\text { creat }]_{\mathrm{p}}$. Model assumptions and performance were evaluated by examining mulitcollinearity, standardised residuals, Cook's distances, leverage values and by performing the Durbin-Watson test. Once the formula was derived it was tested with the data from an additional 25 cats. Statistical significance was set at $P<0.05$.

The median (range) of [creat $]_{\mathrm{p}}$ and FFM:BW for the 55 cats in which the formulae were developed were 145.8 (91.4-357.9) $\mu \mathrm{mol} / \mathrm{l}$ and $71(53-83) \%$ respectively. The derived prediction formula for FFM was: $-0.164+(0.41 \times \mathrm{BW}(\mathrm{kg}))+(0.054 \times$ scapula height $(\mathrm{cm}))+(0.098 \times$ right forelimb circumference $(\mathrm{cm}))-(0.028$ $\times$ pelvic height $(\mathrm{cm})),\left(R^{2}=0.87, P<0.001\right)$. Variables describing signalment and plasma parameters were not significant in the multivariable regression model to predict GFR. FFM estimated using the derived formula was also not significant in the model. Only a single zoometric measurement variable remained signficant in the model with $\left[\mathrm{creat}_{\mathrm{p}}^{-1}\right.$. The derived eGFR formula was: $0.408+$ $\left(243.11 \times\left[\right.\right.$ creat $\left._{\mathrm{p}}^{-1}\right)-(0.014 \times$ pelvic circumference $(\mathrm{cm})),\left(R^{2}=\right.$ $0.64, P<0.001)$. The model explained additional variation over [creat $]_{\mathrm{p}}^{-1}$ alone, $R^{2}=0.61, P<0.001$. However when the eGFR formula was tested on the additonal 25 cats it showed no advantage over $[\text { creat }]_{\mathrm{p}}^{-1}\left(\mathrm{eGFR} R^{2}=0.44, P<0.001\right.$ vs $[\text { creat }]_{\mathrm{p}}^{-1} R^{2}=0.45, P$ $<0.001)$.

This study has derived a useful and accurate predictor for FFM in cats. However, inclusion of FFM did not improve prediction of GFR. A larger scale study may identify further variables allowing a more precise eGFR formula to be developed in cats. 
036- ESVNU - VITIELLO

URINARY PARAMETERS: EVALUATION OF NEW KITS IN LIQUID CHEMISTRY IN DOGS AND CATS. Tiziana Vitiello. University of Milan, Italy, MILAN, Italy

Urinary dipsticks have limits of applicability in dogs and cats, and new methods for quantitative assays of urinary parameters are necessary. In this study we tested new human kits for the assessment of specific gravity (USG), $\mathrm{pH}$, nitrite, protein, glucose, ketones, and bilirubin in urine of dogs and cats. Urine samples ( $84 \mathrm{dogs}, 47 \mathrm{cats})$ were analysed: USG by refractometer and $\mathrm{pH}$ by bench $\mathrm{pH}-$ meter; USG, $\mathrm{pH}$, nitrite, protein, glucose, ketones and bilirubin by Combur Test ${ }^{\mathbb{R}}$. The same parameters were detected with liquid chemistry method (LCM) using human kits (BEN Biochemical Enterprise, Milan) by automated spectrophotometer Cobas Mira ${ }^{\circledR}$. Linearity and repeatability tests were applied. Statistic analysis was performed by JMP7 (SAS Inc.).

$\mathrm{pH}$ : LCM (range 5-10) showed a good correlation with $\mathrm{pH}$-meter ( $\rho>0,97$ in dog and $\rho>0,98$ in cat), except for samples with $\mathrm{pH}$ below 5.5. Nitrite: LCM presents good repeatability and linearity. Since the known unreliability of nitrite pad in dogs and cats (high false negative), we compared nitrite levels with the bacteriuria by microscopic examination of sediments. LCM nitrites were found in all samples; statistical analysis didn't evidence a significant relationship between nitrite level and presence of bacteria, except for a significant positive trend in presence of rods in dog's urines ( $p=$ 0.01 ). These observations could support that urinary nitrites don't result only from the bacterial metabolism but also from the endogenous catabolism of nitric oxide, as well as in humans. Urinary protein: LCM based on pyrogallol red, is already widely used in veterinary medicine. Glucose: LCM had good repeatability and linearity, however they were influenced by ketones. Spearman's correlation of the LCM with dipstick results were not satisfactory due to the high sensitivity of LCM which allows an earlier detection of glycosuria. Ketones: excellent linearity and repeteability were assessed. Comparison between LCM and dipstick resultes weren't performed because the low number of ketonuric samples. Bilirubin: showed good repeatability and linearity. Furthermore, in our study a significant difference between LCM bilirubin and semiquantitative ranges identified by dipstick in urine of dogs was founded $(\mathrm{p}=$ $0.0003)$. We pointed out the occurrence of false negative results using the dry chemistry. False negatives are documented in human urine samples containing nitrites and ascorbic acid. USG: LCM kit has a range set for human being; this assumption limits its use in small animals. Moreover, the kit turned out to have a poor reliability compared with values detected by refractometer also for values of USG within the range kit.

Except for USG, all LCM kits showed reliable results and they could be introduced into routine laboratory analysis after having established reference values in healthy subjects.

037- ESVNU - ROSSI

ANALYTICAL VARIABILITY OF URINE PROTEIN-TOCREATININE RATIO DETERMINATION IN DOGS. Gabriele Rossi $^{1}$, Luca Giori ${ }^{1}$, Simona Campagnola ${ }^{1}$, Andrea Zatelli ${ }^{2}$, Eric $\mathrm{Zini}^{3}$, Saverio Paltrinieri ${ }^{1} .{ }^{1}$ University of Milan, MILANO, Italy, ${ }^{2}$ Clinica Veterinaria Pirani, REGGIO EMILIA, Italy, ${ }^{3}$ Clinic for Small Animal Internal Medicine - University of Zurich, ZURICH, Switzerland

Levels of renal proteinuria affect morbidity and mortality in dogs. Determination of urine protein-to-creatinine (UPC) ratio is widely used to classify dogs as proteinuric $(\mathrm{P})$, borderline proteinuric (BP) or non-proteinuric (NP), based on UPC ratio of $<0.2$, $0.2-0.5$, and $>0.5$, respectively. Information regarding analytical pitfalls of UPC determination is not yet available. Aims of the study were to assess imprecision of the UPC ratio, the influence of dilutions on the accuracy of UPC ratio, and the effect of storage at different temperatures on UPC ratio.

Urine samples from 26 dogs (10 NP, 9 BP, 7 P) were analyzed. UPC ratio was determined 20 times (intra-assay imprecision), using pyrogallol for urinary protein (UP) in undiluted samples, and the Jaffè method for urine creatinine (UC) in samples routinely diluted $1: 20$, immediately before the spectrophotometrical analysis; $\mathrm{UC}$ was also measured at 1:10 and 1:100 dilutions to assess the influence of serial dilution. Thereafter, aliquots were stored at room tempera- ture (RT), at $4{ }^{\circ} \mathrm{C}$ and at $-20^{\circ} \mathrm{C}$. Stability was assessed in aliquots stored at RT after $12,24,48$ and $72 \mathrm{~h}$, at $4^{\circ} \mathrm{C}$ after $12,24,48$ and $72 \mathrm{~h}$, as well as after $1,2,3$ and 4 weeks, and at $-20^{\circ} \mathrm{C}$ also after 2,3 and 6 months. Inter-assay imprecision was assessed daily for 20 days using 5 refrigerated urines on which aliquots to measure UC were pre-diluted before storage.

Median intra-assay coefficient of variations (CVs) were $1.4 \%$ for UC, $7 \%$ for UP and $7.9 \%$ for UPC. CVs progressively increased in urine with lower UPC. Inter-assay CVs were $12 \%$ for UC, $35 \%$ for UP and $34 \%$ for the UPC ratio. UC and UPC ratio at $1: 100$ dilution were respectively significantly higher and lower than those recorded at 1:10 dilution. Overestimation of UPC ratio at 1:10 dilution was more evident in urine with high UC. At RT, UPC ratio significantly increased at $12 \mathrm{~h}$ and continued to increase until $72 \mathrm{~h}$ post collection. UPC ratio did not significantly vary in refrigerated urine over a one month period, although median UPC ratio tended to increase over time, and in frozen urine over a 6 month period

In conclusion, the intra-assay imprecision of UPC ratio measurement is high at low values of UPC, potentially leading to misclassification of urine with UPC ratio close to 0.2 or 0.5 . The high inter-assay variability may be due to artifacts depending on storage of pre-diluted urine. This high variability, however, does not affect routine UPC ratio evaluation, since the analysis of pre-diluted urine is not commonly performed in practice. Samples must thus diluted immediately before determination of UP and UC, and the use of 1:100 dilution in urine with high UC is recommended to avoid overestimation of UPC ratio. Storage at RT is not recommended because rapidly increases UPC ratio.

\section{8- ESVNU - MAUREY-GUENEC}

MICROBIOLOGIC FINDINGS AND ANTIBIOTIC RESISTANCE TRENDS IN CANINE POPULATION-ACQUIRED FIRST URINARY TRACT INFECTIONS AT NATIONAL VETERINARY SCHOOL OF ALFORT: 543 CASES (20022007). Christelle Maurey-Guenec, Morganne Canonne-Guibert, Ghita Benchekroun, Henri Jean Boulouis, dan Rosenberg. National Veterinary School of Alfort, MAISONS ALFORT, France

Antimicrobial resistance in uropathogens complicates therapy and has potential public health consequences. We estimated the prevalence and analysed the trend of antibiotic resistance of uropathogens over a 5-year period in a cohort of dogs with a first episode of culture-proven urinary tract infection presenting at $\mathrm{Na}$ tional Veterinary School of Alfort

Clinical records of dogs admitted in Veterinary Teaching Hospital of Alfort between 1st January 2002 and 31th December 2007 and requiring urinary culture were retrospectively analysed. Inclusion criteria were: 1 / a significant bacteriuria (greater than 103 colonies/ $\mathrm{mL}$ of urine) after antepubic cystocentesis. 2/ a clinical record explicitly documenting a first occurrence of UTI. Colony numbers were recorded on Mac Conkey agar, identification was based on standard biochemical tests and antimicrobial susceptibility was determined by the Kirby-Bauer disk diffusion method. Multi Drug Resistant (MDR) isolate was defined as resistance to at least three classes of antibiotics. The significance of observed differences was tested with Chi-square.

Over the study period, 543 cases were included (representing 613 isolates). The most common isolates were E. coli $(n=278)$, Staphylococcus intermedius $(n=78)$, Proteus mirabilis $(n=54)$ and Enterococcus faecalis $(n=47)$. Their prevalence remained stable over 6 years. $34 \%$ of isolates $(n=213)$ were MDR ( $63 \%$ of Enterococcus faecalis $(n=30), 51 \%$ of Proteus mirabilis $(n=28), 26 \%$ of E.coli $(\mathrm{n}=72)$ and $1 \%$ of Staphylococcus intermedius, $(\mathrm{n}=1)$. The prevalence of MDR decreased significantly $(\mathrm{p}<0,001)$ for $\mathrm{E}$. coli and was stable for the others species over the 6 years. Only urinary catheterization increased the risk to isolate a MDR uropathogen. Resistance to ampicillin, amoxicillin-clavulanic acid and marbofloxacin decreased over six years, only the frequency of resistant to marbofloxacin Enterococcus faecalis isolates increased.

Case selection (first episode versus recurrent urinary tract infection) may modify prevalence of uropathogens and antimicrobial resistance, antibiotic use being recognized as the main force producing antibiotic resistance. The trends of antibiotic susceptibility are favourable at Veterinary Teaching Hospital of Alfort, particularly for $\beta$-lactamines. Nevertheless, the increasing resistance to 
marbofloxacin among Enterococcus faecalis isolates is a new finding in canine practice.

039- ESVNU - DORSCH

URINARY CONCENTRATIONS OF FIBRONECTIN AND TFF2 IN CATS WITH BACTERIAL URINARY TRACT INFECTION AND UROLITHIASIS. Roswitha Dorsch ${ }^{1}$, Stephanie Lemberger $^{1}$, Cornelia Deeg ${ }^{2}$, Barbara Amann', Stephanie Hauck ${ }^{4}$, Katrin Hartmann ${ }^{1}$. ${ }^{1}$ Clinic for Small Animal Internal Medicine, MUNICH, Germany, ${ }^{2}$ 2Institute for Veterinary Physiology, Department of Veterinary Sciences, LMU, MUNICH, Germany, ${ }^{3}$ Institute for Veterinary Physiology, Department of Veterinary Sciences, LMU, MUNICH, Germany, ${ }^{4}$ Institute for Protein Sciences, Helmholtz Center, MUNICH, Germany

Feline idiopathic cystitis (FIC) is common in domestic cats. To date, no definitive etiology has been established and diagnosis is still made by exclusion of other diseases of the lower urinary tract. In a previous study of the authors the quality of proteinuria in cats with FIC was evaluated in search of etiologic information and diagnostic markers. Two interesting differentially expressed proteins were identified, validated and quantified. Compared to healthy controls, cats with FIC had significantly higher urinary concentrations of fibronectin and significantly lower urinary concentrations of trefoil factor 2 (TFF2).

Purpose of this study was evaluation of the specificity of these findings for FIC by evaluation of fibronectin and TFF2 levels in cats with other diseases of the lower urinary tract (urolithiasis and bacterial urinary tract infection).

Urine supernatants of cats with bacterial urinary tract infection (UTI) (13), cats with urolithiasis (12) and healthy controls (18) were included. Protein concentration was measured via Bradford method. Urine was separated by one-dimensional gelelectrophoresis and Western Blots with polyclonal antibodies were performed. For quantification of band densities the Image Quant Program was used.

Protein measurement showed a statistically significant $(\mathrm{p}<0.001)$ higher concentration of protein in the urine of cats with UTI (mean $3.34 \mathrm{mg} / \mathrm{ml}+/-3.98$ ) and urolithiasis (mean $5.12 \mathrm{mg} / \mathrm{ml}+/-4.45)$ compared to healthy controls $(0.81 \mathrm{mg} / \mathrm{ml}+/-0.24)$. There were no significant differences in urinary fibronectin concentrations between healthy controls and cats with bacterial UTI $(\mathrm{p}=0.82)$, and between healthy controls and cats with urolithiasis $(\mathrm{p}=0.81)$. Regarding TFF2 concentrations, a significant difference between healthy controls and cats with bacterial UTI $(\mathrm{p}=0.24)$ was also not identified.

Results revealed that high quantities in fibronectin and low quantities in TFF2 are not detected in cats with other diseases of the lower urinary tract and therefore indicate that this is a specific finding in cats with FIC. TFF2 belongs to a family of proteins that are rapidly up-regulated in the setting of mucosal damage or injury, where they contribute to epithelial restitution and immune response. Deficiency in this factor in cats with FIC could result in a higher susceptibility to irritants, ongoing inflammation and recurrent clinical signs. Damaged urothelium and increased permeability may result in muscular and vascular fibrosis, detachment of fibronectin, leakage into the urine and higher urinary fibronectin concentration.

\section{0- ESVNU - NICKEL}

ASSESSMENT OF NORMAL AND ABNORMAL ANATOMY OF THE URETERO-VESICAL JUNCTION IN BRIARD DOGS BY ENFORCED DIURESIS B-FLOW SONOGRAPHY. Rafael Nickel $^{1}$, Svenja Hischer ${ }^{1}$, Stephan Hungerbühler ${ }^{2}$. ${ }^{1}$ NORDERSTEDT, Germany, ${ }^{2}$ Kleintierklinik der Tierärztlichen Hochschule, HANNOVER, Germany

Ectopic ureters occur quite often in Briard dogs. Investigating the inheritance and development of genetic markers require identification of phenotypic carriers, which may be non-symptomatic. Sonography was evaluated for diagnosis of ectopic ureters and is accurate, but not as reliable as CT. Endoscopy and CT are obviously not useful for population screening. B-Flow sonography is a novel colorflow imaging technique using digital encoding technology to enhance weak signals from flowing compounds, eliminating competing signals from stationary tissues and suppressing noise. The purpose of this study was to evaluate B-flow sonography during enforced diuresis by dimazon for the imaging of the uretero-vesical junction and assessment of normal and abnormal anatomy in Briard dogs. Briard dogs in this study were non-symptomatic, client-owned and examined with owner's consent without sedation. A pilot study had proven the effect of dimazon on the identification of the ureteral orifice and the negligible influence of bladder volume on measurements of the distance between uretero-vesical junction (UVJ) and vesico-urethral border (VUB). Six adult males and 6 adult females were examined 10 minutes after s.c. injection of dimazon. B-flow colour images using a $10-14 \mathrm{MHz}$ transducer of a GE Logic $7 \mathrm{Ul}$ trasound unit were obtained in longitudinal and transverse transabdominal scans of the bladder neck region. Jet phenomena of the urine entering the bladder were identified for each ureter and revealed a typical shape (boomerang or sword-like). Imaging allowed assessment of the exact position for each ureter entering the bladder at the base of the jet and measurement of the distance between UVJ and VUB for each ureter. The technique was then applied in 19 mature males, 13 mature females, and 7 puppies at the age of 6 weeks ( 4 $\mathrm{f}, 3 \mathrm{~m}$ ). Body weight ranged from $26-46 \mathrm{~kg}$ in mature, from 7,2 $9,9 \mathrm{~kg}$ in puppies. In 6 dogs ( 4 male, 2 female, one puppy), an abnormal intramural course of the ureter was found and the ureterjet could not be identified, as seen in clinical cases. In the other mature dogs distance between UVJ and UVB was $0,6-3,3 \mathrm{~cm}$ for the left ureter, $0,8-3,2 \mathrm{~cm}$ for the right ureter, $0,8-1,5 \mathrm{~cm}$ and $0,7-1,2 \mathrm{~cm}$ in puppies, respectively. It is concluded that B-flow sonography during enforced diuresis is a suitable imaging technique to assess the UVJ in dogs for screening purposes and anatomic studies. Briard dogs show a wide variation of UVJ anatomy, difference between left and right UVJ position and subtypes of clinically relevant ectopia.

\section{1- ESVNU - ROWLANDS}

THE EFFECT OF BORIC ACID ON BACTERIAL CULTURE OF CAT AND DOG URINE SUBMITTED TO THE LABORATORY BY RAPID SERVICE POSTAL DELIVERY. Mary Rowlands ${ }^{1}$, Rachel Burrow ${ }^{1}$, Peter Cripps ${ }^{1}$, Claire Crompton ${ }^{2}$ Laura Blackwood ${ }^{1}$. ${ }^{1}$ Liverpool University, NESTON, United Kingdom, ${ }^{2}$ Idexx Laboratories, WETHERBY, United Kingdom

Bacterial culture of urine is commonly performed in veterinary practice. The aim of this study was to identify the optimal method of canine and feline urine submission to the laboratory for culture. We also compared the results of culture with findings on sediment examination.

Urine specimens were obtained by cystocentesis from 250 animals (200 dogs and 50 cats) suspected of having urinary tract infections Each specimen was divided into 3 aliquots. The first provided our 'true' reference test result: this was collected without preservative and urine culture, and cytological examination of sediment were performed within two hours of collection on site. The other 2 aliquots were stored at room temperature for up to 7 hours and then posted by guaranteed next day delivery to Idexx Laboratories, $\mathrm{UK}$, where culture was performed. One aliquot was placed in a sterile container without preservative, and the other in a sterile container containing the preservative boric acid. Urine bacterial counts greater than $1 \times 10^{3}$ colony-forming units $/ \mathrm{ml}$ were considered significant.

Forty-seven of the samples were positive in the reference test, and 203 samples were negative. Two of the reference-positive cases did not have culture performed on the postal sample. There was no significant difference between reference test results and those of samples posted without preservative $(p=0.39)$; samples posted in boric acid were significantly less likely to give a positive result $(\mathrm{p}=$ 0.01 ). Samples posted without preservative had a test sensitivity of $82 \%(95 \%$ CI $68 \%-92 \%)$ and a specificity of $98 \%(95 \%$ CI $95 \%$ $99.5 \%)$; corresponding values for boric acid were $73 \%(58 \%-85 \%)$ and $99 \%(96 \%-99.9 \%)$.

Cytological results were used to classify samples as definite bacteriuria, possible or no bacteriuria. When only definite results were classified as positive, cytology had a sensitivity of $74 \%(95 \% \mathrm{Cl}$ $58 \%-86 \%)$ and specificity $92 \%(95 \%$ CI $86 \%-95 \%)$ : when possible bacteriuria was classified as positive the specificity reduced to $75 \%$ $(95 \%$ CI $68 \%-81 \%)$. The sensitivity of pyuria to predict a positive culture was $70 \%(95 \%$ CI $55 \%-83 \%)$ and the specificity $75 \%(95 \%$ CI $68 \%-81 \%$ ). $17 \%$ of samples with a positive culture had normal findings on sediment examination. 
Our findings indicate that to maximise the chance of achieving a true positive result it is better to submit the sample in a plain rather than boric tube for overnight posting. Urine sediment examination is not very sensitive at predicting urinary tract infection and hence urine cultures should always be recommended.

042- ESVNU - HOGLUND

ROUTINE CLINICAL EXAMINATION AFFECTS URINARY DENSITY AND pH IN HEALTHY DOGS OF DIFFERENT BREEDS. Katja Höglund ${ }^{1}$, Sofia Hanås ${ }^{2}$, Cristina Carnabuci ${ }^{3}$, Ingrid Ljungvall, Anna Tidholm ${ }^{4}$, Jens Häggström ${ }^{3}$. ${ }^{1}$ Dept. of Anatomy, Physiology and Biochemistry, Faculty of Veterinary Medicine and Animal Science, Swedish University of Agricultural Sciences, UPPSALA, Sweden, ${ }^{2}$ Djurdoktorn, VÄTERAS, Sweden, ${ }^{3}$ Dept. of Clinical Sciences, Faculty of Veterinary Medicine and Animal Science, Swedish University of Agricultural Sciences, UPPSALA, Sweden, ${ }^{4}$ Albano Animal Hospital, DANDERYD, Sweden

Excitement during examination at a clinic may affect the outcome of diagnostic tests. The aim of the study was to investigate urinary density and $\mathrm{pH}$ before and after clinical examination and to relate findings to stress levels as analysed by urinary catecholamines in healthy dogs.

Privately-owned male dogs aged 2-5 years; Labrador retrievers (43), Cavalier King Charles spaniels (CKCS), (27), Dachshunds (16) and Boxers (14) underwent clinical examination including ECG, echocardiography, haematology, biochemistry and routine urine analysis to verify health status, as part of the EU-funded Lupaproject.

Prior to examination, owners practiced urine sampling at home to train their dogs. On the examination day, dogs were fasted and water was removed at $7 \mathrm{am}$. Voided morning urine samples were collected by owners at home. The examination started at $10 \mathrm{am}$, lasted 2 hours; whereafter another voided urine sample was collected by owners.

Urine density was measured by a digital refractometer. Urine tubes for analysis of catecholamines, pre-treated with $\mathrm{HCl}$ for acidification, were frozen at $-20^{\circ} \mathrm{C}$ for a maximum of two weeks and then transferred to $-70^{\circ} \mathrm{C}$. Analyses of adrenaline and noradrenaline were performed in a proportion of dogs, using ELISA methods.

Data were analysed by non-parametric methods. A value of $\mathrm{P}<$ 0.05 was considered significant for the analyses, except in the pairwise comparison between breeds, when Bonferroni adjustment $(\mathrm{P}<$ 0.008 ) was used.

Urine density was within normal reference range in all dogs, but decreased significantly comparing morning to afternoon urine. Considering breeds separately, urine density decreased in Dachshunds and Boxers, but remained unchanged in the other breeds. Urinary $\mathrm{pH}$ increased significantly comparing morning to afternoon urine. Considering breeds separately, urinary $\mathrm{pH}$ increased in Labradors and CKCSs, but not in the other breeds. Both adrenaline and noradrenaline increased significantly comparing morning to afternoon urine in all dogs.

In conclusion, significant increases in urinary $\mathrm{pH}$, adrenaline and noradrenaline were observed, while urinary density decreased significantly. Diuresis due to excitement causing elevated blood pressure could explain the observed decrease in urine density despite deprivation of drinking water. Increased urinary $\mathrm{pH}$ could have been induced by hyperventilation due to excitement, causing respiratory alkalosis. Certain breed differences were observed, which should be taken into consideration when evaluating results of urinary tests in a clinical environment.

\section{3- ESVNU - PELLIGAND}

EFFECT OF ROBENACOXIB AND KETOPROFEN ON EXOGENOUS SERUM CREATININE CLEARANCE IN CONSCIOUS HEALTHY CATS. Ludovic Pelligand ${ }^{1}$, Ludovic Pelligand $^{1}$, Jon King ${ }^{2}$, Peter Lees ${ }^{1}$, Jonathan Elliott ${ }^{1}{ }^{1}{ }^{1}$ RVC, HATFIELD, United Kingdom, '2Novartis Animal Health, BASEL, Switzerland

Although non-steroidal anti-inflammatory drugs (NSAIDs) are widely used for chronic pain relief in the cat, little is known of their effects on glomerular filtration rate (GFR) in this species in healthy or diseased animals or those receiving concomitant treatment involving other drugs that can also affect GFR. The aim of this study was to investigate the effect of inhibition of cyclooxygenase (COX) isoforms on GFR in young healthy cats.

This study was a placebo controlled cross-over study. Seven healthy young cats received robenacoxib $(2 \mathrm{mg} / \mathrm{kg}$, subcutaneously (sc)), ketoprofen $(2 \mathrm{mg} / \mathrm{kg} \mathrm{sc})$ or an injectable placebo (sc). A bolus dose of $40 \mathrm{mg} / \mathrm{kg}$ creatinine was injected intravenously immediately after drug / placebo administration. Blood samples were taken from a pre-placed jugular catheter pre-injection and at 4, 15, $30 \mathrm{~min}$ and $1,1.5,2,3,4,6,9$ and $12 \mathrm{~h}$ after injection. Serum creatinine, plasma ketoprofen enantiomer and blood robenacoxib concentrations were measured by a validated analytical methods. Serum exogenous creatinine followed a bi-exponential decay and its clearance was calculated as a measurement of GFR (geometric mean, $[95 \% \mathrm{CI}])$.

Mean plasma $\mathrm{S}(+)$ ketoprofen concentration exceeded $\mathrm{IC}_{50}$ for $8 \mathrm{~h}$ and remained above $\mathrm{IC}_{80} \mathrm{COX}-1$ for more than $12 \mathrm{~h}$. Blood robenacoxib concentration was above $\mathrm{IC}_{50} \mathrm{COX}-2$ for 6 to $8 \mathrm{~h}$ but never reached $\mathrm{IC}_{50} \mathrm{COX}-1$. There was no significant difference in serum exogenous creatinine clearance after administration of robenacoxib $(2.76 \mathrm{~mL} / \mathrm{kg} / \mathrm{min},[2.27-3.36])$, ketoprofen $(2.83 \mathrm{~mL} / \mathrm{kg}$ / min, [2.42-3.32]) or placebo $(2.81 \mathrm{~mL} / \mathrm{kg} / \mathrm{min},[2.33-3.39])$

In conclusion, central compartment COX-1 or COX-2 acute inhibition in healthy cats did not alter the GFR measured by serum clearance of exogenously administered creatinine.

\section{4- VBPS - HOGLUND}

BLOOD PRESSURE AND HEART RATE RESPONSES DURING DIFFERENT CLINICAL SITUATIONS IN HEALTHY DOGS OF FOUR BREEDS. Katja Höglund ${ }^{1}$, Sofia Hanås ${ }^{2}$, Cristina Carnabuci ${ }^{3}$, Ingrid Ljungvall ${ }^{3}$, Anna Tidholm ${ }^{4}$, Jens Häggström ${ }^{3}$. ${ }^{1}$ Dept. of Anatomy, Physiology and Biochemistry, Faculty of Veterinary Medicine and Animal Science, Swedish University of Agricultural Sciences, UPPSALA, Sweden, ${ }^{2}$ Djurdoktorn, VÄSTERÅS, Sweden, ${ }^{3}$ Dept. of Clinical Sciences, Faculty of Veterinary Medicine and Animal Science, Swedish University of Agricultural Sciences, UPPSALA, Sweden, ${ }^{4}$ Albano Animal Hospital, DANDERYD, Sweden

Excitement during examination at a clinic may affect accuracy of blood pressure (BP) and heart rate (HR) recordings. The aim of the study was to investigate BP and HR responses during different clinical situations in healthy dogs and to evaluate possible breed differences.

Privately-owned male dogs aged 2-5 years; Labrador retrievers (43), Cavalier King Charles spaniels (CKCS), (27), Dachshunds (16) and Boxers (14) underwent clinical examination including ECG, echocardiography, haematology, biochemistry and urine analysis to verify health status, as part of the EU-funded Lupa-project. BP and HR were measured in a quiet room by high definition oscillometry (HDO) in standing dogs with cuff placed at the base of tail. Before measurements, dogs were allowed to adapt to environment for 15 minutes together with owners. Measurements were performed during four situations. After stabilisation of BP, six recordings were first made by the veterinarian (VET) with owner holding the dog. Then veterinarian left the room. Second, owner (OWNER) alone made four recordings. Then owner left the room. Third, veterinarian made 2 recordings (STRESS) followed by fourth; 2 recordings while alerting the dog with a squeaky toy (NOISE).

BP and HR data was averaged for each situation. Data was analysed by non-parametric methods. A value of $\mathrm{P}<0.05$ was considered significant for analyses, except in pair-wise comparison between breeds, when Bonferroni adjustment $(\mathrm{P}<0.008)$ was used

Systolic (SBP) and diastolic (DBP) blood pressures were within normal reference range in all dogs. VET recordings were compared to the other situations for SBP, DBP and HR. STRESS values increased significantly regarding SBP, and DBP values increased significantly during both STRESS and NOISE in all dogs. HR values decreased significantly during OWNER recordings compared to VET recordings in all dogs.

Comparing breeds, no significant differences were found in SBP values during any situation. DBP VET values were significantly lower in Labradors compared to all other breeds and DBP OWNER values were significantly lower in Labradors compared to 
Dachshunds. HR was significantly lower in Labradors compared to CKCSs for VET, OWNER and STRESS recordings.

In conclusion, SBP and DBP increased when owners left their dogs, presumably a stress-induced reaction. HR decreased when recordings were made by owners alone, indicating a 'white-coat effect' of the veterinarian. Labradors had lower DBP and HR during several situations. Hence, breed differences should be taken into consideration when evaluating BP and HR in a clinical environment.

\section{5- VBPS - WIBERG \\ INDIRECT BLOOD PRESSURE MEASUREMENT IN HEALTHY DOGS - COMPARISON OF THREE METHODS AND ASSESSMENT OF BREED AND STRESS LEVEL EF- FECT ON SYSTOLIC ARTERIAL PRESSURE. Maria Wiberg ${ }^{1}$, Eija Seppälä ${ }^{2}$, Hannes Lohi ${ }^{2}{ }^{1}$ Faculty of Veterinary Medicine, University of Helsinki, HELSINKI, Finland, ${ }^{2}$ Department of Veterinary Bioscience, University of Helsinki, HELSINKI, Finland}

The accuracy of the blood pressure (BP) measurement can be influenced by several factors, such as the used technique, breed, and stress level of the dog. The purpose of this study was to compare the systolic arterial pressure (SAP) measured on dogs by three different indirect measurement devices: Doppler, high definition oscillometry (HDO) and oscillometry (OS). The study has been part of the EU funded LUPA project (eurolupa.org), aiming at the discovery of genetic determinants for BP as well as cardiovascular and metabolic parameters in dogs. This study included 120 clinically healthy, nonobese male dogs, aged 2-5 years: German shepherd dogs (GSD; $\mathrm{n}=$ 49), Finnish Lapphunds (FLH; $n=47$ ) and Dachshunds (DH, n = 24). BP was measured under standardized and calm environmental conditions in an animal hospital. The measurements with the three devices were made simultaneously or directly one after the other, while dogs were in lateral recumbency. Several prior measurements were taken from each dog before the average of four stable and consecutive measurements was calculated. During each measurement, the effect of stress was estimated. The stress level scores were: calm/sleepy, still but tense, restless, very restless (afraid / aggressive), and measurement impossible. Acceptable SAP results with parallel use of all three devices were obtained with 84 of 120 dogs. The study revealed no significant difference in SAP when comparing the results of all three devices: Doppler (Mean \pm SD: $135.6 \pm$ $12.9 \mathrm{mmHg})$, HDO $(138.6 \pm 12.4)$, and OS $(138.9 \pm 11.1)$. However, there was a tendency that Doppler showed lower results compared with two other devices. Both, the stress level and the breed had a significant effect on the SAP results $(\mathrm{p}<0.001)$. There was the tendency for higher SAPs with higher stress levels. GSDs had significant higher SAP (Mean \pm SD: $142.3 \pm 12.6 \mathrm{mmHg}$ ) than FLH $(135.6 \pm 11.4)$, and DH $(131.7 \pm 9.3, \mathrm{p}<0.001)$. In conclusion, under standardized environmental condition Doppler, HDO, and OS give comparable results. Stress level should be taken into consideration when assessing SAP results. However, breed seems to have an important influence on SAP. The breed differences could be genetically determined.

\section{6- VBPS - MERVEILLE}

EFFECT OF STRESS ON BLOOD PRESSURE MEASURED BY DOPPLER ULTRASONOGRAPHY AND HIGH DEFINITION OSCILLOMETRY IN A LARGE POPULATION OF WORKING DOGS. Anne-Christine Merveille ${ }^{1}$, Géraldine Battaille $^{1}$, Anne-Sophie Lequarré, Kathleen Mc Entee ${ }^{2}$ ${ }^{1}$ University of Liège, LIĖGE, Belgium, ${ }^{2}$ Université libre de Bruxelles, BRUSSELS, Belgium

The stress induced by the indirect blood pressure measurement procedure may contribute to increase systolic blood pressure and sometimes lead to a false diagnosis of hypertension. Cortisol dosage has already been used as an indicator of stress state in dogs.

The purpose of this study was to compare, in a well standardized population of working dogs, the influence of stress on systolic blood pressure measured by two indirect blood pressure devices: Doppler ultrasonography and high definition oscillometry (HDO). This study is included in the lupa project, a large European collaboration aiming at the identification of genetic variants influencing blood pressure

First, we tested the intra-day ( 5 measures) and inter-day (5 exams) repeatability of the two devices in 5 beagle dogs. The variation coefficients for systolic arterial pressure (SAP) measured by Doppler and HDO were lower than $10 \%$.

Thereafter, we included 70 healthy Belgian Shepherds from Belgian police department and from Belgian army. All dogs were male, working dogs, between 2 and 6 years old. The SAP was always measured by the same trained operator, under the same standardized procedure, in a calm environment. The Doppler measurement was made at the beginning of the exam and the HDO measurement 20 minutes after the Doppler test. At the end of the exam, a blood sample was taken to measure cortisol level. At each measurement, stress level and difficulty to perform the exam were scored by a four levels scale.

The SAP measured by Doppler and HDO were highly correlated $(\mathrm{R}=0.429, \mathrm{p}<0,001)$. Nevertheless, SAP measured by the Doppler device $(159 \mathrm{mmHg} \pm 3.374)$ was higher $(\mathrm{p}<0,001$.) than SAP measured by HDO $(143 \mathrm{mmHg} \pm 1.877)$. The SAP measured by the Doppler device was positively correlated to the stress level $(\mathrm{R}=$ $0.612, p<0.001)$, the difficulty of measurement $(R=0.394, p<$ $0.01)$ and blood cortisol concentration $(\mathrm{R}=0.336, \mathrm{p}<0.02)$ while only a weak correlation was observed between SAP measured by HDO and the stress level $(\mathrm{R}=0,262, \mathrm{p}=0,045)$.

These results suggest that the SAP value measured by a Doppler device is more importantly influenced by the stress level than the SAP value measured by HDO. Therefore, in nervous dogs such as working Belgian Shepherds, the HDO method seems more suitable than the Doppler method.

\section{7- ESVIM - ISCAID - MYLONAKIS} SERUM ACUTE PHASE PROTEINS IN NATURALLY-OCCURRING CANINE MONOCYTIC EHRLICHIOSIS (EHRLICHIA CANIS). M.E. Mylonakis ${ }^{1}$, J.J. Ceron ${ }^{2}$, L. Leontides $^{3}$, V.I. Siarkou ${ }^{4}$ S. Martinez ${ }^{2}$, A. Tvarijonaviciute ${ }^{2}$, A.F. Koutinas ${ }^{1}$, S. Harrus ${ }^{5}$. ${ }^{1}$ Companion Animal Clinic and ${ }^{4}$ Laboratory of Microbiology and Infectious Diseases, Faculty of Veterinary Medicine, Aristotle University of Thessaloniki, Greece, ${ }^{2}$ Department of Animal Medicine and Surgery, Faculty of Veterinary Medicine, University of Murcia, Spain, ${ }^{3}$ Laboratory of Epidemiology, Biostatistics and Animal Health Economics, School of Veterinary Medicine, University of Thessaly, Greece, ${ }^{5}$ Koret School of Veterinary Medicine, The Hebrew University of Jerusalem, Israel.

Serum acute phase proteins (APPs) were measured and associated with the clinical and clinicopathological variables in dogs naturally infected with Ehrlichia canis. C-reactive protein (CRP), serum amyloid-A (SAA), haptoglobin, ceruloplasmin and albumin concentrations were compared between 27 dogs with spontaneous non-myelosuppressive canine monocytic ehrlichiosis (CME; Group A), 29 dogs with myelosuppressive CME (Group B) and 7 healthy dogs (Group C). APP concentrations were associated with the clinical outcome (recovery or death), adjusting for selected clinical and hematological variables. Diagnosis of CME was based on clinical and clinicopathological findings on admission, seropositivity to E. canis, PCR amplification of E. canis specific 16S rDNA and/or the observation of Ehrlichia sp. morulae in blood smears, and bone marrow (BM) cytology. Acute phase protein concentrations were determined in serum samples collected on admission. Increased concentrations of CRP, SAA, haptoglobin, and ceruloplasmin were found in $100,64.3,43.5$, and $100 \%$, of dogs with CME, respectively; hypoalbuminemia was found in $87 \%$ of the dogs. Mean concentrations of CRP, SAA and haptoglobin were significantly higher in group $\mathrm{B}$, compared to either group $\mathrm{A}$ or $\mathrm{C}$ dogs, but no significant differences were found in the concentrations of ceruloplasmin and albumin by applying ANOVA. Multivariable logistic regression analysis indicated that APP concentrations were not associated with the disease outcome; the latter was strongly associated with pancytopenia (odds ratio for death, 22.7) and neutropenia (odds ratio for death, 7.7). In conclusion, CRP, SAA and haptoglobin concentrations appeared to be significantly higher in dogs with myelosuppressive CME compared to non-myelosuppressive CME, but were not useful for predicting the clinical outcome. 
048- ESVIM - ISAID - GARDEN

OF MICE, MEN AND DOGS? A POPULATION OF CANINE CD4+CD25HIGH FOXP3 + T CELLS EXHIBITS SUPPRESSIVE PROPERTIES IN VITRO. Oliver Garden ${ }^{1}$, Dammy Pinheiro ${ }^{1}$, Yogesh Singh ${ }^{1}$, Richard Appleton ${ }^{1}$, Flavio Sacchini ${ }^{\mathrm{T}}$, Kate Walker ${ }^{1}$, Alden Chadbourne ${ }^{1}$, Charlotte Palmer ${ }^{1}$, Elizabeth Armitage-Chan ${ }^{1}$, Ian Thompson ${ }^{2}$, Lina Williamson ${ }^{3}$, Fiona Cunningham ${ }^{1} .{ }^{1}$ The Royal Veterinary College, LONDON, United Kingdom, ${ }^{2}$ Novartis Animal Health Inc, BASEL, Switzerland, ${ }^{3}$ Novartis Institute for Biomedical Research, CAMBRIDGE, United States of America

Naturally occurring regulatory $\mathrm{T}$ cells (Tregs) play a key role in the maintenance of peripheral tolerance, accounting for $3-10 \%$ of peripheral $\mathrm{CD}^{+} \mathrm{T}$ cells. They are identified on the basis of high constitutive expression of both the IL-2 receptor á chain (CD25) and the transcription factor FOXP3. Preliminary studies conducted by us and others have demonstrated FOXP 3 expression by $\mathrm{CD} 4^{+}$ and $\mathrm{CD}^{+} \mathrm{T}$ cells isolated from the blood and peripheral lymph nodes of systemically healthy dogs. However, little is known about Treg function in this species. Here we report the isolation and suppressive properties of these cells.

Polyclonal stimulation of lymphocyte preparations with concanavalin A (ConA) in vitro over 72 hours resulted in an increase in both the proportion and median fluorescence intensity of FOXP3 expression by canine $\mathrm{CD}^{+} \mathrm{T}$ cells $(4.8 \pm 0.6 \%$ (mean $\pm \mathrm{SEM})$ at time $0(n=9)$ versus $9.3 \pm 3.9 \%$ at 72 hours $(n=5))$. Subsequent removal of the stimulus followed by extended culture led to the disclosure of distinct $\mathrm{CD}^{+} \mathrm{FOXP}^{\text {high }} \mathrm{IFN}^{-} \gamma$ and $\mathrm{CD} 4{ }^{+} \mathrm{FOXP} 33^{\text {intermediate }} \mathrm{IFN} \gamma^{-/+}$populations, respectively thought to represent Tregs and activated conventional $\mathrm{T}$ cells.

ConA-activated FOXP3-pre-enriched lymphocytes were sorted on the basis of both $\mathrm{CD}^{+}$and $\mathrm{CD} 25^{\text {high }}$ expression by FACS ${ }^{\mathrm{TM}}$ and cultured alone or with responder $\mathrm{T}$ cells. Activated $\mathrm{CD} 4^{+} \mathrm{CD} 25^{\text {high }} \mathrm{T}$ cells were anergic and suppressed the proliferation of magnetically-isolated third party $\mathrm{CD}^{+} \mathrm{T}$ cells prestimulated with ConA by $66.7 \pm 6.8 \%$ (mean \pm SEM) $(n=5)$, measured by the incorporation of tritiated thymidine after 72 hours of co-culture In contrast, contemporaneously activated $\mathrm{CD} 4^{+} \mathrm{CD} 25^{-} \mathrm{T}$ cells proliferated robustly and showed no suppressive properties in vitro. Additional interrogation of $\mathrm{CD} 4{ }^{+} \mathrm{CD} 25^{\text {high }}$ $\mathrm{T}$ cells by reverse transcriptase-quantitative PCR demonstrated a regulatory phenotype, with a greater abundance of transcripts encoding FOXP3 and lower abundance of transcripts encoding IFN $\gamma$, IL-9 and IL-17, when compared to CD4 ${ }^{+} \mathrm{CD} 25^{-}$T cells.

In summary, we have demonstrated a population of $\mathrm{CD} 4{ }^{+} \mathrm{CD} 25^{\text {high }}$ FOXP $3^{+}$T cells in the dog that exhibits similar phenotypic and functional characteristics to naturally occurring Tregs of man and mouse. Further work is ongoing to elucidate the specific mechanisms of suppression by this population in vitro.

049- ESVIM - ISCAID - NIENHOFF

PREVALENCE OF METHICILLIN-RESISTANT STAPHYLOCOCCUS ISOLATES IN DOGS ATTENDING A GERMAN VETERINARY TEACHING HOSPITAL. Ulrike Nienhoff ${ }^{1}$, Kristina Kadlec ${ }^{2}$, Iris F. Chaberny ${ }^{3}$, Jutta Verspohl', Gerald F Gerlach $^{1}$, Stefan Schwarz ${ }^{2}$, Daniela Simon ${ }^{1}$, Ingo Nolte ${ }^{1}$. ${ }^{1}$ University of Veterinary Medicine Hannover, Foundation, HANNOVER, Germany, ${ }^{2}$ Institute of Farm Animal Genetics, Friedrich-Loeffler-Institut (FLI), NEUSTADT-MARIENSEE, Germany ${ }^{3}$ Hannover Medical School, HANNOVER, Germany

During September 2007 - January 2009 dogs admitted to the Small Animal Hospital of the University of Veterinary Medicine Hannover were screened for the presence of coagulase-positive methicilin-resistant staphylococci (MRS). The aim of the study was to determine the prevalence of MRS among dogs entering a German clinic and to identify risk factors for the carriage of MRS.

In total, 815 dogs were sampled before entering the clinic. A questionnaire for background information on the dog and its owner was completed. Swabs were taken from the pharyngeal and the perineal region and tested for staphylococci. The staphylococcal species was identified by biochemistry and methicillin-resistant Staphylococcus pseudintermedius (MRSP) were confirmed by RFLP-PCR of the pta gene. MRS isolates were identified by a chromogenic agar, oxacillin disk diffusion and the presence of PBP2a and mecA. The detected methicillin-resistant $S$. aureus (MRSA) and MRSP isolates were characterized by SCCmec typing, SmaI pulsed-field gel electrophoresis (PFGE), and antimicrobial susceptibility testing to 25 agents by broth microdilution according to CLSI recommendations. The MRSA isolates were also subjected to spa typing, as well as ApaI PFGE. A risk factor analysis for MRSP carriage in dogs was performed.

Among the 815 dogs sampled, 40 (4.9\%) dogs harboured $S$. aureus and $697(85.5 \%)$ dogs harboured $S$. pseudintermedius. Three $(0.4 \%)$ dogs were positive for MRSA and $61(7.5 \%)$ dogs for MRSP. The MRSA isolates harboured SCCmec type II, IV and V and belonged to the spa types t014, $\mathrm{t} 032$ and $\mathrm{t} 034$. In addition to $\beta$-lactams two isolates were resistant to macrolides, lincosamides (ML) and (fluoro)quinolones (FQ) and one isolate to $\mathrm{ML}$ and tetracycline (TC). All MRSA isolates showed different SmaI and ApaI patterns. The MRSP isolates harboured SCCmec II-III. They showed very similar susceptibility patterns with resistance to $\beta$-lactams, ML, FQ, TC, chloramphenicol, gentamicin, trimethoprim and sulfamethoxazole and susceptibility to quinupristin/dalfopristin, vancomycin and tiamulin. The MRSP isolates differed distinctly in their SmaI patterns. Among the 64 dogs, 27 dogs harboured an MRS isolate in each site sampled with indistinguishable isolates in all cases. The highest evaluated risk factors for MRSP were former hospitalization and previous antibiotic therapy. Of the 48 dogs, which had been hospitalized within 6 months before sampling, $42(87.5 \%)$ dogs also had received antimicrobial agents within the last six months.

The occurrence of MRSA in dogs is rare, but multi-resistant MRSP isolates occur frequently in dogs. This study identified prior hospitalization and/or antibiotic therapy as main risk factors for MRSP carriage in dogs. Therefore infection control measures need careful attention and antimicrobial therapy should be evaluated for every single case.

\section{0- ESVIM - ISCAID - GRELLET}

\section{EVALUATION OF CANINE CALPROTECTIN IN FECES} FROM A LARGE GROUP OF PUPPIES. Aurélien Grellet ${ }^{1}$, Romy Heilmann ${ }^{2}$, Jan Suchodolski ${ }^{3}$, Alexandre Feugier ${ }^{4}$, Gregory $^{2}$ Casseleux ${ }^{4}$, Vincent Biourge ${ }^{4}$, Thierry Bickel ${ }^{1}$, Bruno Polack ${ }^{\mathrm{T}}$, Dominique Grandjean ${ }^{1}$, Jorg Steiner ${ }^{2} .{ }^{1}$ Ecole Vétérinaire d'Alfort, MAISONS ALFORT, France, ${ }^{2}$ Gastrointestinal Laboratory; Texas A\&M University, TAMU, United States of America, ${ }^{3}$ Gastrointestinal Laboratory; Texas A\&M University, TAMU, United States of America, ${ }^{4}$ Royal Canin, AIMARGUES, France

Calprotectin $(\mathrm{CP})$ is a heterodimeric protein complex abundant in neutrophils and macrophages. $\mathrm{CP}$ is contained in infiltrating myelomonocytic cells at sites of inflammation, where it is actively or passively released into the extracellular space as a result of cell disintegration. To screen patients prior to more invasive investigations, several noninvasive markers have been suggested in human patients with inflammatory gastrointestinal conditions. The concentration of fecal CP has been shown to be a useful marker for organic disease being higher in patients with inflammatory bowel disease than in healthy controls. In dogs a radioimmunoassay for the quantification of canine calprotectin (cCP) has recently been developed for fecal samples. The assay was described as sensitive, linear, accurate, precise, and reproducible [Heilmann RM. AJVR 2008; 69: 845]. To our knowledge fecal cCP concentrations have only been described in healthy adult dogs. This study aims at investigating fecal $\mathrm{cCP}$ in puppies with and without diarrhea at weaning.

Faecal samples were collected prospectively from 271 puppies $(4$ to 10 weeks of age). For each puppy the fecal consistency was scored using a 5-point numerical scale. cCP was measured as described previously. Following zinc sulfate flotation of fecal samples, microscopic examination was performed to identify parasitic ova, cysts, and oocysts. Data were not normally distributed. Non parametric tests were used according to the number of groups considered (Kruskal Wallis test or Mann-Whitney U test). Groups differed significantly for a P-value $<0.05$. Data are shown in the test as medians.

Fecal calprotectin concentration differed significantly in puppies younger or older than 8 weeks $(21.32$ vs $6.47 \mu \mathrm{g} / \mathrm{g} ; \mathrm{P}<0.001)$ $19.8 \%$ of puppies had normal fecal consistency. Faecal calprotectin concentration was not linked to the faecal quality. $31.3 \%$ of puppies were infested by Isopora spp (more than 1000 oocysts/g of feces). An infection by Isospora spp induced significantly to higher levels of 
Ccp in puppies $(\mathrm{P}<0.001)$. However the concentration of fecal cCP was not influenced by the type of Isospora isolated.

Our study revealed the age dependent characteristic of $\mathrm{CCP}$ as observed in children [Rugtveit J. J Pediatr Gastro Nutr 2002; 34 323]. The higher concentrations of cCP observed in younger puppies may be linked to a higher permeability of the intestinal mucosa or might also be associated to the presence of milk in the regime. The higher cCP concentrations in puppies infested by Isospora spp. could be explained by the inflammatory response to the protozoan. This hypothesis needs to be confirmed by biopsies. Further research into the clinical usefulness of the measurement of fecal cCP concentrations in dogs with histologically confirmed inflammatory conditions are warranted and are being conducted.

051- ESVIM - ISCAID - MCCLURE SERIAL C-REACTIVE PROTEIN CONCENTRATIONS AS A PREDICTOR OF OUTCOME IN PUPPIES INFECTED WITH PARVOVIRUS. Vanessa McClure ${ }^{1}$, Mirinda van Schoor ${ }^{2}$, Amelia Goddard $^{2}$, Thompson Peter ${ }^{3}$, Mads Kjelgaard-Hansen ${ }^{4}$ ${ }^{1}$ University of Pretoria, Faculty of Veterinary Science, PRETORIA, South Africa, ${ }^{2}$ University of Pretoria, Department of Companion Animal Clinical Studies, PRETORIA, South Africa, ${ }^{3}$ University of Pretoria, Department of Production Animal Studies, PRETORIA, South Africa, ${ }^{4}$ University of Copenhagen, Department of Small Animal Clinical Sciences, COPENHAGEN, Denmark

Canine parvovirus (CPV) remains a leading cause of enteritis in young dogs. To date no agent-specific treatment exists, so treatment remains symptomatic and supportive. Without treatment CPV infection is often fatal. Due to the high cost associated with treatment, early and more effective prediction of outcome will have both an economic and clinical impact. Objective and easily accessible parameters for outcome are preferred. C-reactive protein (CRP) is a major positive acute phase protein in dogs. It has been used extensively in human and animal medicine as a quantitative marker for inflammatory activity in disease processes and is often useful as a prognostic indicator, especially when serial measurements are used.

The aim of this study was to evaluate serial CRP values as a predictor of outcome in puppies suffering from CPV enteritis. Seventynine client-owned puppies, diagnosed with CPV and admitted to the isolation ward of the Onderstepoort Veterinary Academic Hospital, were included in the study. Serum for CRP measurements was collected at admission and after 12- and 24 hours. CRP concentrations were determined using an automated human CRP turbidometric immunoassay, previously validated for use in dogs.

Association of CRP concentrations and changes in CRP concentrations with survival, were estimated using logistic regression, adjusting for age, weight and sex. Clinical performance was evaluated by means of receiver-operating characteristic (ROC) curves. Mortality fraction was $20 \%(16 / 79)$. Median CRP concentrations on admission, $12 \mathrm{~h}$ and $24 \mathrm{~h}$ after admission for survivors were $104.8 \mathrm{mg} / 1,89.2 \mathrm{mg} / \mathrm{l}$ and $68 \mathrm{mg} / \mathrm{l}$, and for non-survivors $155 \mathrm{mg} / 1$, $151.3 \mathrm{mg} / \mathrm{l}$ and $128.5 \mathrm{mg} / \mathrm{l}$ respectively. There was a significant negative association between survival and CRP concentration on admission $(\mathrm{p}=0.04), 12 \mathrm{~h}$ after admission $(\mathrm{p}=0.005)$ and $24 \mathrm{~h}$ after admission $(p=0.003)$. Survival was not significantly associated with change in CRP between admission and $12 \mathrm{~h}(\mathrm{p}=0.33)$, admission and $24 \mathrm{~h}(\mathrm{p}=0.62)$ and 12 and $24 \mathrm{~h}(\mathrm{p}=0.99)$

Despite the significant association between CRP and survival, ROC analysis demonstrated that discriminative ability of CRP alone predicting survival was not acceptable (area under the ROC curve for CRP on admission, $12 \mathrm{~h}$ and $24 \mathrm{~h}$ was $0.69,0.78$ and 0.79 respectively). Together with other known prognosticators however, like blood leukocyte changes, CRP may prove to be a useful early predictor.

\section{2- ESVIM - ISCAID - VANHERBERGHEN} CYTOKINE EXPRESSION BY ASPERGILLUS FUMIGATUS STIMULATED PERIPHERAL BLOOD MONONUCLEAR CELLS FROM DOGS WITH SINO-NASAL ASPERGILLOSIS. Morgane Vanherberghen ${ }^{1}$, Fabrice Bureau ${ }^{2}$, Iain Peters ${ }^{3}$, Laurence Fievez ${ }^{2}$, Frédéric Billen ${ }^{4}$, Cécile Clercx ${ }^{4}$, Dominique Peeters ${ }^{4}{ }^{1}$ LIĖGE, Belgium, ${ }^{2}$ Biochemistry and Molecular Biology,
University of Liège, Belgium, ${ }^{3}$ School of Clinical Veterinary Science, University of Bristol, United Kingdom, ${ }^{4}$ Companion Animal Clinical Sciences, University of Liège, Belgium

Cytokine gene expression in nasal mucosa from dogs with sinonasal aspergillosis (SNA) is characterised by increased mRNA expression of IFN- $\gamma$ and other pro-inflammatory cytokines. Failure to clear the infection, despite this local Thl inflammatory response, may be related to the increased IL-10 and/or TGF- $\beta$ expression, presumably by regulatory $\mathrm{T}$ cells, in this nasal mucosa. However, these mRNA expression studies have used mucosal biopsies rather than isolated T-cells. The aim of this study was to measure cytokine expression by peripheral blood mononuclear cells (PBMC), isolated from dogs with and without SNA, when cultured with Aspergillus fumigatus conidia.

PBMC were used as insufficient cells were obtained from mucosal biopsies. PBMC were isolated and cultured from dogs with SNA (n $=7)$ and healthy controls $(n=4)$ using standard methods under different conditions: no stimulation, non-specific stimulation with PMA/ionomycin and stimulation with $\mathrm{A}$. fumigatus conidia. Cell proliferation was assessed by thymidine incorporation and the CD4:CD8 ratio, before and after culture, by flow cytometry. The concentration of IL 10 and IFN- $\gamma$ in the culture supernatant was measured by ELISA; whilst the IFN- $\gamma$, IL 4, IL 10, IL 13 and TGF $\beta$ mRNA expression in the PBMC was measured by real-time quantitative RT-PCR (qRT-PCR). The results of the measurements were compared, between the 2 groups, using the Mann-Whitney test and considered significant when $\mathrm{p}<0.05$

The cell viability was always greater than $90 \%$. The proliferation ratio of the PBMC from both study groups, stimulated with PMA ionomycin, ranged from 4 to 20 . However, only PBMC from dogs with SNA displayed a proliferation ratio greater than 3 following conidia stimulation. The CD4:CD8 ratio increased, following conidia stimulation, in PBMC collected from dogs with SNA only.

IFN- $\gamma$ mRNA and protein expression was greater in both groups following non-specific stimulation, but only the former was statistically significant. IFN $-\gamma$ mRNA and protein expression was significantly increased following conidia stimulation in SNA dogs only. IL-10 mRNA and protein expression was significantly decreased in both groups following conidia challenge, but there was no difference with non-specific stimulation. No differences in IL-4, IL 13 and TGF- $\beta$ mRNA were found. These results suggest that Th1 cells, specifically sensitised to A. fumigatus conidia, but not regulatory T cells secreting IL-10 and/or TGF- $\beta$ are present in the blood of dogs with SNA.

053- ESVIM - ISCAID - GALLAGHER

CLINICAL, CLINICOPATHOLOGICAL AND RADIOGRAPHIC FEATURES AND OUTCOME OF ANGIOSTRONGYLOSIS IN DOGS FROM IRELAND. Barbara Gallagher, Sheila Brennan, Carmel Mooney. University College Dublin, DUBLIN, Ireland

Angiostrongylus vasorum is a metastrongyloid parasite known to infect dogs, causing a wide variety of clinical signs, with potentially fatal consequences. It is increasingly reported in dogs across Europe. Although recognised in Ireland since 1973, there are no large series of cases yet reported.

The aim of this study was to identify signalment, geographical location, clinical, clinicopathological and radiographic features and outcome in a series of dogs from Ireland.

The case records of all dogs presenting to the University Veterinary Hospital (UVH) between 1999 and 2009 were retrospectively reviewed. In total 23 animals with a positive diagnosis of angiostrogylosis as determined by modified Baermann $(\mathrm{n}=16)$, BAL $(\mathrm{n}=1)$, PCR $(\mathrm{n}=1)$ or post mortem examination $(\mathrm{n}=5)$ were identified. The majority $(\mathrm{n}=21(91 \%))$ lived on the east coast. The group comprised $9(39 \%)$ males and $14(61 \%)$ females including 19 pedigree (German shepherd $(\mathrm{n}=3)$, Labrador retriever $(\mathrm{n}=2)$, Jack Russell terrier $(\mathrm{n}=2)$ and 1 each of a variety of other breeds) and 4 crossbreeds. The median age was 1.6 years (range $0.3-12.0$ years) and $8(35 \%)$ cases were $>2$ years. The clinical signs included cardiorespiratory $(\mathrm{n}=14(61 \%))$, coagulopathy $(\mathrm{n}=13(57 \%))$ and other $(\mathrm{n}=14(61 \%))$ less specific signs. Cough $(\mathrm{n}=9)$, dyspnoea $(\mathrm{n}$ $=4)$, nasal discharge $(\mathrm{n}=3)$ and tachypnoea $(\mathrm{n}=3)$ were the most common cardiorespiratory abnormalities. Of the animals with clinical evidence of a primary or secondary coagulation defect, 
excessive haemorrhage from a wound $(n=4)$, haemoptysis $(n=3)$, epistaxis $(n=3)$ and haematoma $(n=3)$ were the most common signs. Two of these cases were severely anaemic $(\mathrm{PCV}<0.2 \mathrm{~L} / \mathrm{L})$. Four had severe thrombocytopenia $(<60 \times 109 / \mathrm{L})$. PT and aPTT values, assessed in 12 of the animals with clinical evidence of coagulopathy, were prolonged in $3(25 \%)$. BMBT was performed in 8 of these animals and was prolonged in $5(63 \%)$ cases. Vague clinical signs of exercise intolerance $(n=6)$, lethargy $(n=4)$ and weakness $(\mathrm{n}=2)$ were also identified. Three $(13 \%)$ animals had only vague clinical signs. Thoracic radiographs $(\mathrm{n}=21)$ identified abnormalities in $20(95 \%)$ cases. These included bronchointerstitial $(n=7$ $(33 \%))$, interstitial $(n=6(29 \%))$ alveolar-interstitial $(n=4(19 \%))$ and alveolar $(\mathrm{n}=3(14 \%))$ patterns.

Three $(13 \%)$ animals died before or within 24 hours of treatment A full course of fenbendazole $(50 \mathrm{mg} / \mathrm{kg}$ PO q 24 hours for at least 5 days) was administered in 20 cases. Of these, $18(78 \%)$ animals responded and recovered fully. There was limited response in $2(9 \%)$ animals that were subsequently euthanased. Both these dogs were older ( 10 and 12 years, respectively).

Angiostrongylosis is not uncommon in Irish dogs. However, by contrast to previous reports angiostrongylosis is not confined to young dogs and some present with non-specific clinical and not cardiorespiratory nor coagulopathic signs.

\section{4- ESVIM - ISCAID - MERCIER}

TOLL- AND NOD-LIKE RECEPTOR EXPRESSION IN CANINE SINO-NASAL ASPERGILLOSIS AND IDIOPATHIC LYMPHOPLASMACYTIC RHINITIS. Elise MERCIER ${ }^{1}$, Iain PETERS $^{2}$, Cécile CLERCX ${ }^{1}$, Michael DAY ${ }^{2}$, Dominique PEETERS ${ }^{1}$. ${ }^{1}$ Faculty of Veterinary Medicine, LIEGE, Belgium, ${ }^{2}$ School of Veterinary Science, University of Bristol, BRISTOL, United Kingdom

Sino-nasal aspergillosis (SNA) and idiopathic lymphoplasmacytic rhinitis (LPR) are two of the most common causes of nasal discharge in dogs. Previous studies have shown that in these diseases there are distinct cytokine and chemokine gene expression profiles in the nasal mucosa. The innate immune system relies on a variety of pattern recognition receptors, such as Toll-like receptors (TLR) and NOD-like receptors (NLR), to sense microbial structures that are present in pathogens. Activation through these receptors leads to the production of proinflammatory cytokines. Innate immunity has gained significant attention in human medicine as differential expression and polymorphism of certain TLRs has been shown to occur in chronic rhinosinusitis and in response to fungal infections. The aim of this study was to compare the expression of mRNA encoding TLR 1 to 10 and NLR 1 and 2 in nasal mucosal biopsies from dogs with SNA or LPR with that found in control animals.

Total RNA was isolated from biopsies collected from dogs with SNA $(n=13)$, LPR $(n=9)$ and control dogs $(n=13)$. The quality and quantity of the RNA was assessed by automated electrophoresis. TLR (TLR1 to 10) and NLR (1 and 2) mRNA expression was measured by quantitative real-time RT-PCR. Expression was normalised using three stably expressed housekeeper genes (RPL13A, RPS 18 and TBP). For each sample, a relative copy number was calculated for each gene and expression differences among groups were assessed using Kruskal-Wallis tests. Significant group differences were further assessed using the Mann-Whitney U test.

Sino-nasal aspergillosis was associated with significantly increased expression of mRNA encoding TLR1, 2, 4, 6, 7, 8, 9, 10 and NLR2 relative to controls $(\mathrm{P}<0.05)$. Lymphoplasmacytic rhinitis was associated with significantly increased expression of mRNA encoding TLR1, 6, 7 and 8 relative to controls $(\mathrm{P}<0.01)$. There was significantly greater expression of mRNA encoding TLR1, 4, 6, 7, 8, 9, 10 and NLR2 in dogs with SNA than in dogs with LPR $(\mathrm{P}<0.05)$.

Results of the present study show that: (1) TLR (except TLR3 and 5) and NLR2 expression is increased in SNA, but it is not clear whether this increased expression reflects an abnormality involved in the disease pathogenesis or whether it simply reflects the inflammatory environment associated with the disease, and (2) there are numerous differences in TLR and NLR expression between dogs with SNA and LPR, confirming the distinct inflammatory/immune processes involved in the pathogenesis of these two diseases.
055- ESVIM - ISCAID - GLAUS

PLASMA D-DIMERS AND SERUM FRUCTOSAMIN CONCENTRATIONS IN BEAGLES EXPERIMENTALLY INFECTED WITH ANGIOSTRONGYLUS VASORUM. Tony Glaus $^{1}$, Jose Matos ${ }^{1}$, Manuela Schnyder ${ }^{2}$, Monique Wenger ${ }^{1}$, Barbara Riond ${ }^{1} .{ }^{1}$ ZURICH, Switzerland, ${ }^{2}$ Institute of Veterinary Parasitology, Switzerland

Thromboembolism (PTE) in dogs is probably underdiagnosed.Its presence may be suspected in patients with documented hypoxemia affected with a disease with known risk for PTE, coagulation abnormalities, suspicious radiographic findings, and, with increasing expertise in echocardiography, the recognition of pulmonary hypertension. Depending on the severity of PTE however, arterial oxygen content, routine coagulation parameters (PT, PTT, TT), thoracic radiographs and echocardiography may be unremarkable. For most clinicians, plasma D-dimers have become an important tool to ruleout or -in PTE. Angiostrongylus vasorum infection in dogs consistently causes severe pulmonary lesions with PTE at the time of patency. Unassociated with PTE, in dogs infected with $A$. vasorum serum fructosamine concentration has recently been shown to be decreased and its measurement suggested as valuable diagnostic parameter in dogs displaying few or atypical signs. We therefore measured plasma D-dimers using an immunoturbidimetric method and serum fructosamine to assess their diagnostic sensitivity in 6 Beagles experimentally infected with 200 L3 A. vasorum larvae. Dogs were examined before infection (T0), once during patency 7 12 weeks post infection (T1), and once 1-5 days after parasiticide treatment (T2).

At $\mathrm{T} 1$ all dogs showed mild hypoxemia with a median $\mathrm{PaO} 2$ of $85 \mathrm{mmHg}$ (range $76-89 \mathrm{mmHg}$ ) and corresponding $\mathrm{SaO} 2$ of $96 \%$ $(95-97 \%)$. At T2 hypoxemia was more severe $(\mathrm{PaO} 276 \mathrm{mmHg}, 62$ $81 \mathrm{mmHg} ; \mathrm{SaO} 296 \%$ (89-96\%). None of the dogs showed relevant changes in PT, PTT or TT. In all dogs, PTE was evident on angioCT. The values for plasma D-dimers were $0.17(0.12-0.35) \mathrm{ug} / \mathrm{ml}$ at $\mathrm{T} 0,0.37(0.26-1.21) \mathrm{ug} / \mathrm{ml}$ at $\mathrm{T} 1$, and $0.50(0.26-2.37) \mathrm{ug} / \mathrm{ml}$ at $\mathrm{T} 2$. One, five, and four dogs had D-Dimer concentrations $>0.30 \mathrm{ug} / \mathrm{ml}$ at $\mathrm{T} 0, \mathrm{~T} 1$, and $\mathrm{T} 2$, respectively. The values for serum fructosamine were $207(161-248)$ umol/1 at T0, i.e. below the normal range in our lab $(207-324 \mathrm{mmol} / \mathrm{ml})$ in 3 of 6 dogs before infection, and did not decrease during infection: 223 (205-249) umol/1 at T1, and 216 (206246) $\mathrm{umol} / \mathrm{l}$ at $\mathrm{T} 2$

In conclusion, determination of D-dimers by immunoturbidometry was not sensitive to detect PTE, when using a low cut-off of $0.30 \mathrm{ug} / \mathrm{ml}$. Angiostrongylus vasorum infection did not result in a decreased fructosamine concentration.

\section{6- ESVIM - ISCAID - PAUL}

EVALUATION OF THE EFFECT OF HAEMATOCRIT AND ACCURACY OF TWO POINT OF CARE GLUCOMETERS IN DOGS. Amanda Paul ${ }^{1}$, Robert Shiel ${ }^{2}$, Florence Juvet ${ }^{2}$, Carmel Mooney $^{2}$, Caroline Mansfield ${ }^{1}{ }^{1}$ Murdoch University, MURDOCH, Australia, ${ }^{2}$ School of Agriculture, Food Science and Veterinary Medicine University College, BELFIELD, DUBLIN, Ireland

Hand-held POC glucometers are widely used in veterinary hospitals for measurement and monitoring of blood glucose. It is important to evaluate POC glucometers in the species in which they are used as different glucometers may perform differently from a laboratory standard or each other and may differ at extremes of blood glucose concentration or haematocrit. The aim of this study was to compare canine blood glucose measurements of two POC glucometers against a reference method and to assess the impact of haematocrit upon glucose concentration. The Ascensia Elite ${ }^{\mathbb{R}}$ a portable glucometer developed for use in people, and the AlphaTrak $^{\mathrm{TM}}$ hand-held glucometer specifically developed for veterinary use were evaluated.

One hundred and thirty nine greyhounds were sampled as they have a naturally high haematocrit and it was suspected that this high haematocrit results in aberrant blood glucose measurements when measured by portable POC glucometers. Sixteen anemic dogs and twenty nine dogs with normal haematocrit were also tested to examine glucometer measurements with a greater range of haematocrit. Glucometer measurements were compared to blood glucose measured by an automated hexokinase chemistry system, on fluoride oxalate samples. 
The effect of haematocrit on glucose concentration was significant in both POC glucometers when compared to the laboratory plasma hexokinase method. The AlphaTrak ${ }^{\mathrm{TM}}$ glucometer was more imprecise in samples with lower haematocrit whilst the Ascensia Elite $\mathrm{XL}^{\circledR}$ glucometer had more variation in dogs with increased haematocrit. The Ascensia Elite $\mathrm{XL}^{\circledR}$ glucometer demonstrated increasing difference in blood glucose from the reference method and most results had greater than $1.5 \mathrm{mmol} / \mathrm{L}$ ( $20 \%$ difference) from the reference method when the hematocrit was greater than $0.5 \mathrm{~L} / \mathrm{L}$. Similarly at a hematocrit of $0.3 \mathrm{~L} / \mathrm{L}$, the AlphaTrak ${ }^{\mathrm{TM}}$ glucometer had differences of $1.3-2.7 \mathrm{mmol} / \mathrm{L}$ or approximately $20 \%$ of laboratory reference range which increased to $2.4-3.3 \mathrm{mmol} / \mathrm{L}$ difference at hematocrits of $0.2 \mathrm{~L} / \mathrm{L}$ and $0.09 \mathrm{~L} / \mathrm{L}$ respectively.

The ability of point-of-care blood glucometers to reliably report results equivalent to laboratory plasma concentrations is important and can impact on clinical decision making. The AlphaTrak ${ }^{\mathrm{TM}}$ is more likely to accurately represent blood glucose in dogs with normal or increased haematocrits and the Ascensia Elite $\mathrm{XL}^{\circledR}$ is more likely to accurately represent blood glucose at lower haematocrits. If monitoring trends of blood glucose, one glucometer should be selected as there is significant difference between blood glucose results in different glucometers.

057- ESVIM - ISCAID - BEXFIELD

NEXT GENERATION SEQUENCING AND TRANSCRIPTOME SUBTRACTION FOR VIRAL IDENTIFICATION IN CANINE TISSUE. Nicholas Bexfield ${ }^{1}$, Gordon Daly ${ }^{1}$, Penny Watson ${ }^{1}$, Laurence Tiley ${ }^{1}$, Jon Heeney ${ }^{1}$, Paul Kellam ${ }^{2}$. ${ }^{1}$ University of Cambridge, CAMBRIDGE, United Kingdom, ${ }^{2}$ Wellcome Trust Sanger Institute, HINXTON, CAMBRIDGE, United Kingdom

Epidemiological studies suggest that numerous infectious agents, including viruses, may contribute to the pathogenesis of a broad range of human and animal diseases. Advances in technology have led to a shift from traditional methods of discovering these new pathogens to modern molecular methods. One of these, next generation sequencing (NGS), involves the parallel sequencing of millions of DNA molecules from a sample of interest. Methods are then employed to remove host sequences thereby enriching for pathogen. The sequencing of complementary DNA (cDNA), rather than genomic DNA, allows the transcribed portion of the genome to be analysed. A method based on NGS of cDNA and subtraction of host sequences from public databases has been developed for viral identification in humans, and is known as transcriptome subtraction. The aim of this study was to validate a method of NGS and transcriptome subtraction for use on canine tissue by using a known virus positive tissue and a combination of public database subtraction together with subtraction against a non-infected tissue.

RNA was extracted from liver tissue of a dog infected with canine parvovirus $(\mathrm{CPV}+\mathrm{ve})$, and from liver tissue of a breed and age matched canine parvovirus negative dog $(\mathrm{CPV}-\mathrm{ve})$. All samples were collected with informed and written owner consent. RNA was converted to cDNA, amplified using a random polymerase chain reaction and sequenced using NGS methodology. Resulting sequences were trimmed, screened against a vector database and fragments shorter than 30 base pairs were removed. Following this, sequences from the CPV+ve sample were aligned to the dog chromosome (NCBI dog chromosome build 2.1), and those with sequence homology eliminated.

Remaining sequences from the CPV+ve sample were also subtracted from those of the CPV2-ve sample. Resulting CPV+ve sequences were interrogated against viral databases.

Sequencing of the CPV+ve and CPV-ve liver samples yielded 8.40 million and 7.80 million sequences respectively. Alignment to the dog chromosome removed $65.5 \%$ of the CPV + ve sequences leaving 2.90 million sequences. A further 2.84 million were removed after subtraction from the CPV-ve sample leaving 60 thousand $(0.7 \%)$ of the initial CPV2+ve reads. Interrogation of viral databases resulted in 33 matches to CPV.

We have demonstrated the ability of NGS and transcriptome subtraction for viral identification in canine tissue. Following alignment and subtraction from the dog chromosome, significant number of sequences still remained. Additional subtraction against a non-infected sample resulted in a marked reduction in sequences, thereby enabling the interrogation of viral databases. This method may have clinical utility in the identification of previously unknown pathogens in animal samples, and further work in canine clinical samples is ongoing.

\section{8- ESVIM -ISCAID - DIQUÉLOU}

EFFECT OF TRAINING ON CLINICAL AND BIOLOGICAL VALUES IN MILITARY DOGS. Armelle Diquélou', Sabine Courtin $^{1}$, Guillaume Lemaire ${ }^{1}$, Thomas Normand ${ }^{2}$. ${ }^{1}$ Ecole Nationale Vétérinaire de Toulouse/Internal Medicine, TOULOUSE, France, ${ }^{2}$ Centre national d'Instruction Cynophile de la Gendarmerie, GRAMAT, France

Military dogs' training is expensive and time consuming, and some of them have to be retired early in their career because of exercise intolerance. Early detection of those dogs would be interesting, but very little data is available concerning such a population. Aims of the study: to describe the effect of training on simple clinical and biological data before and after a standard exercise in order to gather basic data and determine potentially interesting variables.Material and methods: Seventeen dogs (15 Belgian Malinois, 1 Belgian Tervueren and 1 German Shepherd, aged 2 to 4 years) ran the same $5 \mathrm{~km}$ run with their handler at an approximate speed of $10 \mathrm{~km} / \mathrm{h}$, at the beginning and the end of their 3 months training in the CNICG. Heart (HR) and respiratory (RR) rates were measured just before (T0), at the end (T1) and 15 minutes after the run (T2); electrocardiogram $(\mathrm{EKG})$ and rectal temperature $(\mathrm{RT})$ were recorded at T0 and T2. Biological data [microhematocrit $(\mu \mathrm{Ht})$, plasma total proteins $(\mathrm{TP})$, creatinine $(\mathrm{C})$, creatine kinase $(\mathrm{CK})$ and lactates $(\mathrm{L})$ ] were determined on blood samples obtained at T0 and T2. Water intake between $\mathrm{T} 1$ and $\mathrm{T} 2$ was recorded. Biological data were considered different if they were outside the critical difference interval. Statistical analysis (paired Wilcoxon test) was performed using Stata software.Results: No dogs exhibited exercise intolerance; all EKG were normal. As expected, RR and HR increased at T1 compared to $\mathrm{T} 0$ and decreased at $\mathrm{T} 2$ at the beginning and the end of the training period. However, T0 HR at the end of the training was significantly lower $(\mathrm{p}<0,05)$ than at the beginning. Rectal temperature was higher at T2 than at T0 in 8 and 13 dogs at the beginning and the end respectively, with 1 dog having a $\mathrm{RT}_{\text {persistently }}>39^{\circ} 3 \mathrm{C}$.

Total protein, $\mu \mathrm{Ht}$ and creatinine were analytically equivalent between $\mathrm{T} 0$ and $\mathrm{T} 2$ at both start and end of the training for all dogs except one (different in each case). No relation was observed between water intake and $\mu \mathrm{Ht}$ or TP at T2. Lactate was elevated at T2 compared to T0 in 5 dogs at the beginning and 1 dog at the end of the training. Concerning CK, the same 5 dogs had an increased plasma concentration after the run compared to $\mathrm{T} 0$ both at the beginning and the end of the training period.

All these dogs will be surveyed in order to know if they develop exercise intolerance during their career.Conclusion: The collection of this clinical and biological data was easy and not expensive. Training had a significant impact on resting HR. HR, RT and CK before and after effort may be of interest in order to predict exercise intolerance.

\section{9- ESVIM - ISCAID - MERVEILLE}

PREVALENCE OF THE MUTATION RESPONSIBLE FOR PRIMARY CILIARY DYSKINESIA IN A LARGE POPULATION OF EUROPEAN AND AMERICAN OLD ENGLISH SHEEPDOGS. Anne-Christine Merveille, Géraldine Battaille, Hélène Tregan, Frédéric Billen, Cécile Clercx, Anne-Sophie Lequarré. University of Liège, LIĚGE, Belgium

Primary ciliary dyskinesia (PCD) is a rare condition arising due to defects of the motile cilia. Affected animals are characterized by recurrent inflammation of the upper and lower respiratory tract, have reduced fertility and can also show a situs inversus. This disease has been described in several dog breeds and is usually recessively inherited. We recently identified a non-sense mutation in a new PCD causative gene within a large European family of Old English sheepdogs (OES) in which we detected more than 30 affected dogs. This large number suggests a high prevalence of the responsible mutation within the European OES population. Two OES with a perfectly similar phenotype have been reported during the eighties in United States (Randolph et al., 1984). The aim of this study was to assess the frequency of the responsible mutation both in the European and the American OES populations. 
For this purpose, we developed a rapid and reliable diagnostic genetic test using a Taqman probe detecting the mutation. Compared with the traditional sequencing method, this test gave $100 \%$ sensitivity and specificity. Blood samples of 180 OES from 16 different European countries and 105 DNA samples of American OES coming from a US dog DNA bank were analyzed.

In European countries, the mutation reached an allelic frequency of $15 \%$ and we identified carriers spread in 9 different European countries. A greater number of carriers have been found in Belgium, Denmark, France and Spain. In contrast, the allelic frequency of the mutation in American OES was only 4\%. The difference in allelic frequency for this mutation between European and American OES underlines the existence of stratification between these two populations of OES

Interestingly, all European carriers are related to one common ancestor, a bitch coming from an American line and widely used during the eighties. The intensive use of this bitch in Europe is probably responsible for the spread of the mutation in the European population of OES and can be described as a founder effect. This has led to the regular birth of puppies suffering from PCD. The systematic use of this genetic test for the detection of carrier dogs could lead to the eradication of this disease in this breed.

\section{0- ESVIM - ISCAID - KRAFFT}

ENDOTHELIN-1 AS A SERUM BIOMARKER IN IDIOPATHIC PULMONARY FIBROSIS IN DOGS. Emilie $\mathrm{Krafft}^{1}$, Henna Heikkilä ${ }^{2}$, Pascale Jespers ${ }^{3}$, Kathleen McEntee ${ }^{3}$, Michae Day $^{4}$, Dominique Peeters ${ }^{1}$, Minna Rajamäki ${ }^{2}$, Cécile Clercx ${ }^{1}$. ${ }^{1}$ Faculty of Veterinary Medicine, LIĖGE, Belgium, ${ }^{2}$ Faculty of Veterinary Medicine, HELSINKI, Finland, ${ }^{3}$ Faculty of Medicine, Free University of Brussels, BRUSSELS, Belgium, ${ }^{4}$ School of Clinical Veterinary Science, University of Bristol, BRISTOL, United Kingdom

Idiopathic pulmonary fibrosis (IPF) is an interstitial fibrotic pulmonary disease, mainly described in the West Highland White Terrier (WHWT). The diagnosis is challenging and ultimately relies on lung histopathology. Differential diagnosis includes mainly chronic bronchitis. Identification of biomarkers specific for the disease would be very helpful. Endothelin-1 (ET1) is a proinflammatory and pro-fibrotic peptide that has been shown to be elevated in the serum and bronchoalveolar lavage fluid (BALF) of humans with IPF. The aim of the present study was to compare serum and BALF ET1 levels in dogs with IPF versus healthy dogs and dogs with other chronic pulmonary diseases.

Twelve dogs with IPF (eleven WHWT, one Scottish Terrier, mean age 12 years, range $8-15)$, six dogs with eosinophilic bronchopneumopathy (EBP) (various breeds, 7 years, 1-12), ten dogs with chronic bronchitis (CB) (various breeds, 8.5 years, 1-12), thirteen privately-owned healthy WHWT $(9$ years, $3-14)$ and twelve healthy experimental beagle dogs (7 years, 3-11) entered the study. Diagnosis was established after standard clinical work up, including clinical, radiographical, bronchoscopic (and BALF analysis) examinations, as well as, in dogs with IPF, either lung high resolution computed tomography (three dogs) or histopathology (five dogs) or both (three dogs). ET1 concentration in serum from all dogs and in BALF from five dogs of IPF, WHWT, CB groups was determined by ELISA (Endothelin-1 Assay kit, IBL; sensitivity $0.23 \mathrm{pg} / \mathrm{mL}$ ). Results in the different groups were compared using non-parametric test (Mann Whitney).

Serum ET1 concentration was elevated in dogs with IPF (median; interquartile range $=2.32 \mathrm{pg} / \mathrm{mL} ; 2.05-3.38)$ compared to healthy beagle dogs $(1.28 ; 1.07-1.53)$ and healthy WHWT $(1.56 ; 1.25-1.85)$, $(\mathrm{p}<0.001)$. No significant difference in ET1 values $(\mathrm{p}=0.066)$ was detected between healthy beagle dogs and WHWT. Serum ET1 value in IPF dogs was higher than in EBP dogs $(0.94 ; 0.68-1.01)(\mathrm{p}$ $=0.001)$ and than in CB dogs $(1.54 ; 0.74-1.82)(\mathrm{p}=0.005)$. Bronchoalveolar lavage fluid ET1 was below the detection limit in the five WHWT and in the five CB dogs, while ET1 was detected in the BALF of the 5 IPF dogs $(0.90 \mathrm{pg} / \mathrm{mL} ; 0.79-1.02)$.

The present study shows that (1) serum ET1 values are significantly elevated in IPF dogs compared to healthy animals, both beagles and WHWT; (2) serum ET1 values are significantly elevated in IPF dogs compared to EBP and CB; (3) ET1 seems to be detectable in the BALF of IPF dogs only.
061- ESVIM - ISCAID - KRAFFT

IS TRANSFORMING GROWTH FACTOR BETA 1 INVOLVED IN THE PATHOGENESIS OF IDIOPATHIC PULMONARY FIBROSIS IN DOGS? Emilie Krafft ${ }^{1}$, Henna Heikkilä ${ }^{2}$, Davide de Lorenzi $^{3}$, Pascale Jespers, Kathleen McEntee ${ }^{4}$, Anne-Sophie Lequarré $^{1}$, Dominique Peeters ${ }^{1}$, Minna Rajamäki ${ }^{2}$, Cécile Clercx ${ }^{1}$. ${ }^{1}$ Faculty of Veterinary Medicine, LIÈGE, Belgium, ${ }^{2}$ Faculty of Veterinary Medicine, HELSINKI, Finland, ${ }^{3}$ Veterinary Clinic S. Marco, PADUA, Italy, ${ }^{4}$ Faculty of Medicine, Free University of Brussels, BRUSSELS, Belgium

Idiopathic pulmonary fibrosis (IPF) in dogs is an emerging chronically progressive interstitial lung disease of unknown etiology, characterized by irreversible scarring of the lung that mainly occurs in the West Highland White Terrier (WHWT). Like in humans, IPF is unresponsive to current therapy and the basic mechanism underlying pathogenesis remains unknown. Among the many factors (growth factors, cytokines and chemokines) that have been involved in the pathogenesis of IPF in humans, the role of transforming growth factor beta 1 (TGF- $\beta 1$ ) has clearly been shown. Transforming growth factor beta 1 is a potent profibrotic cytokine, which has been found in increased concentration in blood and bronchoalveolar lavage fluid in humans with IPF.

The aim of the present study was to determine serum TGF- $\beta 1$ level in dogs with IPF versus healthy dogs and dogs with other chronic pulmonary diseases.

Thirteen dogs with IPF (twelve WHWT, one Scottish Terrier, mean age 12 years, range 10-15), fourteen dogs with eosinophilic bronchopneumopathy (EBP) (various breeds, 6 years, 1-12), ten dogs with chronic bronchitis (CB) (various breeds, 9 years, 1-13), six privately-owned healthy dogs of various breeds (HVB) (7 years, 4-11) and ten privately-owned healthy WHWT (HW) (9 years, 3-14) entered the study. Diagnosis was established after standard clinical work up, including clinical, radiographical, bronchoscopic (and BALF analysis) examinations, as well as, in dogs with IPF, either lung high resolution computed tomography (six dogs) or histopathology (four dogs) or both (3 dogs). Serum TGF-ß31 concentrations were determined by ELISA (Mouse/ Rat/ Porcine / Canine TGF-ß1 Quantikine ELISA kit, R\&D systems). Age and group influences were analysed by covariance analysis (ANOVA 2). Results in the different groups were then compared using parametric test (Student $t$ test)

A significant but weak increase in TGF- $\beta 1$ values was observed with age. Serum TGF- $\beta 1$ concentration was significantly elevated in dogs with IPF (mean $(\mathrm{ng} / \mathrm{mL}) \pm \mathrm{SEM}=54.6 \pm 12.8)$ as compared to the HVB group $(31.8 \pm 11.0, \mathrm{p}=0.002)$ and to the dogs with EBP $(37.7 \pm 3.4, \mathrm{p}=0.02)$ or $\mathrm{CB}(40.9 \pm 14.0, \mathrm{p}=0.024)$. Serum TGF $\beta 1$ in HW $(63.5 \pm 16.2)$ was significantly higher $(\mathrm{p}<0.001)$ than in HVB while no difference was detected between IPF dogs and HW (p $=0.155)$

Results of the present study show that (1) serum TGF- $\beta 1$ is elevated in IPF in comparison to other chronic respiratory diseases, which is in favour of a role for TGF- $\beta 1$ in the pathogenesis of IPF in dogs and (2) high serum TGF-ß31 levels are however also found in healthy WHWT, which might indicate a breed specificity, related or not to the breed predisposition for IPF.

\section{2- ESVIM - ISCAID - HEIKKILA}

PROCOLLAGEN TYPE III AMINO TERMINAL PROPEPTIDE CONCENTRATIONS IN DOGS WITH IDIOPATHIC PULMONARY FIBROSIS, CHRONIC BRONCHITIS AND EOSINOPHILIC BRONCHOPNEUMOPATHY. Henna Heikkilä ${ }^{1}$, Emilie $\mathrm{Krafft}^{2}$, Jespers Pascale $^{3}$, Kathleen McEntee $^{2}$, Minna Rajamäki ${ }^{1}$, Cécile Clercx ${ }^{2}$. ${ }^{1}$ Faculty of Veterinary Medicine, University of Helsinki, HELSINKI, Finland, ${ }^{2}$ Faculty of Veterinary Medicine, University of Liège, LIĖGE, Belgium, ${ }^{3}$ Laboratory of Physiology, Faculty of Medicine, Free University of Brussels, BRUSSELS, Belgium

Idiopathic pulmonary fibrosis (IPF), a chronic interstitial lung disease affecting both man and the dog, is characterized by accumulation of collagen type I and III within the pulmonary parenchyma. Procollagen type III amino terminal propeptide (PIIINP) is a marker of collagen type III turnover. In man, elevated PIIINP levels are detected in many fibrosing conditions, including IPF.

The aim of this study was to investigate the concentrations of PIIINP in serum and bronchoalveolar lavage fluid (BALF) of dogs 
with IPF, dogs with eosinophilic bronchopneumopathy (EBP) and dogs with chronic bronchitis (CB), and compare the values with those of healthy control dogs.

Fourteen West Highland white terriers with IPF, 19 dogs with CB (various breeds), 22 dogs with EBP (various breeds), 10 healthy West Highland white terriers and 12 healthy laboratory beagle dogs were included in the study. The diagnoses were based on thorough clinical, bronchoscopical and diagnostic imaging findings and BALF analyses. Idiopathic pulmionary fibrosis was confirmed by histopathology in 10 dogs. Concentrations of PIIINP within serum and BALF were analyzed using a commercially available radioimmunoassay (UniqPIIINP RIA, Orion Diagnostica, Finland). Concentrations determined as being below the detection limit were given an artificial value of $0.02 \mu \mathrm{g} / \mathrm{L}$. The groups were compared with Kruskal-Wallis One Way Analysis of Variance on Ranks. Mann-Whitney Rank Sum Test was used for pairwise comparisons. The significance level was set at $\mathrm{P}<0.05$.

There were no statistically significant differences between the groups when comparing serum PIIINP concentrations. The median serum PIIINP concentration was $5,69 \mu \mathrm{g} / \mathrm{L}$ (interquartile range, IQ, $4,48-9,49 \mu \mathrm{g} / \mathrm{L}$ ) in IPF; $6.53 \mu \mathrm{g} / \mathrm{L}$ (IQ $4,00-9,47 \mu \mathrm{g} / \mathrm{L}$ ) in $\mathrm{CB}$; $7,21 \mu \mathrm{g} / \mathrm{L}$ (IQ 4,33-9,38 $\mu \mathrm{g} / \mathrm{L}$ ) in EBP and 8,46 (IQ 7,10-10,39 $\mu \mathrm{g}$ L) in healthy controls. Bronchoalveolar lavage fluid PIIINP concentrations were significantly elevated in dogs with IPF (median $0.40 \mu \mathrm{g} / \mathrm{L}$, IQ $0.17-0.62 \mu \mathrm{g} / \mathrm{L}$ ) compared with healthy controls (median $0.02 \mu \mathrm{g} / \mathrm{L}$, IQ $0.02-0.02 \mu \mathrm{g} / \mathrm{L}), \mathrm{P}<0.001$, and dogs with $\mathrm{CB}$ (median 0.02, IQ 0.02-0.02), $\mathrm{P}<0.001$. Additionally, BALF PIIINP concentrations were significantly elevated in dogs with EBP (median 0.02, IQ 0,02-0,81) compared with dogs with $\mathrm{CB}, \mathrm{P}=0.011$. Furthermore, there were no statistically significant differences between IPF and EBP, $\mathrm{P}=0.292$, between EBP and healthy dogs, $\mathrm{P}=0.074$, or between $\mathrm{CB}$ and healthy dogs, $\mathrm{P}=$ 0.154 .

Our results show that IPF causes an elevation in the BALF PIIINP concentration which differentiates IPF from its main differential diagnosis, CB. Elevated levels of BALF PIIINP can however also be detected in some of the dogs suffering from EBP, possibly arising from secondary fibrotic changes due to chronic inflammatory process. Serum PIIINP is not useful in differentiating respiratory diseases in dogs.

\section{3 - ESVIM - ISCAID - HEIKKILA}

ARTERIAL BLOOD GAS ANALYSIS IN DOGS WITH IDIOPATHIC PULMONARY FIBROSIS. Henna Heikkilä ${ }^{1}$, Cécile Clercx $^{2}$, Minna Rajamäki ${ }^{1}$. ${ }^{1}$ Faculty of Veterinary Medicine, University of Helsinki, HELSINKI, Finland, ${ }^{2}$ Faculty of Veterinary Medicine, University of Liège, LIËGE, Belgium

Idiopathic pulmonary fibrosis (IPF) is a chronic interstitial lung disease which causes progressive respiratory failure. The lung function impairment can be assessed by arterial blood gas analysis.

The aim was to investigate the arterial blood gas values in West Highland white terriers (WHWTs) with IPF and compare them with healthy control WHWTs.

Eleven WHWTs with IPF and 11 healthy WHWTs were included. Idiopathic pulmonary fibrosis was verified by clinica examinations and additionally by histopathology in 10 dogs. The arterial samples were taken from femoral or metatarsal artery from non-sedated dogs breathing room air. Measurements were performed at $37^{\circ} \mathrm{C}$.

The mean duration of symptoms in IPF dogs was 14 months (range 2-29 months). The $\mathrm{PaO} 2$ was significantly lower and the alveolar-arterial oxygen gradient $(\mathrm{P}(\mathrm{A}-\mathrm{a}) \mathrm{O} 2)$ significantly higher in IPF dogs. There were no differences in $\mathrm{PaCO} 2$ between the two groups. The values (given as mean $\pm \mathrm{SD}$ ( range)) were: $\mathrm{PaO} 260.8$ $\pm 15.4 \mathrm{mmHg}(33.5-87.4 \mathrm{mmHg})$ in IPF vs. $99.1 \pm 7.8 \mathrm{mmHg}(89.6$ $113.0 \mathrm{mmHg})$ in controls, $\mathrm{P}<0.001 ; \mathrm{P}(\mathrm{A}-\mathrm{a}) \mathrm{O} 255.3 \pm 16.5 \mathrm{mmHg}$ $(28.0-84.7 \mathrm{mmHg})$ in IPF vs. $17.5 \pm 4.9 \mathrm{mmHg}(10.7-26.8 \mathrm{mmHg})$ in controls, $\mathrm{P}<0.001 ; \mathrm{PaCO} 229.2 \pm 3.9 \mathrm{mmHg}(25.0-35.7 \mathrm{mmHg})$ in IPF vs. $28.7 \pm 3.8 \mathrm{mmHg}(20.5-34.6 \mathrm{mmHg})$ in controls, $\mathrm{P}=0.756$

The results indicate that IPF causes resting hypoxemia measured as a substantial decrease in $\mathrm{PaO} 2$ and an increase in $\mathrm{P}(\mathrm{A}-\mathrm{a}) \mathrm{O} 2$. Hypercapnia is not a feature of IPF. Arterial blood gas analysis is a feasible means for assessing the functional effects of pulmonary pathology in dogs.

\section{4- ESCH - LINDQUIST}

SONOGRAPHIC WHOLE BODY PARAMETERS OF PORTOSYSTEMIC SHUNTS IN 38 DOGS \& CATS. Eric Lindquist, Douglas Casey, Johanna Frank. SONOPATH.COM, SPARTA, United States of America

The purpose of this retrospective study was to develop a reliable set of whole body sonographic positive predictive parameters for diagnosis of porto-systemic shunting. A solitary clinical sonographer experienced in evaluating for portosystemic shunts evaluated the sonograms in 35 dogs and 3 cats. The following sonographic parameters were analyzed: presence of urinary bladder sand/calculi, renal mineralization, renomegaly, microhepatica, portal vein/caudal vena cava ratio (PV/CVC), and portal vein/aorta ratio (PV/AO). Published parameters were utilized to aid in identifying dogs without an EHPSS as those with $\mathrm{PV} / \mathrm{CVC}=0.75$ and $\mathrm{PV} / \mathrm{AO}=0.8$. Nineteen cases were surgically confirmed while the remainder were medically managed or lost to follow-up. Twenty-two cases had a bile acid profile performed with a postprandial value ranging from $93-473 \mathrm{umol} /$ liter.

Five dogs had intrahepatic shunts (IHPSS) while 33 patients had extrahepatic portosystemic shunts (EHPSS).

The 5 dogs with IHPSS all had normal PV/CVC and PV/AO ratios at the level of the portal hilus. Two/5 dogs with IHPSS had bladder calculi/sand, $3 / 5$ had renal mineralization, $2 / 5$ subjective renomegaly, and $5 / 5$ had microhepatica.

Nine/33 EHPSS patients were sonographically identified as gastrocaval (GCV), 18/33 splenocaval (SPLCV), and 6/33 splenoazygus (SPLAZ) shunts.

In the 33 patents with EHPSS, the $\mathrm{PV} / \mathrm{CVC}$ ratio ranged from 0.4-0.67 in GCV patients, 0.28-0.75 in SPLCV shunts, and 0.4-0.63 in SPLAZ shunts. The PV/AO ratio ranged from $0.4-0.71$ in GCV, $0.4-0.78$ in SPLCV, and 0.4-0.68 in SPLAZ shunts.

The following abnormalities were noted: Urinary bladder sand/ calculi: 6/9 GCV, 14/18 SPLCV, 4/6 SPLAZ; renal mineralization: 9/9 GCV, 17/18 SPLCV, 6/6 SPLAZ; renomegaly: 8/9 GCV, 15/18 SPLCV, 6/6 SPLAZ; microhepatica: 9/9 GCV, 18/18 SPLCV, and 6/6 SPLAZ.

In this population of dogs and cats, the presence of urinary bladder sand/calculi, renal mineralization, swollen renal contour, and microhepatica, are reliable, non exclusive, positive predictive factors for the presence of portosystemic shunting but does not distinguish IHPSS from EHPSS. Subnormal PV/CVC and PV/AO ratios are highly reliable indicators of the presence of EHPSS.

\section{5- ESCH - OTTE}

RETROSPECTIVE COMPARISON OF PREDNISONE AND URSODEOXYCHOLIC ACID FOR THE TREATMENT OF FELINE LYMPHOCYTIC CHOLANGITIS. Corma Otte, Robert Favier, Louis Penning, Jan Rothuizen. Utrecht University, UTRECHT, The Netherlands

Although prednisone and ursodeoxycholic acid (UDCA) are recommended treatments for lymphocytic cholangitis (LC), no studies have compared these therapies with regard to survival times and factors affecting prognosis in cats. Therefore, the purpose of this retrospective study was to investigate the effect of treatment regimen on the survival times of cats with LC.

Forty-six cats with LC that were diagnosed and treated at the Utrecht University Clinic for Companion Animals (UUCCA) from 1996-2009 were identified from the central patient registration system. Medical records were reviewed to determine prevalence, signalment, clinical manifestation, and treatment protocol. Median survival times were analyzed with the Kaplan-Meier method. Factors associated with shortened survival times were identified by a multivariate Cox proportional hazard regression analysis. LC occurred in $0.32 \%$ of the Dutch feline referral population. The majority of patients were males $(67.4 \%, \mathrm{P}=0.053)$ but no breed predisposition could be demonstrated $(\mathrm{P}=0.280)$ when the groups were compared to the entire UUCCA feline referral population. Clinical signs included weight loss $(17.3 \%)$, icterus $(16.8 \%)$, vomiting $(14.5 \%)$, anorexia $(13.9 \%)$ and listlessness $(11.0 \%)$, and cat commonly presented with more than one clinical sign. In the multivariate model, female gender, the presence of weight loss, the presence of listlessness, and UDCA therapy were significantly associated with shortened survival times. Therefore, the results of this 
study suggest that cats with LC should preferably be treated with prednisone instead of UDCA.

\section{6- ESCH - DYGGVE}

AUTOANTIBODIES IN DOBERMAN HEPATITIS. Dyggve $\mathrm{H}^{1,2}$, Jarva $\mathrm{H}^{2}$, Spillmann $\mathrm{T}^{1}$, Meri $\mathrm{S}^{2}$, Speeti $\mathrm{M}^{1}$. ${ }^{1}$ Department of Equine and Small Animal Medicine, University of Helsinki, Finland, ${ }^{2}$ Department of Bacteriology and Immunology, Haartman Institute, University of Helsinki, Finland

Doberman hepatitis (DH) is strongly associated with homozygous DLA class II haplotype DRB1*00601/DQA1*00401/ DQB $1{ }^{*} 01303$ and especially with homozygous allele DLADRB1*00601. The disease shows a complex pattern of inheritance, but the strong DLA class II association with DH clearly indicates a role for the immune system in the development of the disease. Many autoimmune diseases are chronic diseases characterized by the presence of autoantibodies. Autoantibodies may also predict specific clinical manifestations, disease severity, and rate of progression. The occurance of autoantibodies indicates a permanent or transient loss of self-tolerance. The aim of this study was to evaluate autoantibodies in the sera of DH patients. We included 1 clinical DH dog and 9 subclinical DH dogs with follow-up samples, and 10 healthy controls in the study. Liver sample was obtained from a euthanized Doberman with mild hepatitis. Western blot assays were used to determine the presence of autoantibodies in DH dog sera towards dog liver proteins with anti-dog IgA as the primary antibody. There was a marked difference between the two groups. In conclusion, autoantibodies against liver proteins were found in all the DH sera before the onset of clinical disease, while the controls showed only weak reactivity. Immune reactivity was also enhanced in $\mathrm{DH}$ patients when compared to disease progression, suggesting a role of these antibodies for the hepatocellular injury. Thus, our findings suggest potential utility of an approach to diagnosis of DH before onset of symptoms that includes screening for autoantibodies to defined antigens.

\section{7- ESVC - GUNTHER}

INFLUENCE OF SAMPLE PREPARATION IN MEASUREMENT OF N-TERMINAL PRO-BRAIN NATIURETIC PEPTIDE (NT-PROBNP) IN CATS. Christina Günther, Nicola Hildebrandt, Esther Haâdenteufel, Estelle Henrich, Sonja Schiller, Matthias Schneider. Justus-Liebig-University Giessen, GIESSEN, Germany

The measurement of NT-proBNP in cats is performed in several study groups by using different types of blood samples (serum, EDTA-plasma, heparin-plasma). The stability of $\mathrm{N}$ terminal pro BNP is unknown in cats. So the manufacturing company of the cat specific NT-proBNP test gives the advice to centrifuge and freeze samples within 30 minutes. A new stabilisation tube shall increase the stability in the way that an unfrozen transport is possible.

Aim of this prospective study was to prove the difference in measurement of NT-proBNP in cats by using variable sample preparations.

Inclusion criterion was a cardiologic examination with concurrent blood withdrawal. The blood was collected from cephalic vein. In each case blood was taken and placed in serum- and EDTAtubes. Centrifugation for preparation of serum and plasma took place within 30 minutes. Two plasma-samples were transferred in stabilisation-tubes. One stabilized sample (plasma-S(+4)) was shipped refrigerated $\left(4^{\circ} \mathrm{C}\right)$, whereas all other samples were frozen at a temperature of $-20^{\circ} \mathrm{C}$ and shipped frozen in special canisters (serum(-20), plasma(-20), plasma $\mathrm{S}(-20))$. The transport was realized by a laboratory-own service. By arrival the laboratory noted the sample's condition (refrigerated/frozen) and excluded samples if necessary. The measurement occurred within $24 \mathrm{~h}$ after blood withdrawal using a commercially available ELISA (VETSIGN Feline Cardio SCREEN NTpro BNP, Biomedica Ltd). Each sample was tested twice. Sample data were analyzed by using a Friedman and Dunn's Multiple Comparison Test.

In a time period of 5 months 20 cats were included. Statistically, there is a significant $(\mathrm{P}<0.0001)$ difference over all groups. The concentrations in plasma-S(-20) were the highest (median 278.5;
IQR $90.5-597.5 \mathrm{pmol} / \mathrm{l})$ but not significant different to plasma$\mathrm{S}(+4)$ (median 271.5, IQR $86.5-552.5 \mathrm{pmol} / \mathrm{l}$ ). The plasma( 20) group (median 254.5, IQR 75.0-471.5 pmol/1) had significant lower concentrations than plasma-S( 20) but not significant different to plasma-S(+4) respectively serum(-20). Serum(-20) itself had significant lower concentrations (median 151.0, IQR 32.5-390.5 pmol/l) than both stabilized groups (plasma-S(-20) and plasma $S(+4)$ ).

In conclusion, the measurement of NT-pro BNP in cats is affected by sample preparation. Stabilization tubes allow refrigerated shipping of EDTA plasma for a period of 24 hours

\section{8 - ESVC - HEZZELL}

THE EFFECT OF PROTEASE INHIBITION ON TEMPORAL STABILITY OF NT-proBNP IN FELINE PLASMA AT ROOM TEMPERATURE. Melanie Hezzell, David Connolly, Rebecca Swan, Hattie Syme. The Royal Veterinary College, NORTH MYMMS, United Kingdom

Concentrations of plasma NT-proBNP may be diminished by post-collection proteolysis. The study hypothesis was that the addition of a protease inhibitor (PI) to feline plasma samples would improve the temporal stability of NT-proBNP.

Blood samples were collected into K3-EDTA-treated tubes from 39 cats with cardiac disease or hyperthyroidism. The samples were separated within 30 minutes of collection and the plasma stored at $-80^{\circ} \mathrm{C}$. The samples were thawed and each separated into 2 aliquots. These aliquots were classified as 'plain' (no PI added) or 'PI' (plasma mixed with PI in a commercially-available tube). Each of the resultant 78 aliquots was subdivided into 5 aliquots, which were stored at room temperature (RT) for zero, 24, 48, 96 or 120 hours before being returned to storage at $80^{\circ} \mathrm{C}$. If insufficient sample volume was available for subdivision into 5 aliquots the 48 hour aliquot was omitted. NT-proBNP was measured using a commercially-available ELISA (Vetsign Feline NT-proBNP, IDEXX). Results are reported as (median [25th, 75th percentile]). Comparisons between plain and PI groups were made using Wilcoxon signed-rank tests. Repeated measures linear mixed models were constructed to assess changes over time.

At time zero there was no difference in NT-proBNP measurements between plain and PI samples $(308.1[28.5,889.9]$ vs. 315.1 [8.7, 926.5] pmol/1; $\mathrm{p}=0.318)$. After 24 hours at RT NT-proBNP was significantly higher in the PI than the plain samples (212.1 [8.7, $694.1]$ vs. 128.8 [8.7, 492.2] pmol/1; p < 0.001). After 48 hours at RT NT-proBNP was significantly higher in the PI than the plain samples $(331.7[8.7,863.3]$ vs. $111.9[8.7,501.1] \mathrm{pmol} / 1 ; \mathrm{p}=0.002)$. After 96 hours at RT NT-proBNP was significantly higher in the PI than the plain samples $(242.4[8.7,531.6]$ vs. $18.3[8.7,168.3] \mathrm{pmol} / 1 ; \mathrm{p}<$ $0.001)$. After 120 hours at RT NT-proBNP was significantly higher in the PI than the plain samples $(197.1[8.7,586.2]$ vs. $8.7[8.7,185.2]$ $\mathrm{p}<0.001)$. An overall effect of time at RT was detected for the plain samples $(\mathrm{p}<0.001)$. Measurements were significantly different between each time point except between 24 and 48 hours $(p=0.151)$ and between 96 and 120 hours $(\mathrm{p}=0.088)$. An overall effect of time at RT was detected for the PI samples $(\mathrm{p}=0.041)$ but there was no significant difference in measurements between any of the individual time points. Without Bonferroni corrections there was a significant difference between time zero and $96(\mathrm{p}=0.038)$ and 120 hours $(\mathrm{p}=$ 0.007) at RT for the PI samples.

In conclusion, the addition of PI to feline plasma significantly reduces, but does not eliminate, the degradation of NT-proBNP at RT. Transportation times of samples $>48$ hours for laboratory analysis may alter the clinical interpretation of results.

\section{9- ESVC - GREEN}

CHANGES IN PLASMA NT-ProBRAIN NATRIURETIC PEPTIDE CONCENTRATION IN DOGS TREATED FOR CONGENITAL HEART DISEASE. Henry Green ${ }^{1}$, Eryn Shipley ${ }^{1}$, Nonya Fiakpui $^{1}$, Sarah Silverman ${ }^{2}$, Daniel Hogan ${ }^{2}$, Kimberly Sederquist ${ }^{2}$. ${ }^{1}$ Purdue Universiy SVM, WEST LAFAYETTE, IN, United States of America, ${ }^{2}$ Purdue University SVM, WEST LAFAYETTE, IN, United States of America

Patent ductus arteriosus (PDA) and pulmonic stenosis (PS) are two of the most commonly treated congenital heart defects in dogs. 
PDA results in volume overload of the left ventricle whereas PS leads to pressure overload of the right ventricle (RV). Definitive therapy is sought in PDA by closure of the patent vessel whereas balloon valvuloplasty treatment for PS typically results in a decrease pressure gradient measurement in the RV. Brain natriuretic peptide (BNP) is released primarily by the ventricular myocardium secondary to stress within the myocytes. The N-terminal portion of this peptide (NT-proBNP) has proven to be a useful measure of BNP release into circulation. Plasma concentration of NT-proBNP has been utilized to assess the presence of ongoing myocardial damage and to assess cardiac therapeutic benefits in human medicine. This pilot study sought to assess changes in plasma NT-proBNP levels in dogs that were treated for PDA and PS.

Twenty dogs diagnosed with PDA and or PS were treated by closure of the PDA or with balloon valvuloplasty for PS. Plasma NTproBNP levels were assessed prior to and 1-month post therapeutic intervention.

Of the twenty cases, PDA was diagnosed in 12 dogs; PS in 6 and 2 dogs were affected and treated for both disorders in one procedure. In PS only group there were 4 males and 2 females whereas in the PDA only group there were 9 females and 2 males. There was 1 male and 1 female affected with both defects. Average NT-proBNP levels were not significantly different in the PS group pre and post samples $(1734 \pm 1198 \mathrm{pmol} / \mathrm{L}$ vs. $1770 \pm 1020 \mathrm{pmol} / \mathrm{L}, \mathrm{p}=0.96)$. In dogs with PDA, while there was a trend for decrease in NT-proBNP levels post closure, this did not reach statistical significance (1574 \pm $942 \mathrm{pmol} / \mathrm{L}$ vs. $1118 \pm 1073 \mathrm{pmol} / \mathrm{L}, \mathrm{p}=0.30$ ); despite normalization of 2D-echocardiogram measures. This trend was more evident when dogs over two years of age were removed from analysis however did not quite reach statistical significance (1232.2 \pm 875.3 vs. $537 \pm 508.8 \mathrm{P}=0.08)$. There was a significant difference in NTproBNP levels in treated PDA vs. treated PS dogs $(537 \pm 508.8$ vs. $1769.8 \pm 1019.7, \mathrm{p}<0.01)$. No difference was noted in the pretreatment groups. The two dogs afflicted with both PDA and PS showed no significant changes in NT-proBNP levels following therapy for both defects.

Plasma NT-proBNP levels tend to remain increased in dogs with PS versus dogs with PDA which likely the result from differences in treatment outcomes for these two diseases. Increased NT-proBNP levels could indicate ongoing myocardial stress despite reduced right ventricular pressures. Older dogs with PDA maintain increased NTproBNP levels one month post closure. This likely represents ongoing myocardial damage or a delayed healing process in older dogs with corrected PDAs. Long term follow-up will be required to help determine this outcome.

\section{0- ESVC - OYAMA}

NOVEL CIRCULATING BIOMARKERS IN DOGS AND CATS WITH HEART DISEASE. Mark Oyama ${ }^{1}$, Dennis Trafny ${ }^{1}, \mathrm{R}$ Gupta $^{2}$, Hani Sabbah ${ }^{2}$. ${ }^{1}$ University of Pennsylvania, PHILADELPHIA, PA, United States of America, ${ }^{2}$ Henry Ford Health System, DETROIT, MI, United States of America

Cardiac biomarkers are used in human medicine for disease screening, diagnosis, monitoring, and risk stratification. We sought to investigate potential biomarkers in dogs and cats with heart disease. Galectin-3 (GAL3), a soluble beta-galactoside-binding lectin that participates in the regulation of cardiac fibrosis and remodeling, is increased in humans with heart failure and provides prognostic information independent of NT-proBNP. Copeptin (CP), the C-terminal portion of prepro-arginine vasopressin, is also increased in humans with heart failure and provides prognostic information that is superior to NT-proBNP. Based on their role as emerging biomarkers in humans, we sought to quantify circulating concentrations of GAL3 and CP in dogs with degenerative mitral valve disease (MVD) and cats with hypertrophic cardiomyopathy (HCM).

Ten dogs and 10 cats were recruited. The canine cohort included 5 healthy dogs with no heart murmur and 5 dogs with moderate to severe MVD. The feline cohort included 5 healthy cats with no heart murmur and normal echocardiograms and 5 cats with moderate to severe HCM. EDTA plasma was obtained from all patients and frozen at $-20 \mathrm{C}$ until batch ELISA for GAL3 and CP.

The following data describe the canine cohort: healthy: age, $5.6 \pm$ 3.2 yrs; sex, 1 FS, 4 MC; MVD: age, $8.8 \pm 2.3$ yrs; sex, 4 FS, 1 MC; wt, $7.25 \pm 1.3 \mathrm{kgs} ;$ LA/Ao, $2.44 \pm 0.61$. Mean GAL3 was not significantly different between healthy and MVD groups (GAL3 healthy, $1135 \pm 156 \mathrm{pg} / \mathrm{ml}$ vs. MVD, $1209 \pm 59 \mathrm{pg} / \mathrm{ml} ; \mathrm{P}=0.34)$ whereas mean CP was significantly higher in dogs with MVD (CP healthy, $14.3 \pm 2.8 \mathrm{pg} / \mathrm{ml}$ vs. MVD, $19.5 \pm 2.3 \mathrm{pg} / \mathrm{ml} ; \mathrm{P}=$ $0.014)$.

The following data describe the feline cohort: age, $3.8 \pm 3.2 \mathrm{yrs}$; sex, $5 \mathrm{MC}$; HCM: age, $7.0 \pm 3.0 \mathrm{yrs}$; sex, $5 \mathrm{MC}$; LA/Ao, $1.35 \pm 0.30$ IVSd, $0.70+0.17 \mathrm{~cm}$; LVPWd, $0.73+0.15 \mathrm{~cm}$. Mean GAL3 was not significantly different between healthy and HCM groups (GAL3 healthy, $1279 \pm 139 \mathrm{pg} / \mathrm{ml}$ vs. HCM, $1337 \pm 80 \mathrm{pg} / \mathrm{ml} ; \mathrm{P}=0.44)$, whereas mean CP was significantly higher in cats with HCM (CP healthy, $13.8 \pm 0.99 \mathrm{pg} / \mathrm{ml}$ vs. HCM, $25.4 \pm 10.8 \mathrm{pg} / \mathrm{ml} ; \mathrm{P}=0.044)$.

The results of this study reveal that $\mathrm{CP}$ is elevated in dogs and cats with heart disease and may be a useful biomarker of MVD and HCM. Additional studies to determine the diagnostic and prognostic value of $\mathrm{CP}$ in larger canine and feline patient populations are warranted.

\section{1 - ESVC - ZOIS}

SERUM CYTOKINE CONCENTRATIONS IN DOGS WITH DIFFERENT DEGREE OF MYXOMATOUS MITRAL VALVE DISEASE. Nora Elisabeth Zois ${ }^{1}$, Sophia Gry Moesgaard ${ }^{2}$, Mads Kjelgaard-Hansen ${ }^{3}$, Caroline Elisabeth Rasmussen ${ }^{2}$, Torkel Falk ${ }^{2}$ Jens Häggström ${ }^{4}$, Henrik Duelund Pedersen ${ }^{5}$, Lisbeth Høier Olsen ${ }^{2}$. ${ }^{1}$ University of Copenhagen, Faculty of Life Sciences, FRED ERIKSBETRG, Denmark, ${ }^{2}$ University of Copenhagen, Department of Basic Animal and Veterinary Sciences, FREDERIKSBERG, Denmark, ${ }^{3}$ University of Copenhagen, Department of Small Animal Clinical sciences, FREDERIKSBERG, Denmark, ${ }^{4}$ Swedish University of Agricultural Sciences, Department of Physiology, UPPSALA, Sweden, ${ }^{5}$ Zealand Pharma, GLOSTRUP, Denmark

Cytokines are soluble polypeptides playing an important role in immunoregulation and inflammation. It has been suggested that changes in concentration of circulating cytokines and/or in local expression of these factors in the heart may be implicated in the pathophysiology of myxomatous mitral valve disease (MMVD) in dogs. Thus, the aim of this study was to investigate the serum concentration of cytokines in dogs with different degree of MMVD. Granolycyte-macrophage colony-stimulating factor (GM-CSF), interferon-? (INF-?), interleukin (IL) 2, IL-4, IL-6, IL-7, IL-8, IL-10, IL-15, IL-18, keratinocyte-derived chemokine (KC), interferon-?induced protein (IP-10), monocyte-chemotactic protein-1 (MCP-1), and tumor necrosis factor a (TNF-a) were simultaneous measured using a commercially available canine specific multiplex immunoassay (Milliplex). The study included 68 dogs divided into 5 groups: 1 ) Cairn Terriers (CT) with no or minimal mitral regurgitation (MR), 2) cavalier King Charles spaniels (CKCS) with no or minimal MR, 3) CKCS with mild MR, 4) CKCS with moderate to severe MR, and 5) dogs of different breed with clinical signs of congestive heart failure (CHF) due to MMVD, stable on treatment. All dogs underwent a clinical examination, hematological and biochemistry evaluation, and echocardiography in connection with the blood sampling. Detectable concentrations of GM-CSF, IL-2, IL-7, IL-8, IL-10, IL-15, IL-18, KC, and MCP-1 were found in the majority of included dogs, while canine IFN-?, IL-4, IL-6, IP-10, and TNF-a could only be measured in few dogs, or not at all Cairn Terriers had a significantly lower serum concentration of MCP-1 than CKCS with no or minimal MR $(\mathrm{P}=.03)$, CKCS with moderate or severe MR $(\mathrm{P}=.03)$, and dogs in CHF $(\mathrm{P}=.001)$ suggesting a breed difference, but also an increase in MCP-1 with disease severity. Assessing the 44 CKCS separately by multiple regression analysis with stepwise, backward elimination, decreasing concentration of IL-7 was associated to increasing MR $(\mathrm{P}=.02)$ and to increasing left atrium size $(\mathrm{P}=.02)$. IL- 8 decreased with increasing left ventricular end-systolic internal dimensions $(\mathrm{P}$ $=.02$ ). Gender and weight were not associated with any of the cytokines. In conclusion, few and weak associations were found: MCP-1 differed between CKCS and CT, and increased with increasing MMVD severity, however, IL-7 and IL-8 decreased with increasing indices of disease severity. These results show that MMVD in dogs is associated with changes in certain inflammatory parameters. 
072- ESVC - TIDHOLM

COMPARISONS OF THREE-DIMENSIONAL AND TWODIMENSIONAL ECHOCARDIOGRAPHIC METHODS IN ESTIMATING LEFT ATRIAL SIZE IN DOGS WITH AND WITHOUT MYXOMATOUS MITRAL VALVE DISEASE. Anna Tidholm ${ }^{1}$, Anna Bodegård Westling ${ }^{1}$, Katja Höglund ${ }^{2}$, Ingrid Ljungvall ${ }^{3}$, Jens Häggström ${ }^{3}$. ${ }^{1}$ Albano Animal Hospital, DANDERYD, Sweden, ${ }^{2}$ Dept of Anatomy, Physiology and Biochemistry, UPPSALA, Sweden, ${ }^{3}$ Dept of Clinical Sciences, Faculty of Veterinary Medicine, UPPSALA, Sweden

The aim of the study was to compare 3 different two-dimensional (2D)-based echocardiographic methods to estimate the indexed size of the left atrium (LA) with realtime three-dimensional echocardiography (RT3D) assessment of LA volume indexed to body weight

Seventy dogs of 33 different breeds were examined with 2D and RT3D echocardiography. LA and aortic (Ao) diameter and area in short-axis view (SAX) and LA diameter in long-axis view (LAX) were determined using $2 \mathrm{D}$ methods. RT3D technique was used to estimate LA volumes. The values of LA size were indexed and comparisons were made between LA volume $/ \mathrm{kg}$ estimated by RT3D echocardiography, LA to Ao diameter ratio in SAX (LA/Ao), LA area to Ao area ratio (LAarea/Aoarea), and LA diameter in LAX to Ao diameter in SAX (LAlax/Aosax) using 2D. The Bland-Altman plot was used to assess the agreement between 2 methods by plotting the mean value of the two methods by absolute difference. Statistical analysis included Wilcoxon signed-rank test and KruskalWallis test.

According to findings on physical examination and 2D/doppler echocardiography, dogs were classified with myxomatous mitral valve disease (MMVD) $(n=44)$ or without heart disease $(n=26)$. Body weight ranged from 2.9 to $39 \mathrm{~kg}$ with a median of $8.7 \mathrm{~kg}$ for dogs with MMVD and $15 \mathrm{~kg}$ for dogs without heart disease. In both dogs with and without MMVD, the RT3D method underestimated LA size in comparison with the LA/Ao ratio at lower values, whereas the LA size was overestimated at higher values. In comparison with LAlax/Aosax, RT3D underestimated LA size at lower values, whereas LA size was overestimated at higher values in MMVD dogs, although the two methods showed comparably good agreement in dogs without heart disease. In both dogs with and without MMVD, LAarea/Aoarea overestimated LA size in comparison with the RT3D method. The difference between methods increased with increasing LA size for all comparisons. Comparisons among the 3 different 2D-based methods for estimation of LA size showed that LAarea/Aoarea and LAlax/Aosax overestimated LA size in comparison with LA/Ao with increasing differences as LA enlarges. Likewise, LAarea/Aoarea overestimated LA size in comparison with LAlax/Aosax.

In conclusion, none of the 2D-based methods showed good agreement with the RT3D method in estimating LA size. The bes agreement was found between RT3D and LAlax/Aosax in dogs without heart disease. As the RT3D estimation of volumes was not evaluated against a gold-standard technique such as magnetic resonance imaging, this new technique could not be evaluated for accuracy.

073-ESVC - HEZZELL

RELATIONSHIPS BETWEEN SYSTOLIC BLOOD PRESSURE MEASUREMENT, ECHOCARDIOGRAPHIC VARIABLES AND OUTCOME IN DOGS WITH MITRAL VALVE DISEASE. Melanie Hezzell, Adrian Boswood, Jonathan Elliott. The Royal Veterinary College, NORTH MYMMS, United Kingdom

Monitoring of systolic blood pressure (SBP) is recommended in dogs with myxomatous mitral valve disease (MMVD). The study hypothesis was that higher SBP would be associated with ventricular hypertrophy and reduced survival times.

SBP was measured in dogs with naturally-occurring MMVD and healthy control dogs by Doppler sphygmomanometry. The mean of at least 5 measurements was used for analysis. Echocardiographic variables were measured in dogs with MMVD by standard techniques. Results are reported as [Median (IQR)]. Comparisons of continuous variables were made between groups with Mann-Whitney tests. Proportions were compared with Fishers' exact test. Survival times (all-cause mortality) were compared by the log rank test and Cox regression. Correlations were assessed using Spearman's correlation coefficient.

One hundred and twenty dogs with MMVD and 24 control dogs were studied. There was no difference in age (years) between normal [9.3 (7.0, 11.1)] and MMVD dogs $[10.0(8.4,11.7)](\mathrm{p}=0.206)$ There was no difference in weight $(\mathrm{kg})$ between normal [11.0 (7.1, $13.5)]$ and MMVD dogs $[10.8(8.3,13.4)](\mathrm{p}=0.723)$. There was no difference in SBP $(\mathrm{mmHg})$ between normal $[158.2(149.5,179.5)]$ and MMVD dogs $[151.3(132.4,178.6)](\mathrm{p}=0.158)$.

In dogs with MMVD LA/Ao [1.3 (1.2, 1.5)], LVEDDN [1.7 (1.5, 1.9)], LVESDN $[1.0(0.9,1.1)$, LVFWD $[0.9(0.8,1.0)]$, LVFWS $[1.2$ $(1.1,1.4)]$, IVSD $[0.9(0.8,1.0)]$ and IVSS $[1.2(1.0,1.3)]$ were measured. 29 dogs had SBP $=180 \mathrm{mmHg}(24.2 \%)$ and 14 had SBP $=$ $200 \mathrm{mmHg}(11.7 \%)$. Dogs were categorised into SBP $<180 \mathrm{mmHg}$ (group 1) and $\mathrm{SBP}=180 \mathrm{mmHg}$ (group 2). There was no difference between groups in the proportions of dogs receiving medications that could potentially affect blood pressure. There was no difference in the proportion of dogs with hyperadrenocorticism between groups $1(\mathrm{n}=1)$ and $2(\mathrm{n}=1)(\mathrm{p}=0.433)$. No dog had clinically evident renal disease.

There was no difference in survival time between groups 1 (median $=889$ days, $95 \% \mathrm{CI}=593.1$ to 1184.9$)$ and $2($ median $=560$ days, $95 \% \mathrm{CI}=444.8$ to 675.2$)(\mathrm{p}=0.298)$. Considered as a continuous variable SBP had no effect on survival $(p=0.530)$.

Weak positive correlations were detected between SBP and LVFWD $(\mathrm{p}=0.035, \mathrm{rs}=0.194)$ and LVFWS $(\mathrm{p}=0.026, \mathrm{rs}=$ 0.205 ). No correlations were detected between SBP and age, weight, heart rate, IVSD, IVSS, LVEDDN, LVESDN, LA/Ao or NT-proBNP.

\section{5-ESVC - COPELAND}

USE OF A SCORING SYSTEM FOR DILATED CARDIOMYOPATHY TO IDENTIFY BREED-SPECIFIC REFERENCE RANGES FOR ECHOCARDIOGRAPHY IN GREAT DANES. Hannah Copeland, Sonja Fonfara, Jordi Lopez-Alvarez, Peter Cripps, Jo Dukes-McEwan. University of Liverpool, NESTON, United Kingdom

Great Danes are well known as a breed predisposed to developing dilated cardiomyopathy. The disease is reported to have an estimated prevalence of $3.9 \%$ in this breed, and the Great Dane is cited as one of the most common breeds with dilated cardiomyopathy.

Koch et al (1996) have published reference ranges for echocardiography in Great Danes and suggested that systolic function of the left ventricle is impaired compared to other breeds.A European Society of Veterinary Cardiology Taskforce recently suggested a scoring system to identify dogs with dilated cardiomyopathy. A score of 6 or higher should identify dogs with DCM, based on major ( 3 points) and minor ( 1 point) criteria.

In this study, 68 Great Danes were screened as part of an ongoing genetic study (The LUPA Project). Dogs were aged between 5 and 12 years. Twenty seven dogs $(39.7 \%)$ were male. Echocardiography was carried out in all dogs and analysed by two authors (HC and JDM) and dogs were assigned a DCM score based on echocardiographic findings. Dogs were considered normal if they had a DCM score of 0-2 (a maximum of two minor criteria allowed), equivocal if they scored 3-5, and affected if the score was 6 or higher. Median values and $95 \%$ confidence intervals for left ventricular dimensions (M mode), indices of systolic function and sphericity index were calculated for each group.

Twenty dogs were classified as normal, 18 dogs were affected and 29 were equivocal. There was no significant difference in body weight $(P=0.62)$ or age $(P=0.78)$ between the groups.

Significant differences were identified between normal and affected dogs for all echocardiographic criteria analysed $(\mathrm{P}=$ 0.03 ). The upper confidence intervals for echocardiographic measurements were compared with those previously identified by Koch et al (1996). In normal Great Danes, the upper confidence intervals for M-mode left ventricular dimensions and Simpson's derived end systolic volume index were lower than those described by Koch et al.

Preliminary findings of this study suggest that the prevalence of DCM in Great Danes in the United Kingdom $(29.4 \%)$ could be higher than previously reported. Echocardiographic results suggest that previously published reference ranges for Great Danes may overestimate normal values for $\mathrm{M}$-mode left ventricular internal dimensions. 
076- ESVC - PAYNE

TRANSMITRAL FLOW VELOCITY PATTERNS AND SURVIVAL IN FELINE HYPERTROPHIC CARDIOMYOPATHY. Jessie Rose Payne ${ }^{1}$, Virginia Luis Fuentes ${ }^{1}$, David J Connolly ${ }^{1}$, Simon Dennis ${ }^{1}$, Adrian Boswood ${ }^{1}$, Tobias Wagner ${ }^{1}$, Pierre Menaut ${ }^{2}$, Dianna Evans ${ }^{1}$. ${ }^{1}$ Royal Veterinary College, HATFIELD, United Kingdom, ${ }^{2}$ Clinique Vétérinaire Aquivet, EYSINES, France

Hypertrophic cardiomyopathy (HCM) is the most common feline cardiomyopathy, and has a very variable prognosis. The objective of this study was to evaluate the prognostic value of echocardiographic measures of diastolic function in cats with HCM.

Clinical and echocardiographic records were reviewed of cats diagnosed with HCM from July 2004 - August 2009 at the Queen Mother Hospital for Animals, Royal Veterinary College. Diastolic function was classified based on early (E) and atrial (A) transmitral flow velocities and tissue Doppler imaging mitral annular early velocities $\left(\mathrm{e}^{\prime}\right)$. Diastolic function was classed as normal (E/A 1-2, E/e $\mathrm{e}^{\prime}$ $<10$ ); delayed relaxation (E/A < 1); pseudonormal (E/A 1-2, E/e $\geq 10)$ or restrictive $(E / A>2)$. Cardiac mortality data were obtained using clinical records and by contacting referring veterinarians, censoring for noncardiac deaths.

Survival data were obtained in 221/304 cats with HCM, with overall median survival $>1,966$ days. Sufficient data to determine the diastolic filling pattern was available in 132 cats, with differing survival between the 4 diastolic function groups (log rank, p < 0.0001 ). Median survival in the normal diastolic function group was $>905$ days; delayed relaxation > 1,947 days; pseudonormal > 1,822 days and restrictive 246 days. There was no difference in survival between normal, delayed relaxation and pseudonormal cats (log rank, $\mathrm{p}=0.1785)$.

Cats with restrictive diastolic function have a worse prognosis than cats with normal, delayed relaxation or pseudonormal diastolic function.

\section{7- ESVC - MARGIOCCO}

PHARMACOKINETICS OF ORAL PIMOBENDAN IN HEALTHY CATS: A SINGLE DOSE STUDY. Andrew Hanzlicek, Marco Margiocco, Ronette Gehring, Butch Kukanich, Katherine Stenske, Michele Borgarelli. Kansas State University, MANHATTAN, KS, United States of America

At this time there is no available information on the pharmacokinetics of pimobendan in cats, and thus the purpose of this study.

Pimobendan (Vetmedin ${ }^{\mathbb{R}} 1.25 \mathrm{mg}$ chewable tablet, Boehringer Ingelheim Vetmedica, Inc. St. Joseph, MO USA) was administered orally to ten adult healthy male castrated domestic short hair cats (mean body weight $=4.57 \pm 0.56 \mathrm{~kg}$; range $=3.60-5.32 \mathrm{~kg}$ ) at a dose of $1.25 \mathrm{mg}$ per cat (mean dose $0.28 \pm 0.04 \mathrm{mg} / \mathrm{kg}$; range = $0.23-0.35 \mathrm{mg} / \mathrm{kg}$ ). Plasma drug concentrations were quantified before and at specified time points after drug administration using a validated high-pressure liquid chromatography/mass spectrometry method.

Plasma pimobendan levels were quantifiable after oral administration of pimobendan in all cats. Time-concentration data for pimobendan were analyzed with a compartmental model $(1 \mathrm{com}-$ partment with first order absorption, lag time and first order elimination) using commercially available software (WinNonlin ${ }^{\circledR}$, Pharsight Corporation, Cary, NC). One cat vomited three times within 10 minutes of drug administration and had very low plasma drug concentrations. Another cat showed delayed absorption. These two cats were excluded from the final descriptive statistical analysis.

After a lag time $\left(\mathrm{T}_{\mathrm{lag}}\right)$ (range $=0.01-0.5$ hours), pimobendan was rapidly absorbed (absorption half-life $=0.2 \pm 0.07$ hours) and fell rapidly (elimination half-life $=1.5 \pm 0.2$ hours). Maximum plasma concentrations $\left(\mathrm{C}_{\max }\right)$ (range: 11.1 to $59.4 \mathrm{ng} / \mathrm{mL}$ ) were predicted between 0.9 and 1.7 hours $\left(\mathrm{T}_{\mathrm{max}}\right)$.

These results show that pimobendan is rapidly absorbed in healthy cats and characterized by $\mathrm{C}_{\max }$ more than four times higher than what has been described in dogs. Also, compared to dogs, our study showed that cats have an elimination half-life approximately three times longer. Differences in plasma concentration profiles between dogs and cats may be attributable to differences in bio- availability, volume of distribution or clearance. Intravenous studies would be needed to distinguish between these factors. This model provides a basis for designing a multiple-dose regimen to attain target plasma concentrations.

078- ESVC - MISBACH

ECHOCARDIOGRAPHIC AND TISSUE DOPPLER IMAGING ALTERATIONS ASSOCIATED WITH SPONTANEOUS CANINE SYSTEMIC ARTERIAL HYPERTENSION. Charlotte Misbach $^{1}$, Vassiliki Gouni ${ }^{1}$, Renaud Tissier ${ }^{2}$, Emilie Trehiou ${ }^{1}$, Amandine Petit ${ }^{1}$, Carolina Carlos Sampedrano ${ }^{1}$, Jean-Louis Pouchelon ${ }^{3}$, Valérie Chetboul ${ }^{3}$. ${ }^{1}$ Unité de Cardiologie d'Alfort, Ecole Nationale Vétérinaire d'Alfort, MAISON-ALFORT, France, ${ }^{2}$ UMR INSERM, Unité de Pharmacie-Toxicologie, Ecole Nationale Vétérinaire d'Alfort, MAISON-ALFORT, France, ${ }^{3}$ UMR INSERM, Unité de Cardiologie d'Alfort, Ecole Nationale Vétérinaire d'Alfort, MAISON-ALFORT, France

Target organs of systemic arterial hypertension (SHT) include eyes, kidney, brain and heart. Feline SHT has been shown to be associated with a wide spectrum of left ventricular (LV) geometric patterns with longitudinal and, to a lesser extent, radial myocardial dysfunction as assessed by tissue Doppler imaging (TDI). However, cardiac morphologic and functional alterations associated with canine SHT have not yet been extensively studied. The aim of this prospective observational study was therefore to describe echocardiographic and TDI findings in hypertensive dogs.

The study population consisted of client-owned dogs with untreated SHT $(\mathrm{n}=30$, SHT group; $9.6 \pm 3.3$ years, $19.7 \pm 11.2 \mathrm{~kg})$, and age- and body-matched healthy dogs $(\mathrm{n}=20$, control group; $8.1 \pm 1.7$ years, $20.4 \pm 13.2 \mathrm{~kg}$ ). Systolic arterial blood pressure (SABP) was measured according to the ACVIM consensus statement using the oscillometric and Doppler methods for dogs $>$ and $<15 \mathrm{~kg}$, respectively. SHT was defined as SABP $>180 \mathrm{mmHg}$. Dogs with SABP between 160 and $180 \mathrm{mmHg}$ or stressed dogs were excluded from the study. All dogs underwent conventional echocardiography. A two-dimensional color TDI examination was performed in all control dogs and in 16/30 dogs with SHT by the same trained observer (VC) who was blinded to the SABP values.

SABP was higher in SHT dogs as compared to controls (197.6 \pm 24.5 vs $135.5 \pm 17.7 \mathrm{mmHg}, \mathrm{p}<0.001) .77 \%(23 / 30)$ of SHT dogs showed an abnormal LV geometric pattern, i.e., symmetric $(78 \%)$ or asymmetric $(22 \%)$ diffuse concentric hypertrophy. None of them showed left atrial dilation. The shortening fraction was higher in the SHT group $(43 \pm 7.9 \%$ vs $35 \pm 3.4 \%$ for controls, $\mathrm{p}<0.05)$. Aortic insufficiency (AoI) associated with proximal aortic dilation was found in 10/30 (33\%) SHT dogs. In TDI, longitudinal left ventricular free wall (LVFW) was altered in SHT dogs at the base (early to late diastolic wave ratio, $\mathrm{E} / \mathrm{A}=0.67 \pm 0.65$ vs $1.4 \pm 0.3$ for controls, $\mathrm{p}<0.001)$. Similar results were observed for longitudinal motion of the interventricular septum $(\mathrm{E} / \mathrm{A}=0.70 \pm 0.43$ vs $1.1 \pm 0.06, \mathrm{p}<$ $0.05)$ and radial motion of the sub-endocardial LVFW $(\mathrm{E} / \mathrm{A}=$ $0.97 \pm 0.54$ vs $1.62 \pm 0.41, \mathrm{p}<0.001)$. Systolic base-to-apex and radial LVFW gradients were also decreased $(\mathrm{p}<0.05)$.

In conclusion, as in feline SHT, canine SHT is associated with diastolic and systolic myocardial dysfunction regardless of myocardial wall thickness. However, unlike feline SHT, it results in a homogeneous LV geometric pattern with a relatively high prevalence of AoI

\section{9- ESVC - PALERMO}

CARDIOMYOPATHY IN BOXER DOGS FROM THE UK: A COMPARISON BETWEEN THE ARRHYTHMIC AND THE MYOCARDIAL DYSFUNCTION FORM. Valentina Palermo ${ }^{1}$, Mike Stafford Johnson ${ }^{2}$, Elisabetta Sala ${ }^{3}$, Paola Giuseppina Brambilla $^{1}$, Mike Martin ${ }^{2} .{ }^{1}$ University of Milan, MILAN, Italy, ${ }^{2}$ Veterinary Cardiorespiratory Centre, KENILWORTH, United Kingdom, ${ }^{3}$ Busto Arsizio Hospital, VARESE, Italy

There are few publications describing populations of Boxers affected by cardiomyopathy; most of the more recent studies come from the USA and no survival studies are available. 
The aim of this study was to retrospectively evaluate signalment, clinical and diagnostic findings, survival and prognostic factors in a population of Boxer dogs with cardiomyopathy from the UK, in order to improve our knowledge of this disease.

Medical records of Boxers referred between 1993 and 2008 in which a diagnosis of ventricular arrhythmias and/or cardiomyopathy was made, were reviewed. Information obtained included clinical presentation, results of electrocardiography, 24-h Holter monitoring, thoracic radiography, Doppler echocardiography and outcome. Dogs were divided into two groups in relation to left ventricular (LV) systolic diameter, normal or dilated (group A and B respectively).

Results. Seventy-nine dogs met the inclusion criteria for the study, 20 in group A and 59 in group B. Males were over-represented in both groups (M:F ratio 1.5:1); mean age of dogs was 91.7 \pm 32.2 months in group A and $68.6 \pm 28.6$ in group $\mathrm{B}(\mathrm{p}=0.002)$. The most common clinical sign was syncope in both groups $(80 \%$ in group A and $67.7 \%$ in group B) and signs of congestive heart failure were common in Boxers with LV dilation. The majority of dogs had ventricular tachyarrhythmias, particularly with left bundle branch block (LBBB) morphology ( 70 and $62 \%$ of group A and B). Right bundle branch block (RBBB) morphology was more frequent in group B dogs. All the dogs in which a Holter was performed showed various grades of ventricular arrhythmias, which were often not detected on an ECG recording. Comparing the two groups, dogs in group A had a better outcome than dogs in group B (median survival time of 124 and 17 weeks respectively, $p<0.0001$ ). In group $B$, dogs with a history of syncope had a worse outcome (median survival time of 10 weeks) compared with dogs not showing syncope (median survival time 24 weeks) $(\mathrm{p}=0.03$ ).

In conclusion, Boxer cardiomyopathy in the UK has close similarities to cardiomyopathy in dogs from USA, but our work showed a different prevalence of the forms of the disease, with most of the dogs having the myocardial dysfunction form. The prognosis was worse in dogs with the myocardial dysfunction form compared to dogs with a normal LV and ventricular arrhythmias. Dogs with LV dilation and syncope had a worse prognosis than those without.

\section{0- ESVC - DENNIS}

EFFECT OF HIGH DOSE ASPIRIN ON SERUM THROMBOXANE B2 IN CATS WITH MYOCARDIAL DISEASE. Simon Dennis, Ludovic Pelligand, Virginia Luis Fuentes, Fiona Cunningham. Royal Veterinary College, HATFIELD, United Kingdom

Inhibition of cyclooxygenase-1 (COX-1) by aspirin has been demonstrated in healthy cats. We sought to investigate the effect of aspirin in cats with myocardial disease. The hypothesis was that high dose aspirin therapy in cats with myocardial disease will effectively inhibit platelet $\mathrm{COX}-1$, reducing serum thromboxane $\mathrm{B}_{2}$ $\left(\mathrm{TxB}_{2}\right)$ concentrations.

In a cohort study, 23 cats were diagnosed with myocardial disease and left atrial dilatation at the Queen Mother Hospital for Animals, Royal Veterinary College. Serum $\mathrm{Tx}_{2}$ was measured ex vivo prior to and 1-3 weeks after the start of aspirin $75 \mathrm{mg}$ PO q72h, which was administered to the cats by their owners at home. Adverse effects potentially related to aspirin therapy were monitored. Concurrent medications for cardiac disease were administered as appropriate.

Twelve cats completed the study, 5 did not return, 4 did not receive aspirin per protocol, and in 2 cats a post-aspirin blood sample was not obtained. Following aspirin therapy, serum $\mathrm{TxB}_{2}$ was reduced in $11 / 12$ cats that completed the study, with a median inhibition of $98.1 \%$ (range 60.6 to $99.8 \% ; \mathrm{P}=0.003$ ). All 6 cats sampled $<1$ day post-pill had $>95 \%$ inhibition of serum $\mathrm{TxB}_{2}$. In the 6 cats sampled $>1$ day post-pill, only 2 had $>95 \%$ inhibition of serum $\mathrm{TxB}_{2}$. The degree of inhibition at $<1$ day was not known for these 6 cats. Twenty nine percent of cats that received aspirin per protocol had gastrointestinal signs, which resolved following cessation of aspirin therapy.

We conclude that administration of $75 \mathrm{mg}$ aspirin $\mathrm{PO} q 72 \mathrm{~h}$ to cats with myocardial disease appears to inhibit platelet COX-1 effectively, but adverse effects were common and the dosing interval may require modification in some animals.

\section{1- ESVC - GREEN}

CARDIAC HEALTH SCREENING in 221 IRISH WOLFHOUND DOGS: THE NORTH AMERICAN EXPERIENCE. Henry Green $^{1}$, Ashley Naramore ${ }^{2}$ Jessica Kirkpatrick ${ }^{3}$, Mariellen Dentino, $^{4}$, William Tyrell, $\mathrm{Jr}^{5}$. ${ }^{1}$ Purdue Universiy SVM, WEST LAFAYETTE, IN, United States of America, ${ }^{2}$ Purdue University, WEST LAFAYETTE, IN, United States of America, ${ }^{3}$ Purdue University SVM, WEST LAFAYETTE, IN, United States of America, ${ }^{4}$ Nephrology Associate, LLC and Indiana University School of Medicine, EVANSVILLE, IN, United States of America, ${ }^{5}$ Chesapeke Veterinary Cardiology Associates, ROCK VILLE, MD, United States of America

Irish wolfhounds (IW) are commonly diagnosed with cardiovascular disease. Atrial fibrillation and cardiomyopathy are the two most commonly diagnosed cardiac disorders in this breed. In a retrospective study of 500 dogs, dilated cardiomyopathy (DCM) was diagnosed in $24 \%$ of dogs and atrial fibrillation (AF) was found in $21 \%$ of this population. There historically appears to be an association of atrial fibrillation with DCM. In this same retrospective study, atrial fibrillation was noted in $87 \%$ of dogs with cardiomyopathy. Of the 49 dogs diagnosed with occult DCM, $73.5 \%$ of this group was in atrial fibrillation. Our study assessed the occurrence of cardiac disease in a non referral population of Irish wolfhounds. Secondarily we sought to compare the incidence of DCM in dogs with atrial fibrillation compared with dogs in normal sinus rhythm.

Over an 8 year period Irish wolfhound dogs over the age of two were recruited to screen for the presence of cardiac disease utilizing electrocardiography and echocardiogram exams. Screening was performed in 221 Irish wolfhounds. Standard lead II rhythm strip ECG's were performed on each dog. Two-dimensional (2D) and Mmode echocardiograms were then recorded and analyzed based on recommendations of the American Society of Echocardiography and the Echocardiography Committee of the Specialty of Cardiol ogy, ACVIM.

Of 221 IW dogs, $51 \%$ (113) were female and 49\% (108) were male. The dogs' average age and weight was $53.6( \pm 24.86)$ month and $64.9( \pm 9.48) \mathrm{kg}$ respectively. Cardiac disorders were noted in 38 $(17.2 \%)$ of dogs that were screened. Atrial fibrillation was found in $26(11 \%)$ dogs, Ventricular (VPC) and atrial (APC) premature complexes were noted in 2 dogs $(0.45 \%)$ each. Dilated cardiomyopathy was diagnosed in $7(3.2 \%)$ dogs. One dog was being treated for congestive heart failure at the time. Three dogs diagnosed with occult DCM were in normal sinus rhythm and four were affected with atrial fibrillation. Disorders of the mitral valve was noted in $3(1.35 \%)$ of dogs, one of which was thought to be congenital based on the dogs age and structural changes. One dog was found to have mild subaortic stenosis. There were no statistical differences in standard LV measurements between AF and NSR dogs; however left atrial measures were significantly increased in dogs with atrial fibrillation.

Our results suggest that the incidence of occult DCM in our study population of wolfhounds is lower than those previously reported in retrospective studies. The presence of atrial fibrillation conferred no difference in the incidence of DCM compared to dogs in normal sinus rhythm. As such until better testing modalities are developed, based on current data, echocardiography screening should continue to be utilized to assess for occult DCM in both IW dogs with NSR as well as those in atrial fibrillation.

\section{2- ESVC - RISHNIW}

SLEEPING RESPIRATORY RATES IN DOGS AND CATS WITHOUT OBSERVABLE CARDIAC DISEASE. Mark Rishniw $^{1}$, Dan Ohad $^{2}$, Francesco Porciello ${ }^{3}$, Ingrid Ljungvall ${ }^{+}$. Veterinary Information Network, DAVIS, CA, United States of America, ${ }^{2} 2$ Koret School of Veterinary Medicine, Hebrew University of Jerusalem, REHOVOT, Israel, ${ }^{3}$ Faculty of Veterinary Medicine, University of Perugia, PERUGIA, Italy, ${ }^{4}$ Faculty of Veterinary Medicine, Swedish University of Agricultural Sciences, UPPSALA, Sweden

Feline and canine left-sided congestive heart failure (CHF) is characterized by an increase in resting respiratory rate. Recent studies have suggested that a resting respiratory rate in hospital $>44$ breaths/minute was the most sensitive and specific indicator of $\mathrm{CHF}$ in dogs. The sleeping respiratory rate (SRR) at home might provide 
additional and more specific indication of onset of CHF in dogs and cats, allowing owners to present patients for evaluation before severe $\mathrm{CHF}$ develops. Indeed, cardiologists have routinely recommended that clients monitor the resting or sleeping respiratory rate of pets with either subclinical heart disease or drugcontrolled $\mathrm{CHF}$ to determine when treatment adjustments might be required. However, little is known about the dynamics of SRR apparently healthy dogs and cats. Therefore, we sought to examine the dynamics of SRR in these species.

We examined SRR in 64 dogs and 27 cats without clinical evidence of diseases likely to impact SRR. Most animals belonged to veterinary students, veterinarians, or veterinary staff in the US, Italy, Israel or Sweden. We acquired 12-14 data points per subject over 1-5 weeks. We regressed average SRR against bodyweight and age, and compared average SRR between males and females. Only 1 dog had a single SRR $>30$ and all dogs had SRRav $<25 ; 25 \%$ of cats had SRRmax $>30$ on $=1$ occasion and 2 cats had SRRav $>30$. SRRav did not correlate with bodyweight or age in dogs, but correlated with age in cats $(r=0.69)$. SRRav did not differ between genders in either dogs or cats. Percentage increase in SRR decreased as SRRmin increased. Dogs had more day-to-day variability in SRR than cats.

These data suggest that dogs without evidence of CHF or clinically apparent cardiac disease have SRR $<30$. Cats often have SRR > 30; the cause for this is unknown. Dogs with higher SRRmin have less day-to-day variability. These data form the basis for further investigations into the utility of SRR in managing patients with severe pre-clinical heart disease or CHF.

083 - ESVC - FERASIN

LACK OF ASSOCIATION BETWEEN CANINE BODY SIZE AND HEART RATE IN VETERINARY CLINICAL SETTINGS. LUC Ferasin ${ }^{1}$, Heidi Ferasin ${ }^{2}$, Christopher Little ${ }^{3}$. ${ }^{1}$ SPECIALIST VETERINARY CARDIOLOGY CONSULTANCY, NEWBURY, United Kingdom, ${ }^{2}$ O'Gorman Slater Main \& Partners - Donnington Grove Veterinary Surgery, NEWBURY, United Kingdom, ${ }^{3}$ Barton Veterinary Hospital, CANTERBURY, United Kingdom

A relationship between body size and heart rate (HR) has been described in several studies. However, body surface area (BSA) appears a more appropriate way to express such relationship. BSA does not have an isometric relationship with mass, and allometric scaling has been introduced to describe this variation in comparative physiology. HR in mammalian species follows a similar relationship, being inversely proportional to the size of the animal and, perhaps based on these considerations, HR in healthy dogs is generally believed to be inversely proportional to the subject's size, with toy breeds showing higher HR than giant breeds. However, this common belief is in conflict with some previous data, as well as our own our clinical experience, having observed over the years a negligible difference between the measured HR in dogs of different sizes presented for clinical examination. Therefore, the first aim of this study was to test the null hypothesis that body size is not correlated to HR in healthy dogs in the clinical setting. A second objective of this investigation was to assess whether other variables, such as gender, breed morphology, age and demeanour, may have a significant effect on dog's resting heart rate.

The investigation was performed via two different studies: a retrospective analysis performed on 243 ECG recordings and a prospective study based on 153 standardised routine clinical examinations. The presence of any linear relationship between body size and HR was assessed by Pearson's correlation test for normally distributed data and by Spearman rank correlation test for nonparametric data. The presence of possible effects of sex, breed morphology, age or demeanour on heart rate and their interaction was assessed by multi-factor analysis of variance (ANOVA) followed by post-hoc Bonferroni test. Where data were not normally distributed, the Kruskall-Wallis test was used instead of ANOVA.

The two separate studies did not show any significant correlation between HR and body weight (rho $=-0.03, \mathrm{P}=0.5705$ and $\mathrm{r}=$ $0.06, \mathrm{P}=0.4682$ respectively). Patient's breed morphology and gender did not appear to affect HR measured under these circumstances. However, dogs under the age of 1 year seem to have significantly higher heart rates than older $\operatorname{dogs}(\mathbf{P}<0.05)$. Finally, patient's demeanour was also found to have a significant influence on HR; lower values were recorded in relaxed dogs, higher rates were documented in excited, nervous subjects $(\mathrm{P}<0.05)$.

Normal heart rate could be erroneously interpreted as bradycardia or tachycardia if body size were to be considered a determinant factor. Instead, HR in healthy dogs undergoing routine clinical examination is related to their demeanour or age, if younger than 12 months, but does not appear to be related to body size.

\section{4- ESVC - LOPEZ-ALVAREZ}

APPLICATION OF ALLOMETRIC SCALING TO DETERMINE THE REFERENCE VALUES FOR THE M-MODE MEASUREMENTS IN DOBERMANNS. Jordi López-Alvarez, Sonja Fonfara, Hannah Copeland, Joanna Dukes-McEwan. University of Liverpool, Small Animal Teaching Hospital, NESTON, United Kingdom

Different reference values have been advocated for the M-mode measurements of the left ventricle for the diagnosis of dilated cardiomyopathy (DCM) in Dobermanns. The majority were calculated as mean \pm standard deviation from a population of animals considered normal and compared with Dobermanns with DCM, without taking into account individual differences in body weight (BW). The aim of this study was to assess the clinical utility of the allometric scaling (AS) proposed by Cornell et al (2004) to determine specific breed reference values for M-mode measurements in Dobermanns of different BW.

This study includes retrospective analysis of a total of 82 echocardiographic exams from 54 Dobermanns ranging from 20 to $53.7 \mathrm{~kg}$. Using the ESVC task force criteria for canine DCM (excluding M-mode measurement criteria) the animals were divided into three groups: Normal ( $=3$ points), Equivocal $(>3$ to $<6$ points) and DCM (preclinical and clinical) (=6 points). The Mmode measurements were analysed using the normal reference values published in 5 different articles and the values considered abnormal in the ongoing PROTECT study. Those measurements were indexed using the AS formulae and analysed with the reference values proposed by Cornell et al. According with the modified ESVC classification the 7 reference values were evaluated in terms of sensitivity, specificity and the area under the curve (AUC) was calculated for the normal group and equivocal and DCM grouped together. Note that AS and PROTECT take into account the BW to give reference values whereas none of the published studies do.

Using the modified ESVC taskforce criteria, 31 scans were included in the normal, 27 in the equivocal and 24 in the DCM groups. No differences in weight were found between groups, whereas the M-mode measurements and systolic parameters were significantly different $(\mathrm{P}<0.001)$. The best discriminatory values between the three groups were Simpson's derived end-systolic volume index $>30 \mathrm{~mL} / \mathrm{m} 2$ and ejection fraction $<50 \%$.

All the M-mode reference values showed much better specificity than sensitivity, reflecting the clinical interest of detecting affected animals rather than ruling out healthy dogs. The more specific classification of the LVID in systole were the PROTECT and AS reference values, whereas Sottiaux was the more sensitive; the best AUC was achieved using AS. The classification of the LVID in diastole was more specific using AS and Calvert, and the more sensitive was Sottiaux; the best AUC was achieved using PROTECT.

In conclusion taking BW into account for the echocardiographic assessment of DCM in Dobermanns improves specificity and sensitivity. A regression analysis, like the Cornell study, in a larger population of animals of different BW would allow optimising the reference values for the M-mode measurements in this breed.

\section{5- ESVC - WENDT}

REPEATABILITY AND INTEROBSERVER VARIABILITY OF PULMONARY TRANSIT TIME (PTT, N-PTT) IN DOGS USING THE ECHOCARDIOGRAPHIC CONTRAST MEDIA SONOVUE. Ralph Wendt ${ }^{1}$, Jan-Gerd Kresken ${ }^{2}$, Jens Häggström ${ }^{2}$. ${ }^{1}$ Tierärztliche Überweisungspraxis Kirschenwäldchen, WETZLAR, Germany, ${ }^{2}$ Clinic for Small Animals, KAISERBERG, Germany

A recent study showed that Pulmonary Transit Time (PTT) is measurable under clinical circumstances with echocardiography and blood pool contrast media SonoVue ${ }^{\mathbb{R}}$. PTT is an index of 
cardiac performance and is the time required for a unit of blood to pass through the lung circulation. PTT is usually normalized for heart rate (nPTT) according to the formula $n P T T=P T T / m R R$, where $m R R$ is the mean RR interval duration. The nPTT is equal to the number of stroke volumes that the pulmonary vascular bed holds at any given moment and it is a measurement which is unaffected by heart rate and body size, but changes with reduced cardiac pump function. The normal range is $3.6-5.3$ in dogs. The objective of the present study was to estimate the repeatability of PTT and nPTT measurements in normal dogs and the interobserver variability in the dogs of the previous study using the echocardiographic bloodpool contrast media SonoVue ${ }^{\circledR}$.

PTT and nPTT were estimated by repeated injections of Son$\mathrm{oVue}^{\circledR}$ into 5 normal dogs of different breeds and sizes (range 3$30 \mathrm{~kg}$ ) that were sedated with Domitor ${ }^{\circledR}$ because of dental procedures. A $0.015-0.03 \mathrm{ml} / \mathrm{kg}$ bolus dose of SonoVue ${ }^{\circledR}$ followed by $5 \mathrm{ml}$ saline was administered into the cephalic vein. The dogs received 2 injections each with 10 minutes between each injection. The PTT and nPTT were measured using the time from the contrast bolus leaving the pulmonary artery to when it was observed in the left atrium (the PA to LA method). The repeatability of the measurement on the recordings was evaluated by having 3 observers of different levels (low, medium and high) of experience. In addition the observers where evaluating the same 40 recordings of normal and abnormal transits reported previously. Values of repeatability is expressed as coefficient of variation $(\mathrm{CV})$.

Heart rate and PTT ranged substantially between the 5 dogs subjected to repeated injections of SonoVue ${ }^{\circledR}$ and between the transit studies within each dog owing to the sedation; heart rate ranged between 32 to 208 BPM , PTT between 1.9 to $9,04 \mathrm{sec}$, and nPTT ranged between 3.8 to 7.8 . The median within subject variation of nPTT was $16 \%$ (interquartile range (IQR 12 to $39 \%$ ). The median PTT of the 40 transit studies examined by 3 observers were $2.1 \mathrm{sec}$ (IQR 1.2 to $2.9 \mathrm{sec}$ ) and the median nPTT was 5.0 (IQR 3.7 to 4.7 ). The median inter observer variation for PTT and nPTT were $3.2 \%$ (IQR 1.2 to $8.6 \%$ ) and $2.0 \%$ (IQR 1.1 to $8.0 \mathrm{sec}$ ), respectively.

To our knowledge, this is the first study aimed at estimating the within dog variation and the observer variation of PTT and nPTT. It shows that within-dog variation is higher than the inter observer variation, but that both these sources of variation is within reasonable limits for a clinical physiological test.

\section{6- ESVC - OLIVEIRA \\ RETROSPECTIVE REVIEW OF CONGENITAL HEART DE- FECTS IN 976 DOGS. P. Oliveira, O. Domenech, J. Silva, C.} Bussadori. Clinica Veterinaria Gran Sasso, MILANO, Italia

Early recognition of cardiovascular malformations is of great importance to achieve appropriate medical/surgical management, improve outcome and provide an accurate prognosis. Knowledge of prevalence is helpful. The aim of this study was to review the prevalence of congenital heart defects in a large population of dogs in Italy. The medical records of 4480 dogs diagnosed with cardiovascular disease at Clinica Veterinaria Gran Sasso between 1997 and 2010, were reviewed. Congenital heart disease was diagnosed in 976 dogs $(21.7 \%)$. Single defects were present in 832 cases $(85 \%)$; 2 concurrent defects in 132 cases $(14 \%)$ and 3 concurrent defects in 12 cases $(1 \%)$ corresponding to a total of 1132 heart defects. The most common were pulmonic stenosis (PS) $(32 \%)$, subaortic stenosis (SAS) $(21 \%)$ and patent ductus arteriosus (PDA) $(20 \%)$, followed by ventricular septal defect (VSD) $(7.5 \%)$, valvular aortic stenosis (AS) $(5.6 \%)$, tricuspid dysplasia (TD) (3\%), mitral dysplasia $(1.9 \%)$, double chamber right ventricle $(1.2 \%)$ and atrial septal defect $(1 \%)$. Among the most common defects, the presence of a concurrent defect was observed in $31 \%$ of the times for SAS, mostly PS $(51 \%) ; 25 \%$ of the times for PS, with SAS $(36 \%)$ and VSD (26\%) being the most frequent; and in only $9.5 \%$ of PDA cases, mostly with concurrent PS $(45 \%)$. Interestingly, VSD was associated with another defect in $48 \%$ of the cases, and mostly PS (65\%). Seventy-seven breeds were represented, with Boxer $(26 \%)$ and German Shepherd $(10 \%)$ being the most common, followed by mixed breed dogs $(9.6 \%)$. Breed predilection (odds ratio(OR) $>1.5, \mathrm{p}<$ 0.05 ) was observed for: 8 breeds in the case of PS, of which the French Bulldog (OR:21), American Staffordshire (OR:10), English Bulldog (OR:5.9) and Boxer (OR:4.8) stand out; 8 breeds in the case of PDA, of which the Australian Shepherd (OR:40), German Shepherd (OR:6.8) and Belgian Shepherd (OR:5.7) stand out; 6 breeds in the case of SAS, of which the German Shepherd (OR:15) stands out; 6 breeds in the case of AS, of which the Bull Terrier (OR:60) stands out; 3 breeds in the case of TD, of which the Labrador Retriever (OR:15.5) stands out. Gender distribution was similar to that of the overall population with males being slightly more frequent $(54 \%)$ than females $(46 \%)$. A statistically significant predisposition for males was observed in the cases of PS (OR:1.5), SAS (OR:1.7) and aortic stenosis (OR:2.6) and for females in the case of PDA (OR:2.7) and VSD (OR: 2). Mean age at presentation was approximately 40 months for most defects. The results of this study are mostly in accordance to previous reports with however a higher relative prevalence of PS, with Boxer as the most common breed in PS, SAS and AS. SAS, PS and VSD may frequently be associated with other heart defects. PS associated with SAS and PS associated with VSD may predominate.

\section{7- ESVC - SAVARINO}

ECHOCARDIOGRAPHIC CHARACTERIZATION OF LEFT VENTRICULAR FALSE TENDONS IN A CAT POPULATION: A RETROSPECTIVE STUDY. Paolo Savarino ${ }^{1}$, Marco Margiocco $^{2}$, Emily Olson ${ }^{2}$, Alberto Tarducci ${ }^{1}$, Michele Borgarelli ${ }^{2}$. ${ }^{1}$ Faculty of Veterinary Medicine of Torino, GRUGLIASCO, TO, Italy, ${ }^{2}$ Kansas State University, MANHATTAN, KS, United States of America

Th aim of this study was to describe prevalence and echocardiographic appearance of left ventricular false tendons in a feline population.

Echocardiograms from 136 cats were reviewed. A left ventricular false tendon was defined as a discrete hyperechoic linear structure crossing the left ventricular cavity, non associated with the mitral valve. False tendons were classified according to their direction and areas of insertion on the ventricular endocardium.

False tendons were detected in 39 of 136 cats $(28,7 \%)$. Twentyfive cats had a single, 12 had 2 , and 2 had 3 false tendons.

From the right parasternal short axis view the following anatomic patterns of false tendons were identified: from the apex of the posterior papillary muscle to the posterior portion of the interventricular septum, from the anterior papillary muscle to the anterior portion of the interventricular septum, along the interventricular septum in an anterior-posterior direction, and between the two papillary muscles. From the long axis right parasternal and left apical views, three different patterns of false tendons were identified: transverse, diagonal, and longitudinal (base-to- apex).

In the 14 cats with more than one false tendon, two different patterns were identified within the same patient in 6 cats and three different patterns were simultaneously present in 1 cat.

Ten of 39 cats with false tendons had a mid-ventricular obstruction demonstrated by echo-Doppler ( 6 of them were diagnosed with hypertrophic cardiomyopathy - HCM), and 7 cats had left ventricular outflow tract (LVOT) obstruction ( 5 of which were diagnosed with $\mathrm{HCM}$ ). In the 6 cats without a diagnosis of HCM the mid-ventricular or LVOT obstruction were judged to be secondary to the presence of a false tendon. This study shows that false tendons are relatively common in a population of cats referred for an echocardiogram and can be associated with mid-ventricular or LVOT obstruction in the absence of phenotypic changes indicative of cardiomyopathy.

088- ESVC - HOEPFNER

LONGTERM OUTCOME OF DOGS WITH PULMONIC STENOSIS WITH AND WITHOUT BALLOON VALVULOPLASTY. Robert Hoepfner ${ }^{1}$, Christophe Lombard ${ }^{1}$, Simone Jenni' ${ }^{2}$ Tony Glaus'. 'Small Animal Clinic University of Berne, BERNE, Switzerland, ${ }^{2}$ Small Animal Clinic University of Zurich, ZURICH, Switzerland

Percutaneous balloon valvuloplasty (PBV) is the recommended treatment for dogs with severe or moderate but symptomatic valvular pulmonic stenosis (PS). However, clear data to support 
this recommendation, specifically data with long term follow-up of such dogs with or without PBV, are scant. Therefore the aim of this retrospective study was to evaluate long-term-outcome in dogs with PS treated with or without PBV.

All dogs presented at the Universities of Zurich and Berne since 1994 with a diagnosis of PS were analyzed. Dogs were included, if a follow-up till at least 5 years of age was present or if they were lost before that age due to cardiac related death (CD). CD was defined as sudden cardiac death or euthanasia due to intolerable clinical signs related to PS. The degree of PS was defined as moderate and severe based on a peak transvalvular pressure gradient (PG) of 50-80 and $>80 \mathrm{mmHG}$, respectively, on the first day of presentation. Dogs were grouped in those with and without PBV. Dogs with PBV were further characterized in respect to their PG after intervention.

121 dogs were diagnosed with PS. Of these, 56 had moderate or severe PS, reached an age of at least 5 years or had died related to PS. Of these, 28 (1 with moderate $(\mathrm{PG} 73 \mathrm{mmHg}$ ), and 27 with severe PS, median PG $125 \mathrm{mmHg}(97-152)$ had received $\mathrm{PBV}$. Of the 28 dogs without PBV, 9 had moderate (median PG 59 (5073) $\mathrm{mmHg}$ ) and 19 severe PS (median 119 (80-175) $\mathrm{mmHg}$ ). Median follow-up was to an age of 78 (60-155) months for dogs with, and 99 (63-148) months for dogs without PBV. CD occurred in 7 dogs with and 6 dogs without PBV. Of these, there was 1 dog in each group with a pressure gradient $<120 \mathrm{mmHg}$. The dog with PBV presenting with right heart failure had a PG of $109 \mathrm{mmHg}$ before and $79 \mathrm{mmHg}$ after PBV, and had died at 26 months of age; the dog without PBV presenting with syncope had a PG of $73 \mathrm{mmHg}$ and died at 8 months of age. In the other 6 dogs with PBV and CD, median PG was $135(120-152) \mathrm{mmHg}$ before and $80(36-121) \mathrm{mmHg}$ after the intervention; death occurred at 29 (5-56) months of age. Of these, 3 were in right sided heart failure and 1 showed syncope at the time of diagnosis. In the other 5 dogs without PBV, median PG was $135(121-175) \mathrm{mmHg}$, and CD occurred at $27(13-52)$ months of age. For dogs with a gradient $>120 \mathrm{mmHg}$, CD significantly more often occurred in dogs without PBV (5 of $8(63 \%)$ versus 6 of 17 $(35 \%))$.

In conclusion, dogs with PS and a PG $>120 \mathrm{mmHg}$ clearly benefit from PBV. PS does not appear to compromise survival time in dogs if $\mathrm{PG}$ is $<100 \mathrm{mmHg}$. PBV may be recommended for all dogs with a $\mathrm{PG}>100 \mathrm{mmHg}$ or those symptomatic due to PS.

\section{9- ESVC - ATENCIA}

THORACOSCOPIC PARTIAL PERICARDECTOMY FOR MANAGEMENT OF PERICARDIAL EFFUSION IN DOGS: 12

CASES. Sabela Atencia, Ronan Doyle, Nat Whitley. Davies Veterinary Specialists, HIGHAM GOBION, United Kingdom

Canine pericardial effusion (PE) is commonly either of idiopathic or of neoplastic origin. For cases which have required repeated periocardiocentesis, partial pericardectomy is indicated to establish drainage into the pleural cavity preventing recurrence of cardiac tamponade. The aim of this study was to report on the indications, complications and outcome of thoracoscopic partial pericardectomy.

Medical records of 12 dogs which underwent thoracoscopic partial pericardectomies for PE between January 2007 and January 2010 at Davies Veterinary Specialists were reviewed.

Median age was seven and a half years. There were six females (five neutered) and six males (1 neutered). Nine were large or giant breeds, including three golden retrievers.

Weight range was 6 to $91 \mathrm{~kg}$, (median $41 \mathrm{~kg}$ ). Median duration of clinical signs before surgery was 4.5 months. Eleven cases had pericardiocentesis (median of two drainages prior to surgery). A diagnosis of idiopathic pericardial effusion (IPE) was made in nine. Three cases had heart base masses present (histopathology not performed).

In all cases a sub-xiphoid thoracoscopic approach was performed under general anaesthesia with positive-pressure ventilation, and a pericardial window was created in the ventral pericardium via right and left intercostal instrument portals. The area of resected pericardium ranged from 8 to 25 square centimetres. Median surgery time for thoracoscopy was 53 minutes, (range 45 to 80 ). Median time to discharge after surgery was one and a half days (maximum 8 days). Major intraoperative complications occurred in one case which required a sternotomy to manage mediastinal haemorrhage uncontrollable via thoracoscopy. Of the remaining 11 cases, nine had chest drains placed. Seven were removed on the evening of surgery and in two cases post-operative pleural effusion required a chest drain for four days.

One case (with a cardiac mass) suffered suspected pulmonary thromboembolism, but recovered and was discharged six days after surgery. One case developed superficial portal wound infections post-discharge. Nine cases had no surgery related complications.

Of the nine dogs with IPE, one was lost to follow up at 6 months, two were euthanized for unrelated reasons at 3 and 9 months after surgery. Six are still alive at the time of writing (range 7 to 30 months post surgery). The three dogs with neoplasia-related PE survived 20, 30 and 75 days post operatively respectively.

Conclusion: this technique offers low morbidity, short hospitalisation times and excellent long term control of PE.

090- ESVC - PORCIELLO

TRANSTHORACIC ULTRASOUND-GUIDED INTERVENTIONAL CARDIAC PROCEDURES IN THE DOG: A PRELIMINARY STUDY. Francesco Porciello ${ }^{1}$, Francesco Birettoni ${ }^{1}$, Domenico Caivano ${ }^{1}$, Mark Rishniw ${ }^{2}$, Patrizia Knafelz ${ }^{3}$, Sydney Moise ${ }^{4}$. ${ }^{1}$ Faculty of Veterinary Medicine - University of Perugia, PERUGIA, Italy, ${ }^{2}$ Veterinary Information Network, DAVIS, CA, United States of America, ${ }^{3}$ Veterinary Hospital "Gregorio VII", ROME, Italy, ${ }^{4}$ College of Veterinary Medicine Cornell University, ITHACA, NY, United States of America

Fluoroscopically-guided interventional cardiac procedures impart a risk of radiation exposure. Ideally this exposure risk should be minimized or avoided. Transesophageal echocardiographic (TEE) guidance has reduced fluoroscopy time, but its use is limited by cost and availability. We evaluated the feasibility of performing interventional cardiac procedures with transthoracic echocardiographic (TTE) guidance exclusively, ie. without fluoroscopy.

We recruited 6 dogs: 3 with pulmonic stenosis (PS) and 3 with patent ductus arteriosus (PDA) for either TTE-guided balloon valvuloplasty (BV) or percutaneous ductal occlusion with an Amplatz Canine Ductal Occluder (ACDO).

Each dog was anesthetized and positioned on a standard echocardiography table in right lateral recumbency (PS) or left lateral recumbency (PDA). Standard percutaneous access was performed.

In PS dogs, the wedge-pressure catheter, guide wire and BV catheter were directed from the right atrium through the right ventricle into the right outflow tract by 2-dimensional echocardiographic monitoring from the right parasternal short axis view. Once the balloon was positioned across the pulmonic valve, it was inflated while being visualized by TTE. Five balloon inflations were performed in each dog and the gradient, evaluated after $24 \mathrm{~h}$ dropped from 62 to $30 \mathrm{mmHg}, 124$ to $62 \mathrm{mmHg}$, and 101 to $64 \mathrm{mmHg}$ respectively.

In PDA dogs, the guide wire and ACDO delivery set were directed from the aorta through the PDA into the main pulmonary artery (MPA) by 2-dimensional echocardiographic monitoring from the left cranial parasternal view. The ACDO was advanced through the delivery set until the flat distal disk was visualized within the MPA by TTE. The distal disk was positioned against the ductal ostium and the coupled proximal disk was deployed within the ductal ampulla while being visualized by TTE. Each of the 3 dogs was examined after the procedure and found to have either no flow or trivial residual flow across the ductus. Thoracic radiographs confirmed the proper positioning of the devices.

The guide wires, BV catheters and ACDO appeared hyperechoic on TTE images and TTE guidance provided images of a quality sufficient to clearly monitor the procedures in real-time. Real-time monitoring also allowed for immediate corrections to catheter or device positioning and assessment of procedural success. The procedures were successful and without complications in all patients.

We have demonstrated that TTE monitoring can guide every step of pulmonic valvuloplasty and transcatheter ACDO embolization procedures without requiring fluoroscopy. Our findings should allow cardiologists to perform these procedures more safely (by eliminating radiation exposure), and with lesser requirements for specialized equipment (fluoroscopy units and TEE). 
091 - ESVE - GILOR

GLP-1 MIMETIC EXENATIDE POTENTIATES INSULIN SECRETION IN HEALTHY CATS. Chen Gilor, Tonya Ridge, Thomas Graves. University of Illinois, URBANA, IL, United States of America

GLP-1 is an incretin hormone secreted from the intestines in response to specific nutrients. It potentiates insulin secretion, inhibit glucagon secretion, slows the rate of gastric emptying and increases satiety. Exenatide is a synthetic GLP-1 mimetic that is used in people to treat type 2 diabetes mellitus (DM). It is as effective as insulin glargine with fewer side effects.

We have studied the effect of exenatide on insulin secretion in 9 healthy research cats. In the first days of experiment, cats received glucose $(1 \mathrm{~g} / \mathrm{kg})$ via a previously placed nasoesophageal tube. Blood glucose concentrations (BG) were measured thereafter every 5 minutes until euglycemia was restored. Two - three days later, an isoglycemic clamp (IGC) was performed. BG was measured every 5 minutes and glucose was infused intravenously to achieve a BG curve similar to the one recorded during the oral glucose challenge. Insulin concentration were measured at baseline and at 15, 30, 45, $60,75,90,120$, and every 30 minutes after that until the end of the clamp. Two weeks later, exenatide $\left(1 \mathrm{mcg} / \mathrm{kg}\right.$, Byetta $\left.{ }^{\mathrm{TM}}\right)$ was injected subcutaneously. BG was measured every 15 minutes for 120 minutes and then an isoglycemic clamp was performed as described above. Insulin concentrations were measured at baseline and at 15 , $30,45,60,75,90$ and 120 minutes and during the IGC as described above. The area under the curve (AUC) of the insulin concentration and all statistical analysis were done using computer software (GraphPad Prism). Data are presented as mean \pm SEM

Serum insulin concentrations peaked 15 minutes after exenatide injection (Baseline: $301 \pm 47 \mathrm{ng} / \mathrm{L}, 15$ minutes: $724 \pm 110 \mathrm{ng} / \mathrm{L}, \mathrm{P}=$ $0.009)$ and then decreased below baseline at 45 minutes $(237 \pm 53$, P $=0.29)$. This was followed by a slight decrease in blood glucose at 45 minutes (mean decrease $6.9 \pm 3.2 \mathrm{mg} / \mathrm{dl}, \mathrm{P}=0.06$ ). Insulin AUC during the IGC was significantly higher after exenatide injection $(P$ $=0.02$ ) although the difference in total glucose infused during IGC was not significant (IGC without exenatide $0.49 \pm 0.06 \mathrm{~g} / \mathrm{kg}$, IGC with exenatide $0.56 \pm 0.09 \mathrm{~g} / \mathrm{kg}, \mathrm{P}=0.35$ ).

Exenatide potentiated insulin secretion both in euglycemia and in hyperglycemia. The insignificant difference in the total glucose in fused during the IGC might be the result of unexpected effects of exenatide on glucagon secretion or hepatic glucose production and put in question the usefulness of exenatide in treating feline DM.

\section{2- ESVE - FORCADA}

A MISSENSE MUTATION IN THE CODING SEQUENCE OF MC4R (MC4R:c.92 C > T) IS ASSOCIATED WITH DIABETES MELLITUS IN DSH CATS. Yaiza Forcada, Angela Holder, Rosanne Jepson, David Church, Brian Catchpole. Royal Veterinary College, NORTH MIMMS, United Kingdom

Diabetes mellitus is one of the most common feline endocrinopathies and is considered to have a similar pathophysiological basis to human type 2 diabetes. Several studies have identified risk factors for development of diabetes mellitus in cats, which include age, obesity, inappropriate diet and physical inactivity. However, to date, no specific genetic risk factors have been identified. Genome-wide association studies in humans have identified several genes that predispose to obesity and/or diabetes mellitus, one of which is the melanocortin receptor 4 (MC4R) gene. The aim of the current study was to identify polymorphisms (SNPs) in the feline MC4R gene and to use these to perform a case:control study to determine whether these candidate gene SNPs were associated with diabetes mellitus in cats.

Genomic DNA from 10 cats (6 domestic short hair [DSH], 4 Burmese) was initially analysed by PCR and direct sequencing using felMC4R-specific primers, which identified a missense mutation (MC4R:c.92 C > T) in the region encoding the extracellular domain of the receptor protein in DSH cats only. One hundred and nineteen DSH cats were subsequently recruited into the case:control study. Fifty nine cats were obese diabetic ( 29 male, 30 female), mean age 11.8 years (range 6-18 y); mean weight $6.68 \mathrm{~kg}$ (range $5.15-10 \mathrm{~kg}$ ). Sixty lean cats were used as controls ( 30 male, 30 female), mean age 13.81 years (range 9-19y), mean weight $3.99 \mathrm{~kg}$ (range 2.56 $5.68 \mathrm{~kg}$ ). The $\mathrm{T}$ to $\mathrm{C}$ base change alters a restriction site in the sequence recognized by the enzyme BstOI, such that DNA from cats with the mutant $(\mathrm{C})$ allele can be cut, whereas that from the wildtype (T) allele cannot. Primers were designed that flanked the mutation to allow PCR amplification of this region of MC4R from genomic DNA obtained from EDTA blood. The PCR products were purified and subject to restriction fragment length polymorphism (RFLP) analysis. BstOI digestion products were then analysed by agarose gel electrophoresis.

Of the 59 diabetic cats, $32(54 \%)$ were homozygous for the mutation (CC), compared to $21(35 \%)$ of 60 control cats. Statistical analysis (two tailed Fisher's square test) revealed that this difference between groups was statistically significant $(\mathrm{p}=0.0431)$.

In conclusion, this pilot study has identified a missense mutation in the coding sequence of MC4R. This could be an important predisposing factor for development of diabetes and/or obesity in DSH cats. Polymorphisms in a similar region of human MC4R predispose to obesity, which in turn is a major risk factor for Type 2 diabetes.

\section{3 - ESVE - ZINI}

EARLY PREDICTORS OF CLINICAL REMISSION IN CATS WITH DIABETES MELLITUS. E. Zini ${ }^{1}$, M. Hafner ${ }^{1}$, M. Osto ${ }^{2}$, M. Franchini ${ }^{3}$, M. Ackermann ${ }^{3}$, T.A. Lutz ${ }^{2}$, C.E. Reusch ${ }^{1}$. ${ }^{1}$ Clinic for Small Animal Internal Medicine; ${ }^{2}$ Institute of Veterinary Physiology; ${ }^{3}$ Institute of Virology, Vetsuisse Faculty, University of Zurich, Switzerland.

Clinical remission is frequent in cats with well controlled diabetes mellitus but only few studies explored predictors of this phenomenon. We showed that levels of glucose, fructosamine, insulin and insulin growth factor-1 at the time of admission were not associated with remission, whereas the glucagon-to-insulin ratio after arginine stimulation was higher in diabetic cats that later did not require insulin. We also showed that remission can occur in diabetic cats with ketoacidosis. Recently, it was reported that the use of insulin glargine, strict glycemic control, and previous corticosteroid administration were associated with remission. Here, the aim was to identify factors that may predict remission of diabetes and its duration in cats on first admission.

Ninety-one cats with newly diagnosed diabetes were followed-up until death or at least until remission. Using clinical records, information was collected including history, signalment, physical examination, haematological and biochemical profile, and the occurrence and duration of remission. Factors that may predict remission were analyzed with univariate and multivariate logistic regression. Factors associated with remission duration were studied with Kaplan-Meier and Cox proportional hazard models.

Forty-nine $(54 \%)$ cats achieved diabetes remission. Insulin was discontinued after a median time of 48 days (range: 8-385 days). At study end, median remission duration was 75 days (range: 4-3370 days) in cats that died during follow-up and 140 days (range: 13-1180 days) in cats that were still alive. Remission was more likely with increasing age (OR: 1.23 , CI95\%: 1.04-1.46, $\mathrm{p}=0.01$ ) and less likely with increased serum cholesterol (OR: 0.36, CI95\%: 0.12-0.87, $\mathrm{p}=0.04$ ). Duration of remission was shorter with increasing blood glucose at admission (HR: 1.06, CI95\%: 1.01-1.10; $\mathrm{p}=0.02$ ). Factors such as administration of corticosteroids, gender, breed, body weight, hematocrit, leukocyte count, serum glucose, fructosamine, total proteins, albumin, creatinine, urea, kalium, bilirubin and lipase, ketoacidosis, concurrent diseases, and type of insulin were not significant

Age, cholesterol and glucose levels seem to be useful predictors for diabetes remission or duration in cats. Increased chance of remission in older cats may suggest different pathogenic mechanisms underlying diabetes progression. Hypercholesterolemia and hyperglycemia may contribute to decreasing insulin secretion or action in diabetic cats.

\section{4- ESVE - HAFNER}

CONTINUOUS GLUCOSE MONITORING SYSTEM IN DIABETIC CATS: ASSESSMENT OF DIFFERENT SENSOR SITES. M. Hafner ${ }^{1}$, E Zini ${ }^{1}, M$. Osto $^{2}$, M. Franchini ${ }^{3}, M$ Ackermann ${ }^{3}$, T.A. Lutz ${ }^{2}$, C.E. Reusch ${ }^{1} .{ }^{1}$ Clinic for Small Animal Internal Medicine; ${ }^{2}$ Institute of Veterinary Physiology; ${ }^{3}$ Institute of Virology, Vetsuisse Faculty, University of Zurich, Switzerland.

Generating blood glucose curves is an integral part of monitoring diabetes mellitus in cats. The continuous glucose monitoring system 
(CGMS, Guardian REAL-Time ${ }^{\circledR}$, Medtronic, Switzerland) allows glucose curves with high temporal resolution. Glucose readings are obtained via a sensor that at our institution is routinely placed in the subcutaneous tissue of the lateral chest wall. Compared to a reference portable blood glucose meter (PBGM, AlphaTRAK ${ }^{\circledR}$, Abbott, England), the CGMS had accuracy of more than $90 \%$ and concordance of $95.7 \%$. Despite overall good reliability, sensors in the lateral chest wall yielded some readings that substantially deviated from reference. The aim of the study was to assess whether sensors placed in two alternative sites are practical and provide more reliable results.

Paired CGMS sensors were placed in the subcutaneous tissue of the lateral chest wall and dorsal neck, or in lateral knee fold, respectively. Capillary glucose was measured every 2 hours with the PBGM, as reference. Mean difference and standard deviation between PBGM and CGMS readings were calculated. Concordance between measurements collected in the lateral chest wall and neck or knee fold was calculated, at normal, high and low glucose concentrations. Duration of periods in which sensors did not yield glucose readings was also recorded.

Twelve diabetic cats were used with CGMS sensors implanted in the lateral chest wall for 1034 hours, in the neck for 782 hours, and in the knee fold for 370 hours. In the latter site the sensor was often kinked or detached. Relative to PBGM, sensor measurements in the lateral chest wall differed by $-1.3+/-2.5 \mathrm{mmol} / 1$, in the neck by $-1.2+/-2.3 \mathrm{mmol} / \mathrm{l}$, and in the knee fold by $-1.6+/-2.2 \mathrm{mmol} / 1$ In relation to sensors in the lateral chest wall, concordance of measurements in the neck was $80.5 \%$ at normal, $85.6 \%$ at high and $18.4 \%$ at low glucose concentrations; in the knee fold was $69.9 \%$, $72.0 \%$ and $30.8 \%$, respectively. In the lateral chest wall measurements were not provided for $21.3 \%$ of the time, in the neck for $12.6 \%$, and in the knee fold for $8.8 \%$.

Overall, our data suggest that the knee fold site is impractical because the sensor tends to kinking or detaching. In contrast, the two other sites were practical and provided reliable data recording. However, the neck site may be preferable to lateral chest wall because of fewer missing glucose readings. Little concordance at low glucose concentrations suggests that CGMS reliability should be confirmed with a PBGM if hypoglycaemia is anticipated.

\section{5- ESVE - FALL}

REMISSION OF DIOESTRUS DIABETES IN ELKHOUNDS IS PREDICTED BY GLUCOSE CONCENTRATIONS AT DIAGNOSIS AND BY TIME TO SURGERY FROM ONSET OF CLINICAL SIGNS. Tove Fall ${ }^{1}$, Ảke Hedhammar ${ }^{1}$, Annelie Wallberg', Nils Fall ${ }^{1}$, Kerstin Ahlgren ${ }^{2}$, Göran Andersson ${ }^{1}$, Helene Hamlin ${ }^{1}$, Kerstin Lindblad-Toh ${ }^{3}$, Olle Kämpe ${ }^{2}$. ${ }^{1}$ Swedish University of Agricultural Sciences, UPPSALA, Sweden, ${ }^{2}$ Uppsala University, UPPSALA, Sweden, ${ }^{3}$ Broad Institute, CAMBRIDGE, United States of America

Diabetes mellitus in dogs is a heterogeneous disorder. In female elkhounds, the onset of diabetes mellitus is generally related to pregnancy and/or the nine week non-pregnant luteal phase of the œstral cycle. Some dogs recover from their diabetes after termination of the luteal phase, either naturally or after spaying procedures. Medical records from 63 cases of diabetes mellitus in Swedish and Norwegian elkhounds were reviewed and owners were contacted for follow-up information. All dogs in the study were found to be intact females and seven dogs $(11 \%)$ were pregnant at diagnosis. First symptoms of diabetes mellitus occurred with a median of 30 days (IQR 3-45) after œstrus and dogs were diagnosed within a median of 46 days (IQR 27-62) after œstrus. No autoreactivity towards GAD-65 was detected in any of the dogs. Thirty-nine dogs in the study underwent ovariohysterectomy (OHE) and 34 of these were given insulin therapy either with intermediate acting porcine insulin (Caninsulin ${ }^{\mathbb{R}}$, Intervet, Danderyd, Sweden) or recombinant human NPH insulin (Insulatard ${ }^{\circledR}$, Novo Nordisk, Bagsvaerd, Denmark). One dog that did not undergo surgery was also treated with insulin. Eighteen of 39 dogs $(46 \%)$ recovered from their diabetes after OHE and had normal glucose concentrations (after discontinuing insulin treatment in insulin-treated cases) within a median of 11 days (IQR 1-51) after surgery. Of the ten dogs in the study that were not subjected to surgery and survived more than seven days after diagnosis, only one recovered from diabetes. This dog had a new episode of diabetes after the next œstrus and was euthanized.

A logistic model was used to evaluate the association of clinical parameters associated to permanent diabetes mellitus after OHE. The predetermined predictor variables were weeks from onset of symptoms to OHE, glucose concentration at diagnosis and owner's perception of weight loss or not at diagnosis. Six dogs were excluded due to missing variables, hence 33 dogs were included. The median glucose concentrations at diagnosis were $24 \mathrm{mmol} / \mathrm{L}$ (IQR 21-26) and $18 \mathrm{mmol} / \mathrm{l}$ (IQR 12-21) in the permanent diabetes and remission groups, respectively. The median time from onset of symptoms to surgery was 4.4 weeks (IQR 2.9-7.7) in the permanent diabetes mellitus group and 2.4 weeks (IQR 1.4-3.9) in the remission group. Seven out of $17(41 \%)$ dogs included in the model with permanent diabetes mellitus had lost weight whereas two out of $16(13 \%)$ dogs had lost weight in the remission group.

The model showed that higher glucose concentration (OR 1.2, $\mathrm{p}$ $=0.03$ ) at diagnosis and longer time from diagnosis to OHE (OR 1.5 per week, $\mathrm{p}=0.05$ ) was associated with permanent diabetes after OHE. To our knowledge, this study is the first to report risk factors associated to permanent diabetes after $\mathrm{OHE}$ in diœstrus diabetes cases.

096- ESVE - NIESSEN

DIABETES MELLITUS AND EUTHANASIA: HOW OFTEN AND WHY? Stijn Niessen ${ }^{1}$, Sonya Powney ${ }^{1}$, Javier Guitian ${ }^{1}$, Twan Niessen ${ }^{2}$, Paul Pion ${ }^{3}$, Jim Shaw ${ }^{4}$, David Church ${ }^{1} .{ }^{1}$ Royal Veterinary College, NORTH MIMMS, United Kingdom, ${ }^{2}$ Twan Consultancy, VENLO, The Netherlands, ${ }^{3}$ Veterinary Information Network (VIN), DAVIS, CA, United States of America, ${ }^{4}$ Diabetes Research Group, Newcastle Medical School, NEWCASTLEUPON-TYNE, United Kingdom

Although diabetes mellitus (DM) in companion animals represents a treatable disease, clinical experience suggests a proportion of owners decline or cease DM treatment. Frequency of occurrence and factors involved have not been assessed previously. The current study aimed to provide such information. Discussions and pilotsurveys were conducted on this topic with clinicians and diabetic pet owners, leading to the design of a survey aimed at recording clinicians' experiences. 1192 clinicians were subsequently surveyed world-wide. Respondents reported a median of 1 in 10 cats and dogs newly diagnosed with DM to be euthanized on the owner's request at time of diagnosis (cat range: $0-10$, inter-quartile range (IQR): 0-2; dog range: 0-10, IQR: 0-1). A median of 1 in 10 cats was reported to be specifically euthanized because of owners' reluctance to start insulin injections (range: 0-10, IQR: 0-1), whereas most reported that this was typically never the case in any of the newly diagnosed diabetic dogs (range: $0-10$, IQR: $0-1$ ). A further median of 1 in 10 cats and dogs were reported to have their insulin treatment ceased within one year because of lack of success or compliance (range: $0-10$, IQR: 0-2). The following specific factors, involved in the decision to euthanize diabetic animals or stop DM treatment were reported to be "of great importance": "concurrent disease" $(45 \%$ of respondents), "costs" $(44 \%)$, "animal's age"( $37 \%)$, “inadequate control"( $35 \%)$, “pet's welfare" $(35 \%)$, "impact on lifestyle owner" $(32 \%)$ and "injection problems" $(17 \%)$ Owners were reported to be more likely to opt for insulin treatment when animals were insured $(71.5 \%)$ or when owners or close family or friends were diabetic $(88.7 \%)$. Multivariate analysis (ordinal logistical regression) was conducted in order to investigate significance of possible treatment decision influencing factors whilst adjusting for possible confounding demographical factors. Clinicians from Canada and Australia, rural, mixed, non-referral and non-university practices reported to be asked to euthanize newly diagnosed cats and/or dogs more frequently than clinicians from Europe, USA, (sub)urban, 100\% small animal, referral and university practices, respectively. Practice pet-insurance percentage did not significantly influence this. In conclusion, although most diabetic pet owners will opt for treatment, still a significant number of diabetic pets are euthanized either at initial diagnosis or within one year despite available treatment options. Frequency and reasons seem influenced by the species in question and the practice type and location. 
098- ESVE - SMETS

GLOMERULAR AND TUBULAR MARKERS OF RENAL FUNCTION IN DIABETIC DOGS: COMPARISON TO HEALTHY DOGS AND FOLLOW-UP. Pascale Smets ${ }^{1}$, Evelyne Meyer ${ }^{1}$, Bert Maddens $^{1}$, Siska Croubels ${ }^{1}$, Hervé Lefebvre ${ }^{2}$, Dominique Paepe ${ }^{1}$, Sylvie Daminet ${ }^{1}$. ${ }^{1}$ Ghent University, MERELBEKE, Belgium, ${ }^{2}$ Ecole Nationale Vétérinaire, TOULOUSE, France

Diabetic nephropathy is the leading cause of end stage renal disease in humans. Microalbuminuria is an early predictor of glomerular dysfunction and urinary immunoglobulin $\mathrm{G}$ (uIgG) indicates changes in glomerular size selectivity, whereas urinary retinol-binding protein (uRBP) and N-acetyl- $\beta$-D-glucosaminidase (uNAG) reflect tubular dysfunction in human diabetic patients. Currently, effects of diabetes mellitus on canine renal function are unclear.

This study aimed to compare glomerular markers, i.e. urinary protein-to-creatinine ratio (UPC), urinary albumin (uALB), uIgG and glomerular filtration rate (GFR), and tubular markers, i.e. uRBP and uNAG, between diabetic and healthy dogs. Eight newly diagnosed or poorly controlled diabetic dogs and ten elderly, bodyweight matched healthy controls were included. Urinary markers were determined by a validated ELISA or colorimetric assay and expressed as ratio's to urinary creatinine concentration (c). In all dogs, GFR was measured by means of plasma exo- $\left(\mathrm{Cl}_{\text {exo }}\right)$ and endo-iohexol clearance $\left(\mathrm{Cl}_{\text {endo }}\right)$ and expressed as $\mathrm{mL} / \mathrm{min} / \mathrm{kg}$ (WinNonlin ${ }^{\circledR}$ non-compartmental analysis). Five of 8 diabetic dogs were re-evaluated during insulin treatment after 1,3 and 6 months. Urinary markers were re-assessed at all time points and GFR measurement was repeated at 6 months.

In the healthy and diabetic dogs, median (range) UPC was 0.09 $(0.06-0.14)$ and $0.25(0.13-1.79), \mathrm{uALB} / \mathrm{c}$ was $5.6(2.3-50.4)$ and $155.6(52.1-2093.3) \mathrm{mg} / \mathrm{g}, \mathrm{uIgG} / \mathrm{c}$ was $2.1(0.8-5.4)$ and $47.3(12.4$ $168.9) \mathrm{mg} / \mathrm{g}, \mathrm{Cl}_{\text {exo }}$ was $2.1(1.7-3.6)$ and $2.9(1.4-4.6) \mathrm{mL} / \mathrm{min} / \mathrm{kg}$, $\mathrm{Cl}_{\text {endo }}$ was $1.7(1.3-2.8)$ and $2.8(1.5-5.2) \mathrm{mL} / \mathrm{min} / \mathrm{kg}$, uRBP $/ \mathrm{c}$ was $0.1(0.0-0.4)$ and $0.7(0.1-34.7) \mathrm{mg} / \mathrm{g}$ and $\mathrm{uNAG} / \mathrm{c}$ was $2.0(1.2-3.9)$ and $6.2(2.4-10.7) \mathrm{U} / \mathrm{g}$, respectively. Based on a two sample t-test $\mathrm{uIgG} / \mathrm{c}(\mathrm{p}=0.015)$ and $\mathrm{uNAG} / \mathrm{c}(\mathrm{p}=0.005)$ were significantly higher in diabetic dogs compared to healthy controls. No statistically significant difference was detected for UPC, $\mathrm{uALB} / \mathrm{c}, \mathrm{uRBP} / \mathrm{c}$, $\mathrm{Cl}_{\text {exo }}$ or $\mathrm{Cl}_{\text {endo }}$, although marked increases were observed in the majority of diabetic dogs. Analysis of variance did not reveal significant changes in urinary markers or GFR after 1,3 or 6 months of treatment in 5 diabetic dogs.

In conclusion, results of this pilot study suggest glomerular and tubular renal dysfunction in diabetic compared to healthy dogs, indicated by significant increases in $\mathrm{uIgG} / \mathrm{c}$ and $\mathrm{uNAG} / \mathrm{c}$. Urinary markers and GFR in 5 diabetic dogs do not seem to change during treatment over a 6 month follow-up period. Further research in a larger number of dogs is needed to confirm these findings and correlate them to glycemic control

\section{9- ESVE - FRACASSI}

USE OF INSULIN GLARGINE IN DOGS WITH DIABETES MELLITUS. Federico Fracassi ${ }^{1}$, Felicitas Boretti ${ }^{2}$, Nadia SieberRuckstuhl ${ }^{2}$, Claudia Reusch ${ }^{2}$ University of Bologna, OZZANO DELL'EMILIA, Italy, ${ }^{2}$ Clinic for Small Animal Internal Medicine, University of Zurich, Switzerland

Insulin glargine is a synthetic long acting insulin analogue that has been shown to provide effective glycemic control in cats with diabetes mellitus (DM).

Information on its use in dogs is scarce and no clinical studies have been published so far. The objective of this study was to evaluate its safety and efficacy in dogs with DM. Twelve client-owned dogs with DM were included into the study. Median (range) age was 11 years (5-15), 8 were female ( 3 intact, 5 spayed), and 4 were intact male; median (range) body weight was $9.5 \mathrm{~kg}$ (3.7-45.0). Dogs with relevant concurrent diseases such as hypothyroidism, hypercortisolism, neoplasia, renal insufficiency and dogs with prior administration of diabetogenic drugs were excluded. Nine dogs were newly diagnosed and three had been treated with an insulin zinc suspension. All dogs received glargine BID for at least 6 months, re-evaluations were performed after $1,2,4,8,12$ and 24 weeks and included clinical signs, blood glucose curves and measurement of serum fructosamine concentrations. Starting dose was
$0.25-0.5 \mathrm{U} / \mathrm{kg} \mathrm{q} 12 \mathrm{~h}$. Initially, all dogs were markedly hyperglycemic (median $26.4 \mathrm{mmol} / 1$, range 9.6-33.1), and had elevated fructosamine concentrations (median $611 \mu \mathrm{mol} / 1$, range 320-815). Median (range) glucose concentrations $(\mathrm{mmol} / \mathrm{l})$, nadir values $(\mathrm{mmol} / \mathrm{l})$ and fructosamine concentrations (imol/1) at 1, 2, 4, 8, 12, 24 weeks after beginning glargine were 17.9 (5.2-30.5), 15.7 (3.5-31.8), 593 (359$842) ; 11.0$ (4.8-23.9), 10.1 (3.2-22.6), 503 (418-748); $11.3(4.0-21.8)$, 8.4 (2.2-18.9), 540 (385-663); 11.8 (6.3-15.9), 8.5 (1.8-14.9), 508 (359-597); $10.8(6.3-18.5), 6.5(3.1-16.2), 532$ (461-584); $11.9(5.2$ 17.6), 7.0 (3.3-12.3), 484 (342-691), respectively. Glucose concentrations (median) were significantly $(\mathrm{p}<0.001)$ lower after 24 weeks therapy than before treatment with glargine. Median (range) insulin dose was $0.27 \mathrm{U} / \mathrm{kg}(0.18-0.53) \mathrm{q} 12 \mathrm{~h}$ at admission and increased significantly $(\mathrm{p}<0.05)$ to $0.60 \mathrm{U} / \mathrm{kg}(0.11-1.07)$ after 24 weeks of therapy. No clinical signs that could have been caused by hypoglycemia were reported by the owners. Polyuria/polydipsia was present in $92 \%$ and $8 \%$ of dogs at admission and after 24 weeks of therapy, respectively. Clinical assessment of glycemic control based on the combination of results of blood glucose curves and clinical criteria determined that, after 6 months of therapy, an adequate control of the disease was obtained in 8 dogs $(66 \%)$ and poor control in 4 dogs $(34 \%)$. Based on owner opinion at 24 weeks of therapy only one dog had a poor control of the disease.

The paucity of clinical signs compatible with hypoglycemia, observed also in humans and cats, shows that glargine is safe for the treatment of canine DM. Although not many studies with other types of insulin in dogs are available, success rate with insulin glargine seems to be somewhat lower.

\section{0- ESVE - GALEANDRO}

EVALUATION OF FIVE IMMUNOASSAYS FOR MEASUREMENT OF URINARY CORTICOID CONCENTRATIONS IN DOGS IN COMPARISON WITH GAS CHROMATOGRAPHYMASS SPECTROMETRY RESULTS. Luca Galeandro ${ }^{1}$, Nadja Sieber-Ruckstuhl ${ }^{2}$, Sonja Hartnack ${ }^{3}$, Claudia Reusch ${ }^{2}$, Felicitas Boretti ${ }^{2}{ }^{1}$ Clinic for Small Animal Internal Medicine, ZURICH, Switzerland, ${ }^{2}$ Clinic for Small Animal Internal Medicine, University of Zurich, ZURICH, Switzerland, ${ }^{3}$ Section of Veterinary Epidemiology, University of Zurich, ZURICH, Switzerland

Determination of the urinary corticoid excretion is an important screening test in the diagnosis of hyperadrednocorticism (HAC). Its measurement is mostly done by widely available immunoassays. In humans it is known that among others, cortisol metabolites interfere with cortisol measurement in immunoassays leading to a reduced specificity of those test systems. Systematic evaluation of urinary corticoid assays in dogs is lacking and reference values are often arbitrary chosen from the literature. Gas chromatography-mass spectrometry (GC-MS) is considered to be the gold standard for steroid hormone analysis as it provides a high level of selectivity, accuracy and sensitivity.

Objective of the study was to compare urinary corticoid concentrations of healthy dogs and dogs with suspected HAC obtained by 5 different immunoassays with those obtained by a specific GC-MS method.

Three chemiluminescence assays (Assay A: Access 2, Beckmann Coulter; Assay B: Immulite 2000, DPC Siemens; Assay C: same as Assay B but with trichlormethane extraction of urine) and two RIAs (Assay D: in house RIA, Rijnberk et al 1988; Assay E: RIA Beckmann) were used. Urinary corticoid concentrations were related to urinary creatinine concentrations and ratios calculated (UCCR, expressed as $\times 10^{-6}$ ). Voided urine samples from 10 healthy dogs (median (range) age 6.5years (4-11); median (range) body weight $26 \mathrm{~kg}(21-48)$ ) were collected by the owners during the hospital visit (day 0 ) as well as 6 and 7 days thereafter at home. From 3 dogs with suspected HAC urine was collected in the hospital and analyzed with assays B, E and GC-MS

Median (range) UCCR values in healthy dogs on day 0 were: 12.21 (7.75-19.38); 1.19 (0.77-3.91); 4.35 (2.1-6.0); 2.45 (1.1-4.6) $9.63(5.05-13.65)$ and $1.04(0.46-2.6)$ for Assay A,B,C,D,E and GCMS, respectively. UCCR of healthy dogs were significantly higher with assays $\mathrm{A}, \mathrm{C}$ and $\mathrm{E}$ compared to GC-MS values. With the exception of assay A, UCCR were not significantly different on day 6 and 7 compared to day 0 . With assay A and E, UCCR of 5 and 3 of the healthy dogs, respectively, were in the range suspicious for HAC $\left(>10 \times 10^{-6}\right)$. Best coefficient of correlation was obtained between 
Assay B and GC-MS $\left(\mathrm{R}^{2}=0.8258\right)$. With Assay B, E and GC-MS, 2, 3 and 3 dogs suspected with HAC, had UCCR above the highest value of the healthy dogs with the respective assay.

Our results show, that the different assays have variable performances. In particular two of them exhibited high values in some healthy dogs. Results emphasize that normal range UCCR should be carefully established for each particular assay.

0101- ESVE - BRAUN

COMPARISON OF TWO DOSE RANGES OF TRILOSTANE FOR THE TREATMENT OF PITUITARY-DEPENDENT HYPERADRENOCORTICISM IN DOGS. Claudia Braun ${ }^{1}$ Felicitas Boretti ${ }^{2}$, Claudia Reusch ${ }^{1}$, Nadja Sieber-Ruckstuhl ${ }^{1}$. ${ }^{1}$ Clinic for Small Animals Internal Medicine, University of Zurich, ZÜRICH, Switzerland, ${ }^{2}$ Clinic for Small Animal Internal Medicine, ZURICH, Switzerland

Since several years trilostane is effectively used to treat dogs with pituitary-dependent hyperadrenocorticism (PDH). Initially, a dose extrapolated from human medicine and adjusted to the available capsule sizes was used in our institution. Since April 2006 trilostane is dosed per $\mathrm{kg}$ bodyweight. The objective of our study was to compare the clinical effectiveness, the number of dose adjustments and the side effects of the two different dose ranges. Two groups of dogs with PDH, which had been treated with trilostane for a minimum of three months, were included in this retrospective study. Group 1 (n $=28$ ) consisted of dogs diagnosed between June 1999-April 2006 , which received an initial daily trilostane dose on the basis of 3 categories of bodyweights once daily ( $<5 \mathrm{~kg}, 30 \mathrm{mg}$; 5 to $20 \mathrm{~kg}, 60 \mathrm{mg}$; and $>20 \mathrm{~kg}, 120 \mathrm{mg})$. Group $2(\mathrm{n}=20)$ consisted of dogs diagnosed between April 2006-December 2009, which received 2-5 mg/ $\mathrm{kg}$ trilostane once daily. Dogs were re-evaluated after 1-2,3-6,7-15 weeks, 4-7 and 8-12 months. Starting doses of trilostane were significantly higher in dogs of group 1 (median $6.1 \mathrm{mg} / \mathrm{kg}$, range 3-13) than in those of group 2 (median $3.8 \mathrm{mg} / \mathrm{kg}$, range $2-4.3$ ) and stayed significantly elevated until the re-evaluation at 4-7 months. At the first re-check, $82 \%$ of the owners of dogs of group 1 and $90 \%$ of those of group 2 were satisfied with the general clinical condition of their dogs. Compared to group 2 , significantly more dogs of group 1 had a decrease in polyuria and polydipsia (group $186 \%$, group 2 $53 \%$ ). Polyphagia and activity had improved in $33 \%$ and $81 \%$ of group 1 , and in $43 \%$ and $60 \%$ of group 2, respectively. Cortisol before and after ACTH stimulation was significantly decreased at all time points in both groups. Aldosterone after ACTH was significantly decreased at all re-checks only in group 1 . There were no differences in cortisol or aldosterone concentrations between the two groups at any time point. Endogenous ACTH concentration tended to increase in both groups of dogs, with no significant difference between the two groups. In group 2 a significant higher number of animals needed a dose increase at the first re-check compared to group 1. In group 1 a significant higher number of animals needed a dose reduction at $8-12$ months of therapy compared to group 2 . Side effects requiring an intermittent discontinuation of trilostane occurred in $25 \%$ of dogs of group 1 and $10 \%$ of dogs of group 2 . In both groups, trilostane had to be withdrawn in $1 \mathrm{dog}$. We conclude that, although dogs are started on a lower trilostane dose when dosed per kg bodyweight, clinical improvement and decrease in cortisol concentrations are comparable. Side effects leading to intermittent discontinuation of trilostane tended to occur more often in the dogs dosed on bodyweight categories, but definitive withdrawal of trilostane was required with equal frequency.

0102 - ESVE - FANINI

EVALUATION OF SERUM FREE-THYROXINE CONCENTRATIONS DETERMINED BY CHEMILUMINESCENT ASSAY IN DOGS. G. Fanini ${ }^{1}$, F. Fracassi ${ }^{2}$, M. Di Tommaso ${ }^{1}$, E. Garbatini $^{2}$, P. Schenck ${ }^{3}$, A. Boari ${ }^{1}$. ${ }^{1}$ Department of Veterinary Clinical Sciences, University of Teramo, TERAMO, Italy, ${ }^{2}$ Veterinary Clinical Department, University of Bologna, BOLOGNA, Italy; ${ }^{3}$ DCPAH, Michigan State University

The measurement of Free-Thyroxine (fT4) by modified equilibrium dialysis (MED) has been demonstrated to be more accurate than other methods, and is therefore considered the single preferred test for assessing thyroid gland function in dogs. For most European practitioners the diagnosis of canine hypothyroidism is constrained by lack of availability of fT4MED, and fT4 is determined by other methods such as chemiluminescence $(\mathrm{CH})$. Little data are available regarding the diagnostic reliability of this assay. The aim of this study was to evaluate the accuracy of the chemiluminescent assay. Eighty canine serum samples (17 healthy, 26 hypothyroid, 8 hypothyroid on therapy, 1 hyperthyroid, 28 non thyroidal illness) were included in this study. Diagnosis of hypothyroidism was confirmed by the results of rhTSH stimulation test. In each sample the FT4 concentrations [fT4] were measured by $\mathrm{CH}$ method ([fT4]CH - Immulite ${ }^{\circledR} 2000$, Diagnostic Products Corporation, Los Angeles, CA) and by MED assay ([fT4]MED - Antech Manufacturing, Irvine, CA ) were measured. The laboratory reference ranges for [fT4] CH and [fT4]MED were 3.5-29.0 pmol/L and $6.0-42.0 \mathrm{pmol} / \mathrm{L}$, respectively. Linear regression was calculated between [fT4]CH and [fT4]MED measurements. The agreement between the two methods was assessed using Bland-Altman (B-A) analysis. For all statistical analyses, a $P$ value $<0.05$ was considered significant. The mean of [fT4]CH and [fT4]MED values was $15.1 \mathrm{pmol} / \mathrm{L}( \pm 9.3$ standard deviation $[\mathrm{SD}]$, range 3.1-57.1) and $15.7 \mathrm{pmol} / \mathrm{L}( \pm 14.3 \mathrm{SD}$, range $0.0-61.0)$, respectively. The regression analysis showed a coefficient of determination of $0.73(\mathrm{P}<$ $0.001)$. The B-A analysis showed a mean difference of $+0.6 \mathrm{pmol} / \mathrm{L}$ $( \pm 7.9 \mathrm{SD})$ and limits of agreement (mean $\pm 1.96 \mathrm{SD})$ of +16.1 and 14.9. For values with an average [fT4]MED and [fT4]CH below $10 \mathrm{pmol} / \mathrm{L}$, the B-A analysis showed a mean difference of $-4.2 \mathrm{pmol} / \mathrm{L}( \pm 3.4 \mathrm{SD})$ and limits of agreement (mean $\pm 1.96 \mathrm{SD})$ of +2.6 and -10.9 . The findings of this study suggest that overall, the [fT4]CH assay tends to underestimate the [fT4]MED with a mean difference $(+0.6 \mathrm{pmol} / \mathrm{L})$ which is not clinically significant, but the limits of agreement could be clinically significant. However, for values with an average [fT4]MED and [fT4] CH below $10 \mathrm{pmol} / \mathrm{L}$ the [fT4]CH overestimates the [fT4]MED with a mean difference and limits of agreement that may influence the clinical decision in relation to the laboratory reference range of the [fT4] $\mathrm{CH}$. This behaviour of the [fT4]CH assay can be an important limitation in its use in the diagnosis of canine hypothyroidism.

\section{3- ESCG - JERGENS}

INTERPLAY OF COMMENSAL BACTERIA, HOST GENE EXPRESSION, AND CLINICAL DISEASE ACTIVITY IN THE PATHOGENESIS OF CANINE INFLAMMATORY BOWEL DISEASE. Albert Jergens ${ }^{1}$, Dan Nettleton ${ }^{1}$, Jan Suchodolski ${ }^{2}$, Scot Dowd? Joerg Steiner ${ }^{2} .{ }^{1}$ IowaState University, AMES, IOWA, United States of America, ${ }^{2}$ GI Laboratory, Texas A\&M University, COLLEGE STATION, TX, United States of America, ${ }^{3}$ Research and Testing Laboratory, LUBBOCK, TX, United States of America

Canine inflammatory bowel disease (IBD) is one form of chronic enteropathy thought to be caused by the interplay of genetic, immunologic, and enteric microbial factors. Although an important role for mucosal bacteria in the pathogenesis of IBD has been proposed, studies investigating the association between microbiota composition and host gene expression are lacking. Moreover, changes in microbiota composition alter mucosal gene expression which leads to intestinal inflammation and phenotype of disease in IBD dogs. In the present study, we examined the relationship between gene expression (determined by Affymetrix DNA microarrays) patterns, intestinal microbiota composition (determined by bacterial tag-encoded FLX $16 \mathrm{~S}$ rRNA gene pyrosequencing) and clinical disease severity (determined by CIBDAI score) in dogs with IBD.

Samples of intestinal mucosa were collected by endoscopy or surgery from healthy dogs $(\mathrm{n}=6)$ and dogs diagnosed with moderate $(\mathrm{n}=10$; CIBDAI $=6-8)$ or severe $(\mathrm{n}=8$; CIBDAI $>9)$ IBD. Five dogs with severe IBD had PLE. Total RNA was extracted and utilized for microarray analysis using the Affymetrix GeneChip ${ }^{\mathbb{R}}$ Canine Genome 2.0 Array. Seventeen marker genes (pilot data) were selected for comparison to disease severity and changes in microbial composition. Pyrosequencing for microbial diversity was performed on cDNA samples from each dog.

Comparison of mean gene expression levels showed that 11/17 genes involved in cell replication (GCG, RNASE1, CDCA3), innate 
immunity/inflammation (PPARG, CASP3, GMZB), cellular detoxification (ALDH1B1), iron/calcium transport (S100G, SLC40A), intestinal barrier function (CLDN8, MTIE), and extracellular matrix degradation (MMP1) were differentially expressed $(\mathrm{p}<0.05)$ between dog groups. Dogs having moderate IBD, PLE alone, or severe IBD with PLE had the greatest number $(p<0.05)$ of differentially expressed genes. There were only few differences in gene expression patterns between dogs having moderate versus severe IBD without PLE. Intestinal inflammation in IBD dogs was also accompanied by significant differences in composition of the intestinal microbiota. Specifically, the proportions of members of Bacteroidales and Clostridiales (i.e., genus Faecalibacterium, Ruminococcus, and Dorea within the Clostridium clusters IV and XIVa) were significantly reduced in the IBD $\operatorname{dogs}(\mathrm{p}<0.01)$. There were relatively few differences in microbiota composition between moderate versus severe IBD dogs; however severe IBD dogs with PLE did show differences $(\mathrm{p}<0.05)$ in some bacterial populations as compared to control dogs and IBD dogs without PLE.

In summary, we report differential gene expression patterns and altered microbial diversity in dogs with moderate and severe IBD. These changes were most significant in IBD dogs with PLE suggesting that the presence of PLE may be associated with a more severe disease phenotype.

0104- ESCG - SCHNYDER

DYSREGULATION OF TLR2 AND 4 IN DOGS WITH CHRONIC ENTEROPATHIES. Iwan Burgener ${ }^{1}$, Michaela Schnyder $^{2}$, Anna Oevermann ${ }^{1}$, Marcus Doherr ${ }^{1}$, Andreas Zurbriggen ${ }^{1}$, Iwan Burgener ${ }^{1}$. ${ }^{1}$ University of Bern, BERN, Switzerland, ${ }^{2}$ Department of Clinical Veterinary Medicine, University of Bern, BERN, Switzerland

Inflammatory Bowel Disease (IBD) is characterized by persistent or recurrent clinical signs of gastrointestinal disease associated with histologic evidence of inflammation. Genetic susceptibility, dysregulation of the immune response, breakdown of tolerance and environmental triggers are thought to be critical in the pathogenesis of IBD. Toll like receptors (TLR) recognize microbe associated molecular patterns and are supposed to play an important role in the regulation of inflammation in the gastrointestinal tract. TLR2 recognizes lipopeptides, peptidoglycan and lipoteichoid acid, whereas TLR4 detects lipopolysaccharide (LPS) from gram negative bacteria. The aim of this study was to determine the expression of TLR2 and 4 in dogs with IBD and food responsive diarrhea (FRD) in comparison to healthy control dogs (HCD).

Biopsies from duodenum and colon were taken from $20 \mathrm{HCD}$ and 40 dogs with chronic enteropathies (CE; 20 IBD, 20 FRD) before and after standard therapy. The formalin-fixed biopsies were incubated overnight with the primary antibody (purified polyclonal rabbit-anti-canine TLR4) or unpurified serum (for TLR2) followed by a secondary biotinylated mouse anti-rabbit IgG and amino-9ethyl-carbazole as chromogen. The staining was interpreted in the epithelium itself and in mucosal cells with a scoring system published elsewhere (Frolova 2008). Comparison between IBD, FRD and HCD were made with a Kruskal-Wallis one-way ANOVA with Bonferroni test. $\mathrm{P}<0.05$ was considered significant.

TLR2 + cells were downregulated in the duodenum and colon in FRD and IBD compared to HCD before and after therapy (all $p<$ $0.0001)$. TLR4 + cells were upregulated in duodenum in FRD and IBD before $(p=0.008)$ and in FRD after $(p=0.02)$ therapy compared to HCD. In the colon, TLR4+ cells were significantly upregulated in FRD and IBD before $(p=0.0009)$ and after $(p=$ 0.0002 ) therapy. In regard to the epithelium, the expression of TLR2 was higher in FRD before therapy $(\mathrm{p}=0.009)$ compared to HCD. No expression of TLR4 was seen in the epithelium.

In conclusion, TLR2 is surprisingly downregulated in invading cells in duodenum and colon in dogs with CE, but upregulated in the epithelium of FRD before therapy. TLR4 is upregulated in invading cells in duodenum and colon in FRD and IBD, but not expressed on the epithelium. Therefore, the invasion of TLR4 positive cells in IBD and FRD could be a key feature promoting the increased inflammation in chronic enteropathies. Furthermore, the blockage of TLR4 with antagonists like TOLLIP could potentially reduce the inflammation in dogs suffering of IBD.
0105- ESCG - BELSHAW

SERUM THYMIDINE KINASE ACTIVITY IN CANINE INFLAMMATORY BOWEL DISEASE AND GASTROINTESTINAL LYMPHOMA. Zoe Belshaw ${ }^{1}$, Clive Elwood ${ }^{2}$, Ed Hall ${ }^{3}$, Ian Battersby ${ }^{2}$, Karin Allenspach ${ }^{4}$, Jane Dobson ${ }^{5}$, Henrik Von Euler ${ }^{6}$, Gerry Polton ${ }^{7}$ Penny Watson ${ }^{5}{ }^{1}$ University of Nottingham, NR LOUGHBOROUGH, United Kingdom, ${ }^{2}$ Davies Veterinary Specialists, United Kingdom, ${ }^{3}$ University of Bristol, United Kingdom, ${ }^{4}$ Queen Mother Hospital, Royal Veterinary College, United Kingdom, ${ }^{5}$ Queen's Veterinary School Hospital, University of Cambridge, CAMBRIDGE, United Kingdom, ${ }^{6}$ Swedish University of Agricultural Sciences, Sweden, ${ }^{7}$ North Downs Referrals, United Kingdom

Differentiating canine inflammatory bowel disease (IBD) from gastrointestinal lymphoma (GI-LSA) is of huge prognostic significance, but remains a major diagnostic challenge. Haematology, biochemistry, imaging and endoscopic biopsy all fail to clearly distinguish between the diseases, and full thickness biopsies are not considered appropriate in a number of cases. Thymidine kinase (TK) is a cytoplasmic enzyme involved in the one step salvage pathway of pyrimidine synthesis. TK activity is generally downregulated in the G2 phase of the cell cycle and the enzyme should not be active in cells undergoing natural apoptosis. Any increase in serum activity of the enzyme therefore reflects an increase in cells dying in the replicative phase, releasing TK into the blood, which is likely to happen in neoplasia. Serum TK activity is now a widely used diagnostic and therapeutic monitoring test for multicentric lymphoma in the dog. However, its activity in GI-LSA and in inflammatory diseases such as canine IBD has not previously been assessed.

This study combines results of an initial pilot and subsequent prospective assessment of the validity of serum TK activity (s-TK) to distinguish canine IBD and GI-LSA. Dogs were eligible for inclusion if they had received investigations to include haematology, biochemistry, assays of serum trypsin like immunoreactivity, cobalamin, folate and ideally canine pancreatic lipase immunoreactivity to exclude pancreatitis, as well as faecal analysis, thoracic and abdominal imaging to rule out disseminated LSA. Dogs should not have received corticosteroids in the previous month which might have put LSA into remission. Diagnosis of IBD or GI-LSA was confirmed by fine needle aspirate, endoscopic or full thickness biopsy, and in some cases of IBD, by response to appropriate symptomatic therapy with adequate follow-up. s-TK was measured by radio-immune assay at the time of initial presentation to the referral centre. Fisher's exact test was used to assess whether there was a statistically significant difference in s-TK between the two groups at different cut-off values where $\mathrm{p}<0.05$.

Twenty eight dogs were recruited, aged 1-10 years, of which five were diagnosed with GI-LSA and twenty three IBD. There was no difference between the groups in any biochemical parameters. s-TK ranged 1-6.4 in the IBD group, and 1.4-17.5 in the GI-LSA group. Using a cut-off of 6.5 , there was a significant difference between groups $(p=0.0017)$, with a sensitivity of $100 \%$ and a specificity of $60 \%$. At this cut off therefore, any animal with a s-TK of $>6.5$ had GI-LSA but not all dogs with GI-LSA had an elevated TK. Whilst greater numbers are needed, this shows promise as a cheap, easy and useful test to aid this common diagnostic challenge.

\section{6- ESCG - GRUTZNER}

SEQUENCING OF THE INTRON REGION OF THE HAS 2 GENE IN COBALAMIN DEFICIENT CHINESE SHAR PEIS AND HEALTHY CONTROLS. Niels Grützner, Danielle J. Lopinski, Micah A. Bishop, Jan S. Suchodolski, Jörg M. Steiner. Gastrointestinal Laboratory, COLLEGE STATION, TX, United States of America

High prevalences of both cobalamin (vitamin B12) deficiency and cutaneous mucinosis have been reported in Chinese Shar Peis (Shar Peis). Previously, cobalamin deficiency in Shar Peis with increased serum methylmalonic acid concentrations (MMA) has been linked to a genomic region on canine chromosome 13 by two genome-wide scans. A significant cosegregation was shown for Shar Peis with an undetectable serum cobalamin and an increased serum MMA concentration and both allele 283 of microsatellite marker FH3619 and two canine single nucleotide polymorphism markers. Cutaneous mucinosis in Shar Peis has been suspected to be hereditary and has 
been linked with an increased hyaluronan synthase 2 (HAS 2) gene expression, a gene that is located in the same genomic region on canine chromosome 13. In one study, a deletion of two nucleotides was found in the intron following exon 2 of HAS 2 , in close proximity to the exon/intron boundary. Therefore, the objective of this study was to evaluate this intron region in dogs with cobalamin deficiency.

Serum samples were collected from 26 unrelated Shar Peis, and serum MMA (reference interval [RI]: $415-1,193 \mathrm{nmol} / \mathrm{L}$ ) and serum cobalamin concentrations (RI: $252-908 \mathrm{ng} / \mathrm{L}$ ) were measured. Genomic DNA was extracted from whole blood. A primer pair was chosen to amplify the subsequent intron region of exon 2 of HAS 2 (Forward: GGATGCTCAATGTTGACTGC; Reverse: TCAGCCAAAACAGACAAGAA), because the intron region following exon 2 showed a deletion of two nucleotides (cytosine and thymine) located at intron positions $87 \mathrm{bp}$ and $88 \mathrm{bp}$, respectively. The identity of the product was verified by direct sequencing. The sequencing results were compared between 12 cobalamin deficient Shar Peis (undetectable serum cobalamin and increased serum MMA concentrations, 5 dogs with the deletion) and 14 healthy control dogs (normal serum cobalamin and serum MMA concentrations, 3 dogs with the deletion). To test whether the occurrence of the deletion within the intron following exon 2 of HAS 2 is independent of the phenotypic expression and the occurrence of allele 283 of FH3619, a Fisher's exact test was used and the odds ratios (OR), and their $95 \%$ confidence intervals (CI) were calculated. Statistical significance was set at $\mathrm{p}<0.05$.

There was no significant association found between cobalamin deficient Shar Peis and the deletion of the two nucleotides $(p=0.40$; $\mathrm{OR}=1.8 ; 95 \% \mathrm{CI}, 0.6-5.5$ ) compared to control Shar Peis. However, the deletion associated with allele 283 of FH3619 in both groups of Shar Peis yielded an OR of 7.8 ( $\mathrm{p}=0.01 ; 95 \% \mathrm{CI}, 1.5-41.0)$.

The results of this study suggest that the deletion of the two nucleotides is significantly associated with allele 283 of FH3619 in the Chinese Shar Peis.

\section{7- ESCG - GRELLET}

PREVALENCE OF TRITRICHOMONAS FOETUS IN PUPPIES FROM FRENCH BREEDING KENNELS. Aurélien Grellet $^{1}$, Thierry Bickel ${ }^{1}$, Bruno Polack ${ }^{1}$, Cassandre Boogaerts ${ }^{1}$, Gregory Casseleux ${ }^{2}$, Vincent Biourge ${ }^{2}$, Dominique Grandjean ${ }^{1}$. ${ }^{1}$ Ecole Vétérinaire d'Alfort, MAISONS ALFORT, France, ${ }^{2}$ Royal Canin, AIMARGUES, France

In recent years Tritrichomonas foetus (TF) has been reported as a naturally occurring pathogen of the large intestine of domestic cats. Both natural and experimental infections in cats with TF have been associated with large bowel intestinal diarrhea. This protozoa has already been identified in young puppies with diarrhea [Gookin JL. J. Parasitol., 2005, 91, 4: 939]. However to our knowledge prevalence of TF in puppies has never been described. The objective of this survey was to estimate the prevalence of TF in puppies from French breeding kennels.

Fresh voided faecal specimens were prospectively obtained from 239 puppies of 25 different breeding kennels. For each puppy faecal quality was scored using a 5-point numerical scale. Detection of TF was done by culture using a commercially available system "In PouchTM TF test" (BioMed Diagnostics, Oregon USA). The pouches were incubated at room temperature. Cultured samples were evaluated by microscopic examination $(40-100 \times$ total magnification) 2 days after incubation for the presence of motile trophozoïtes. Negative cultures were maintained for 15 days, and reevaluated every 2 days. The occurrence of enteric parasites was examined individually in each fecal specimen. All the samples were examined individually for gastrointestinal nematode eggs, coccidial oocysts, other protozoal cysts, using Telemann technique and quantitative McMaster method. An enzyme-linked immunosorbent assay (ELISA; Prospect ${ }^{\circledR}$ Giardia, Oxoid) was used for the detection of Giardia species antigen.

A mean number of 10 puppies were sampled per kennel (range: 4 19). Prevalence of TF was $17.2 \%$ for puppies $(41 / 239)$ and $20 \%$ for the kennels $(5 / 25)$. Giardia sp, Isospora canis, Isospora ohioensis and Toxocara canis were isolated respectively in $42.7 \%(102 / 239)$, $32.6 \%(77 / 236), 10.8 \%(17 / 158)$ and $19 \%(45 / 237)$ of puppies. $31.8 \%$ of puppies $(76 / 239)$ had gastrointestinal troubles. Puppies infected by TF had significantly more digestive problems $(10.8 \%$ vs $30.6 \%$; $<<0,001)$. Co-infection with $\mathrm{TF}$ and Giardia was diagnosed in $13.8 \%$ of puppies $(33 / 239)$.
TF is difficult to distinguish from $\mathrm{P}$. hominis and Giardia spp, but the culture system used in this study did not support growth of this two protozoa. However, the types of trichomonads for which puppies are hosts and the specificity of the culture system with regard to detection of these other types of trichomonads are unknown. An identification of the culture system isolates are in course. The high prevalence of TF can be explained by the age and origin of dogs (puppies from kennels).

TF infected breeding kennels are common and contain a significantly larger number of puppies with diarrhea.

\section{8 - ESCG - UNTERER}

TREATMENT OF HAEMORRHAGIC GASTROENTERITIS IN DOGS WITH AMOXICILLIN/CLAVULANIC ACID - A CLINICAL TREATMENT STUDY. Stefan Unterer, Katrin Strohmeyer, Carola Sauter-Louis, Katrin Hartmann. LMU University of Munich, MUNICH, Germany

Haemorrhagic gastroenteritis (HGE) is a syndrome of unknown aetiology characterized by acute onset of bloody diarrhoea typically associated with severe haemoconcentration. In addition to intravenous fluid therapy, the administration of parenteral antibiotics is recommended routinely based on the hypothesis of a potential bacterial aetiology and the risk of mucosal translocation of intestinal flora. However, inappropriate usage of antibiotics may cause disruption of protective intestinal bacteria, postantibiotic salmonellosis, Clostridium difficile-associated diarrhea, and antibiotic resistance. Thus, the aim of this prospective, placebo-controlled blinded study was to evaluate whether treatment with amoxicillin/clavulanic acid improves the clinical course and outcome of HGE in dogs.

Sixty dogs that presented to the Clinic of Small Animal Medicine of the University of Munich with acute haemorrhagic diarrhoea $(<3$ days) were randomly assigned to either the treatment (amoxicillin clavulanic acid for 7 days) or placebo group. Patients pre-treated with antibiotics, potential signs of sepsis (rectal temperature $>39.5^{\circ} \mathrm{C}$, white blood cell count $<4$ or $>25 \times 10$ E9/1, banded neutrophils $>$ $1.5 \times 10 \mathrm{E} 9 / 1)$, or diagnosed with any disease associated with bloody diarrhoea (e. g., intoxication, endoparasites, parvovirosis, foreign bodies, pancreatitis) were excluded from the study. To evaluate treatment efficacy, the treatment and control group were compared in respect to severity of clinical signs, duration of hospitalisation, and mortality rate. Clinical course of disease was assessed daily by a blinded clinician using a specifically developed HGE activity index that included the parameters general condition, appetite, vomiting, frequency of defecation, consistency of faeces, and dehydration.

Of 60 dogs, 53 dogs completed the study. No significant difference between treatment groups was observed concerning severity of clinical signs based on the HGE index, either on any individual day or over the whole course of disease. In addition, no difference in duration of hospitalisation (mean duration: treatment group 3.3 days, placebo group 3.5 days), study drop-outs, or mortality rate could be detected. Side effects of antibiotic therapy were not observed.

The results of this study suggest that there is no benefit in treating HGE with amoxicillin/clavulanic acid in dogs without signs of sepsis. Since ruling out an enteric bacterial infection is challenging, and bacterial translocation is a potentially life-threatening complication in any patient, dogs with acute bloody diarrhoea of unknown cause still should be monitored very closely. The administration of amoxicillin/clavulanic acid was not associated with obvious side effects. However, the development of bacterial resistance following antibiotics treatment was not addressed in this study.

\section{9 - ESCG - MANDIGERS}

A RANDOMISED POSITIVE-CONTROLLED FIELD TRIAL OF A HYDROLYSED PROTEIN DIET IN DOGS WITH CHRONIC ENTEROPATHY. Paul J.J. Mandigers ${ }^{1}$, Vincent Biourge $^{2}$, Nienke Ankringa ${ }^{3}$, Ted S. van den Ingh ${ }^{4}$, Alexander J. German ${ }^{5} .{ }^{1}$ Department of Clinical Sciences of Companion Animals, Utrecht University, Netherlands, ${ }^{2}$ Royal Canin, Aimargues, France, ${ }^{3}$ Department of Veterinary Pathology, Utrecht University, Netherlands, ${ }^{4}$ TCCI Consultancy BV, Utrecht, The Netherlands, ${ }^{5}$ School of Veterinary Science, University of Liverpool, UK

Dietary management is important for treating canine chronic enteropathies, traditionally using single-source protein diets. 
Recently, hydrolysed protein diets have been developed for companion animals, but such diets have not yet been critically evaluated. The aim of this randomised, positive-controlled, study was to compare the efficacy of a hydrolysed protein diet with a highly digestible (control diet), both of which are commercially available.

Twenty-six dogs, referred for the investigation of gastrointestinal disease participated in the trial. After a thorough diagnostic investigation, which included gastroduodenoscopy, dogs were randomised either to receive the test (hydrolysed protein) or control (highly digestible) diet on a 2:1 basis (test:control). Diets were administered on an open-label basis, and cases were re-evaluated three times (at approximately 2 mo, 6-12 mo and 3 y). Outcome measures included response to clinical signs (complete, partial, none), change in severity of signs (based upon CIBDAI), and need for other therapy.

No significant differences were evident between groups, in terms of baseline characteristics (signalment, body weight, duration of signs), and also in histopathological severity. The majority of dogs had responded by first evaluation, with no difference between groups $(P=0.871)$. However, at both the second $(P=0.0012)$ and third $(\mathrm{P}<0.001)$ re-evaluations, significantly more of the test diet dogs had remained asymptomatic than those on the control diet. Further, the decrease in CIBDAI was significantly greater in dogs on the test diet.

In conclusion, the current study has shown that a hydrolysed diet can be highly effective for long-term management of chronic enteropathies in dogs.

\section{0- ESCG - LEE}

CAPSULE ENDOSCOPY OF DOGS FOR SMALL BOWEL DIAGNOSTIC IMAGING. Alice Lee, Dwight Bowman, Daniel Fletcher, Kenneth Simpson. Cornell University, ITHACA, NY, United States of America

Many advances have been made in human gastrointestinal (GI) endoscopy in recent years, including endoscopic ultrasound, single and double balloon enteroscopy, and capsule endoscopy. Veterinary endoscopy, in contrast, still relies on standard endoscopes that limit small bowel access, and require general anesthesia, which precludes examination of critically ill patients. Capsule endoscopy overcomes these problems with a wireless, ingestible camera. In people, this device has detected lesions such as ulcers, arteriovenous abnormalities, cancer, and parasites. In order to investigate the safety and utility of capsule endoscopy in dogs, a pilot study was undertaken.

Five clinically healthy dogs of varying age (mean: 1.5 years, range: 0.4 to 3 ), weight (mean: $27.1 \mathrm{~kg}$, range: $9.5-57.7$ ), breed (Great Dane, Labrador retriever, pitbull, hound cross, and beagle), and gender ( 3 male, 2 female) were recruited. After a 12-hour fast, 8 antennae were secured to the dog's chest and abdomen with stockinette and a jacket. A data recorder was fastened around the chest. An Elizabethan collar was placed on the dog to prevent bite damage, and the endoscopic capsule (Endo Capsule ${ }^{\circledR}$, Olympus) was administered orally. The dog was permitted its normal activities. Equipment was removed 5-8 hours after capsule ingestion, and images were reviewed. The capsule was recovered fecally.

Dogs tolerated the procedure well. The capsule captured images of the full length of small bowel as well as portions of esophagus, stomach, and colon. Findings included hair, small foreign bodies, erosions, sites of active bleeding, and luminal parasites. Mean gastric and small bowel transit times (TT) were 1.8 hours (range: 0.2 3.6) and 1.8 hours (range: $0.2-2.5$ ), respectively. The capsule passed in the stool within 24 hours of ingestion.

Capsule endoscopy was successfully performed in 5 awake dogs. The longest gastric TT ( $>3$ hours) occurred in the Great Dane and beagle, which may have been due to a prophylactic gastropexy in the Great Dane, and the relatively large size of the capsule compared to the stomach of the beagle. The shortest small bowel TT $(<40$ minutes) occurred in the beagle and the Labrador retriever, which were 5 and 11 months old, respectively. Puppies are known to have shorter GI TT compared to adults, so age alone may account for this observation. However, given the small study population, it is not possible to draw definite conclusions about the effects of age, size, gender, or breed on TT. Preliminary results show that capsule endoscopy allows identification of both benign and pathologic le- sions in dogs, and may be a promising new diagnostic option for evaluating GI disease.

\section{1- ESCG - RUHNKE}

EVALUATION OF AN ADAPTER-MODIFIED USING CHAMBER FOR ASSESSMENT OF ENDOSCOPICALLY OBTAINED COLONIC BIOPSIES FROM CATS AND DOGS. Isabelle Ruhnke ${ }^{1}$, John DeBiasio ${ }^{1}$, Jan Suchodolski ${ }^{1}$, Mark Musch $^{2}$, Jörg Steiner ${ }^{1}{ }^{1}$ Texas A\&M University, Gastrointestinal Laboratory, COLLEGE STATION, TX, United States of America, ${ }^{2}$ Depertment of Medicine, University of Chicago, IL, United States of America

Adapter-modified Ussing chambers allow assessment of endoscopically obtained intestinal biopsies and have facilitated the characterization of various intestinal diseases in humans. In cats and dogs, the feasibility evaluation of endoscopically collected colonic biopsies in an adapter-modified Ussing chamber has not been reported to date. The aim of this study was to investigate the absorptive and secretory capacity of endoscopically obtained colonic biopsies from dogs and cats in an adapter-modified Ussing chamber previously described for the assessment of duodenal biopsies.

16 colonic biopsies from 4 cats and 13 colonic biopsies from 4 dogs with various gastrointestinal diseases were obtained and transferred into an adapter-modified Ussing chamber. All samples were sequentially exposed to $40 \mathrm{mM}$ glucose, $500 \mu \mathrm{M}$ phloridizin, $200 \mu \mathrm{M}$ histamine, $200 \mu \mathrm{M}$ serotonin, $4 \mu \mathrm{M}$ prostaglandin E2 (PGE), $10 \mu \mathrm{M}$ forskolin, $40 \mathrm{mM}$ glucose, and $600 \mu \mathrm{M}$ quabain. Conductance $[\mathrm{mS}$ $\mathrm{cm} 2$ ] and the amplitude of the resulting short circuit current (?Isc) $\left[\mu \mathrm{A} / \mathrm{cm}^{2}\right]$ were calculated.

Mean \pm SD conductance of the feline colonic samples at the beginning and at the end of experiments was $101.6+57.36 \mathrm{mS} / \mathrm{cm} 2$ and $186.7 \pm 153.50 \mathrm{mS} / \mathrm{cm} 2$, respectively (p-value: 0.0006 ). Mean \pm SD conductance of canine colonic samples was $62.66 \pm 35.92 \mathrm{mS}$ $\mathrm{cm} 2$ at the beginning of the experiment and $87.21 \pm 37.98 \mathrm{mS} / \mathrm{cm} 2$ at the end of the experiment (p-value: 0.0010$)$. Feline biopsies did not respond to glucose or phloridizin. A total of $31 \%$ of the feline samples responded to histamine (median? Isc: $10 \mu \mathrm{A} / \mathrm{cm}^{2}$, range: 6 $\left.20 \mu \mathrm{A} / \mathrm{cm}^{2}\right), 44 \%$ to serotonin $\left(10 \mu \mathrm{A} / \mathrm{cm}^{2} ; 6-20 \mu \mathrm{A} / \mathrm{cm}^{2}\right), 31 \%$ to PGE $\left(16 \mu \mathrm{A} / \mathrm{cm}^{2} ; 12-40 \mu \mathrm{A} / \mathrm{cm}^{2}\right), 44 \%$ to forskolin $\left(20 \mu \mathrm{A} / \mathrm{cm}^{2} ; 6\right.$ $\left.110 \mu \mathrm{A} / \mathrm{cm}^{2}\right)$, and $60 \%$ to quabain $\left(28 \mu \mathrm{A} / \mathrm{cm}^{2} ; 12-128 \mu \mathrm{A} / \mathrm{cm}^{2}\right)$. A total of $31 \%$ of canine colonic samples responded to glucose $(25 \mu \mathrm{A}$ $\left.\mathrm{cm}^{2} ; 14-88 \mu \mathrm{A} / \mathrm{cm}^{2}\right), 54 \%$ to phloridizin $\left(30 \mu \mathrm{A} / \mathrm{cm}^{2} ; 28-74 \mu \mathrm{A}\right.$ $\left.\mathrm{cm}^{2}\right), 92 \%$ to histamine $\left(45 \mu \mathrm{A} / \mathrm{cm}^{2} ; 8-364 \mu \mathrm{A} / \mathrm{cm}^{2}\right), 92 \%$ to serotonin $\left(44 \mu \mathrm{A} / \mathrm{cm}^{2} ; 6-60 \mu \mathrm{A} / \mathrm{cm}^{2}\right), 54 \%$ to PGE, $54 \%$ to forskolin $\left(46 \mu \mathrm{A} / \mathrm{cm}^{2} ; 20-196 \mu \mathrm{A} / \mathrm{cm}^{2}\right), 0 \%$ to repeated glucose, and $78 \%$ to quabain $\left(56 \mu \mathrm{A} / \mathrm{cm}^{2} ; 8-344 \mu \mathrm{A} / \mathrm{cm}^{2}\right)$.

The adapter-modified Ussing chamber enables investigation of absorptive and secretory capacity of endoscopically obtained colonic biopsies from cats and dogs. Multiple biopsies from each patient have to be evaluated as not all biopsy samples respond to stimulation with all agents. Large study populations of healthy animals and animals with clearly defined gastrointestinal disorders will be needed to further evaluate this method.

\section{2- ESVCN - HAHN}

EFFECTIVENESS OF BCS FOR ESTIMATION OF IDEAL BODY WEIGHT AND ENERGY REQUIREMENTS IN OVERWEIGHT AND OBESE CATS COMPARED TO DXA. A.L. Lusby $^{1}$, C.A. Kirk ${ }^{1}$, P.W. Toll ${ }^{2}$, I. Paetau-Robinson ${ }^{2}$, G.A. Henry', K.A. Hahn ${ }^{2}{ }^{1}{ }^{1}$ University of Tennessee, College of Veterinary Medicine, KNOXVILLE, TN, United States of America, ${ }^{2}$ Hills Pet Nutrition, TOPEKA, KS, United States of America

With an estimated $35-40 \%$ of pet cats being overweight or obese, veterinarians must accurately assess energy needs to prescribe appropriate food doses. Body condition scoring (BCS) is the most popular and accessible method for estimating degrees of obesity in cats, but these scales were designed to assess animals with body fat percentages below about $45 \%$. Many obese cats have body fat percentages of $50 \%$ and greater. This project compared the accuracy of using body fat percentages to the 5 and 9 point BCS systems for estimating ideal body weight and resting energy requirements 
(RER) in overweight cats. Thirty-six healthy, client-owned cats ranging from 3.1 to $11.5 \mathrm{~kg}$ underwent dual energy $\mathrm{x}$-ray absorptiometry (DXA) scanning to assess their percentage of body fat $(\mathrm{BF}) . \mathrm{BF}$ percentage was then used to estimate ideal body weight, calculate RER, and classify each animal into the 5 and 9 point BCS system. Once a BCS was assigned, the median body fat percentage for each score was used to estimate ideal body weight and RER ( 5 point scale $-4=30 \%, 5=40 \%$; 9 point scale $-6=$ $30 \%, 7=35 \%, 8=40 \%, 9=45 \%$ ). Based on DXA, body fat ranged from $25.5 \%$ to $62.0 \%$ with a mean of $45.3 \%$. To assess the accuracy of BCS for moderately versus morbidly obese cats, patients were divided into two groups: $<45 \%$ body fat $(n=17)$ and $>$ $45 \%$ body fat $(n=19)$. Compared to DXA, estimations of ideal body weight were significantly higher using the $5(5.6 \mathrm{vs} .4 .2 \mathrm{~kg})$ and 9 (5.1 vs. $4.2 \mathrm{~kg})$ point $\mathrm{BCS}$ in cats with $\mathrm{BF}>45 \%(\mathrm{p}<0.01)$ but did not differ in cats with $<45 \% \mathrm{BF}(\mathrm{p}>0.05)$. DXA estimations of RER were also significantly lower than estimations using the 5 (205.2 vs. $253.2 \mathrm{Kcal} /$ day) and $9(205.2$ vs. $237.3 \mathrm{Kcal} /$ day $)$ point scales in cats with $\mathrm{BF}>45 \%(\mathrm{p}<0.01)$, but did not differ in cats with $<45 \% \mathrm{BF}(\mathrm{p}>0.05)$. The results of this study demonstrate current BCS systems provide good estimates of ideal body weight and RER in cats with less than $45 \% \mathrm{BF}$, but are inadequate for calculating RER and ideal body weight in morbidly obese cats (BF > $45 \%)$. As a result, food dose calculations will be overestimated and this may affect weight loss efficacy. As feline obesity rates climb, we must develop new methods to assess our most obese patients and provide better weight management.

\section{3- ESVCN - LERAY}

EFFECT OF DIRLOTAPIDE ON FOOD INTAKE AND PLASMA SATIETY FACTORS IN OBESE DOGS. V. Leray ${ }^{1}$, K Savary-Bataille $^{2}$, S. Serisier ${ }^{1}$, J. Gossellin ${ }^{2}$, P. Nguyen ${ }^{1} .{ }^{1}$ ONIRIS (National Veterinary School Nantes), NANTES, France. ${ }^{2}$ Pfizer Animal Health, 23-25, avenue du Dr Lannelongue F-75668 PARIS Cedex 14

Obesity results from positive energy balance. Food intake is regulated by several peripheral factors and any tool able to reduce it could be useful. Dirlotapide (Slentrol ${ }^{\mathbb{R}}$ ), an inhibitor of the intestinal microsomal triglyceride transfer protein (MTP), has been shown to induce weight loss through food intake reduction and slightly decreased fat absorption.

Our aim was to examine the effects of dirlotapide on food intake, plasma satiety factors levels and the gene expression of adipose-derived satiety factors in obese dogs.

Thirteen obese adult beagle dogs ( 2.8 years, initial body weight (BW): $12.8 \pm 0.6 \mathrm{~kg}$ (mean \pm SEM)) were randomly allocated to a placebo control $(n=5)$ or a dirlotapide $(n=8)$ group. They received amounts of food to maintain their obese BW. Dirlotapide or placebo were administered once daily for 21 weeks according to the Slentrol ${ }^{\mathbb{R}}$ recommended dosing regimen, to maintain a BW loss of $\geq 0.7 \%$ per week. Food intake was recorded daily and BW weekly. Before and after treatment, body condition score (BCS) was evaluated (Laflamme, 1997), and plasma as well as visceral and subcutaneous adipose tissue (VAT and SCAT) samples were taken. Plasma leptin was assayed by ELISA whilst total ghrelin, PYY, active GLP1 were assayed by RIA. Adiponectin mRNA level was assessed by real time PCR. All results are expressed as mean \pm SEM.

During treatment, food intake increased by $4 \pm 3 \%$ in control dogs and decreased by $9 \pm 4 \%$ in dirlotapide-treated dogs. In this group, food intake was $19 \pm 2 \%$ lower in 4 dogs, while almost unchanged in the others. At the end of treatment, neither BW $(-2 \pm$ $2 \%$ ) nor BCS had changed in control dogs whereas they had significantly decreased $(\mathrm{p}<0.001)$ in dirlotapide-treated dogs (BW change of $-22 \pm 2 \%$ and BCS decrease from $6.9 \pm 0.3$ to $4.4 \pm$ 0.3 ). At the end of treatment compared to pre-treatment values, no change in plasma satiety factor levels was seen in placebo dogs, whereas dirlotapide-treated dogs had lower plasma leptin $(1.15 \pm$ $0.43 \mathrm{ng} / \mathrm{mL}$ vs $3.65 \pm 0.82 \mathrm{ng} / \mathrm{mL}, \mathrm{p}<0.005)$ and total ghrelin (934 $\pm 63 \mathrm{ng} / \mathrm{mL}$ vs $1260 \pm 115 \mathrm{pg} / \mathrm{mL}, \mathrm{p}<0.05)$ levels and higher plasma PYY $(547 \pm 47 \mathrm{ng} / \mathrm{mL}$ vs $397 \pm 51 \mathrm{pg} / \mathrm{mL}, \mathrm{p}<0.01)$ and active GLP1 $(198 \pm 9 \mathrm{mmol} / \mathrm{L}$ vs $172 \pm 9 \mathrm{mmol} / \mathrm{L}, \mathrm{p}<0.05)$ levels. In VAT, adiponectin mRNA level remained unchanged in placebotreated dogs whereas it was increased in dirlotapide-treated dogs
$(218 \pm 36 \%$ vs $100 \pm 33 \%, p<0.05)$. In SCAT, no change in adiponectin mRNA level was observed, whatever the treatment.

The prolonged dirlotapide treatment resulted in a BW and BCS decrease in dogs, with a parallel decrease in plasma leptin levels. This could be explained by a decrease in food intake, resulting from a higher satiety that would be linked with the increase in plasma PYY and GLP1 levels, the increase in adiponectin expression and the decrease in plasma total ghrelin levels.

\section{4- ESVCN - GERMAN}

QUALITY OF LIFE IS REDUCED IN OBESE DOGS, BUT IMPROVES AFTER SUCCESSFUL WEIGHT LOSS. Alex German $^{1}$, Shelley Holden ${ }^{1}$, Lesley Wiseman-Orr ${ }^{2}$, Jacqueline Reid $^{2}$, Andrea Nolan ${ }^{2}$, Vincent Biourge ${ }^{3}$, Penelope Morris ${ }^{4}$, Marian Scott ${ }^{2}$. ${ }^{1}$ University of Liverpool, NESTON, United Kingdom, ${ }^{2}$ Pain and Welfare Group, University of Glasgow, GLASGOW, United Kingdom, ${ }^{3}$ Royal Canin Research Center, AIMARGUES, France, ${ }^{4}$ WALTHAM Centre for Pet Nutrition, WALTHAM-ON-THE-WOLDS, United Kingdom

Obesity is now recognised to be an important major medical disease, which can lead to a number of associated medical disorders and can reduce life expectancy. Whilst the condition is likely to have an effect of quality of life, limited objective data exist to support this supposition. Therefore, the aim of the current study was to use a standardised and validated questionnaire to determine health related quality of life, both before and after weight loss, in clientowned dogs with naturally-occurring obesity.

Thirty dogs were included in the study, and represented a variety of breeds and genders. Median (range) age at enrolment was 84 mo $(18-163 \mathrm{mo})$, body weight was $24.9 \mathrm{~kg}(5.2-77.0 \mathrm{~kg})$, and body fat (determined by dual-energy X-ray absorptiometry) was 43\% (27$53 \%)$. At the time of initial enrolment, owners were asked to complete a validated standardised questionnaire to determine quality of life (Wiseman-Orr et al, Am J Vet Res 65, 1077; Wiseman-Orr et al, Am J Vet Res 67, 1826). Owners then completed a follow-up questionnaire after their dog had successfully completed a weight loss programme, and had reached their target weight. The completed questionnaire responses were transformed to scores corresponding to each of four factors (vitality, emotional wellbeing, anxiety and pain), and scored on a scale of 0 to 6 . The scores were then correlated with responses to direct questions about quality of life (QOL) and pain

Initial QOL scores were lower than the control range (established from median questionnaire scores from a healthy population of dogs) for vitality, and higher than the control group for pain score (implying greater pain). Median (range) percentage weight loss was $25 \%(10-44 \%)$, the rate of weight loss was $0.83 \% /$ wk $(0.31-1.39 \%$ wk), and body fat percentage lost was 34\% (13-74\%). Most owners reported that their dog's QOL had improved, and this corresponded to significant improvements in vitality and emotional well-being, and a significant decrease in pain score.

Our results suggest that there is demonstrable improvement in QOL for obese dogs who successfully complete a weight loss programme.

\section{5- ESVCN - JEWELL}

EFFECTS OF ADDED DIETARY ANTIOXIDANTS AND FATTY ACIDS ON CHANGES IN NEUTROPHIL BACTERIAL KILLING PERCENT AND NEUTROPHIL-RELATED GENE EXPRESSION IN DOGS. Dennis Jewell ${ }^{1}$, Kevin Hahn ${ }^{1}$, Lynda Melendez ${ }^{1}$, Rachel Chinn ${ }^{2}$, William Voracheck ${ }^{2}$, M. Gorman ${ }^{2}$, Joe Greitl $^{1}$, Dinesh Joshi ${ }^{1}$, Jean Hall ${ }^{2}$. ${ }^{1}$ Hill's Pet Nutrition, TOPEKA KS, United States of America, ${ }^{2}$ Oregon State University, CORVALLIS, OR, United States of America

Dietary fish oil and antioxidants have been used to modulate immune function in many mammalian species. Previously, it has been shown that feeding high levels of EPA and DHA reduces the delayed-type hypersensitivity skin response in beagles without changing antibody production in response to a novel protein 
immunization. High levels of vitamins $\mathrm{E}$ and $\mathrm{C}$ have also been shown to influence immune responses. This study further investigated the effects of vitamins $\mathrm{E}$ and $\mathrm{C}$, and dietary fish oil on the immune system of dogs.

This study used 50 beagle dogs randomized into 5 dietary groups for 60 days. The study protocol was reviewed and approved by the Institutional Animal Care and Use Committee, Hill's Pet Nutrition, Inc. All foods were complete and balanced and met the nutrient profiles of AAFCO for adult dogs. For 60 days before study initiation, dogs consumed a pretrial food that contained $74 \mathrm{IU} / \mathrm{kg}$ vitamin $\mathrm{E}$ and $0 \mathrm{mg} / \mathrm{kg}$ vitamin $\mathrm{C}$. The 5 test foods were confirmed by analytical methods to contain $>640 \mathrm{IU} / \mathrm{kg}$ vitamin $\mathrm{E}$ and $130 \mathrm{mg} / \mathrm{kg}$ vitamin C (as fed). Foods ranged from low levels of EPA and DHA (pretrial food and lowest test food had 0.01\% EPA and no detectable DHA) to the highest enhanced food of $0.25 \%$ EPA and $0.17 \%$ DHA. Ex vivo bacterial killing of Lactococcus lactis by activated peripheral blood neutrophils was determined after 1 hour incubation. Percent killing was calculated as the percentage of colony forming units plated from neutrophil wells compared to nonneutrophil control wells. Gene expression markers involved in neutrophil killing, migration, adherence or activation were measured and mRNA abundance expressed relative to mRNA of $\beta$-actin (RT$\mathrm{PCR}, \Delta \mathrm{Ct}$ )

Dogs in all treatment groups had increased serum vitamin E concentration $(\mathrm{P}<0.01)$. Neutrophils from dogs in all 5 treatment groups also had increased bacterial killing percent, which was significantly related to gene expression of interleukin-8 receptor, interleukin converting enzyme, and myleoperoxidase $(\mathrm{P}<0.01 \mathrm{r} 2$ $=0.33$ ). Dietary fish oil however, had no effect on neutrophil bacterial killing percent. In summary, there was a significant effect of diets enriched in vitamins $\mathrm{E}$ and $\mathrm{C}$ on increased bacterial killing by circulating neutrophils, and on neutrophil-related gene expression.

0116- ESVCN - JEWELL

PROTEIN CONCENTRATIONS CONSISTENT WITH CONTROLLED PROTEIN RENAL FOODS MAINTAIN LEAN BODY MASS AND HEALTH INDICES IN SENIOR DOGS. Dennis Jewell, Kevin Hahn, Lynda Melendez. Hill's Pet Nutrition, TOPEKA, KS, United States of America

Two studies were used to evaluate the effect of dietary protein varying from $14.8 \%$ to over $30 \%$ dry matter (DM) protein on the senior dog's indices of health and ability to maintain lean body mass (LBM). All dogs were exercised daily, and were provided with regular opportunities for socialization and environmental enrichment. Dog enrichment included toys in their enclosures, paired housing for a portion of each day, and trips to an indoor and/or outdoor group socialization area. The study protocol was reviewed and approved by the Institutional Animal Care and Use Committee, Hill's Pet Nutrition, Inc., Topeka, KS, USA. In the first study, 70 beagle dogs (average age 13.8 years) were fed one of five different foods with protein concentrations, with or without added amino acids, varying from 15.4 to $30.7 \%$ dry matter (DM) protein. In all treatments, over the six month period there was a numeric increase in lean body mass and no change in body fat or bone. There was no linear or quadratic effect of protein or amino acid supplementation on lean body mass. Blood urea nitrogen (BUN) increased linearly with dietary protein concentration. Normal blood albumin, hematocrit, and hemoglobin were maintained as were percentages of lymphocytes, monocytes and neutrophils. There was a quadratic effect of protein concentration $(\mathrm{P}<0.05)$ on change in glomerular filtration rate (GFR) in 6 months with the lowest and highest protein concentration causing an increase in GFR. In the second study a food designed for nutritional support of dogs with renal disease (Prescription Diet ${ }^{\mathbb{R}} \mathrm{k} / \mathrm{d}^{\mathbb{R}}$ ) with $14.8 \%$ (DM) protein was fed for six months to 15 healthy adult dogs (average age 13.0 years). This resulted in an increase in LBM $(\mathrm{P}<0.05)$, a decrease $(\mathrm{P}<0.05)$ in circulating creatinine and BUN, with no change in albumin, hematocrit, or hemoglobin. There was also no change in lymphocyte, monocyte or neutrophil percentages. In conclusion, these data show that controlling dietary protein concentration to levels $(15 \% \mathrm{DM})$ used in foods designed to aid in the management of renal disease is sufficient to meet the protein requirements of the senior dog while maintaining standard indicators of health.
0117 - 150 - ESVCN - HOUSTON

EFFICACY OF A DIET DESIGNED WITH A RELATIVE SUPER SATURATION $<1$ TO DISSOLVE STRUVITE STONES IN THE FELINE BLADDER. Doreen Houston ${ }^{1}$, Heather Weese $^{1}$, Michelle Evason ${ }^{1}$, Ingrid Van Hoek $^{2}$. 'Royal Canin Canada, GUELPH, Canada, ${ }^{2}$ Royal Canin Research Center, AIMARGUES, France

Previous studies have shown the efficacy of canned and dry magnesium-restricted, urine acidifying diets in dissolving struvite stones in cats; the mean times to dissolution in these studies were 26-36 days (canned food) and 34 days (dry food), respectively. Studies have shown that urine supersaturation is primarily responsible for the formation and dissolution of crystals within the urinary tract. A previous study showed the efficacy of a dry diet formulated to generate a urinary struvite relative supersaturation (RSS) $<1$ (Royal Canin Urinary $\mathrm{S} / \mathrm{O}$ ), in dissolving feline struvite uroliths in vitro. The present study was undertaken to determine if a diet with efficacy for dissolving struvite stone in vitro also had efficacy of dissolving struvite stones in vivo

Thirteen privately owned cats suspected of struvite urolithiasis based on radiographs taken by local practitioners were initially included. Cats were kept in their home environment and owners were instructed to feed Urinary S/O either wet (6 cases) or dry ( 7 cases) as the exclusive diet for the duration of the study. Investigational parameters at inclusion included a complete blood count, serum biochemistry, urinalysis, urine culture, and abdominal radiographs. Radiographs and urinalysis were repeated on a weekly basis and evaluated by two board certified internal medicine specialists to mark time of stone dissolution.

Eleven spayed female and 2 neutered male cats with a mean age of $7.50+3.44$ years and mean weight of $6.2+2.02 \mathrm{~kg}$ were included Struvite stones dissolved in a median of 19.5 days (range 14-56 days; mean time of $28.33+18.47$ days) and of 18 days (range 10-39 days; mean time of $20.14+10.12$ days) in cats fed wet or dry food respectively.

Our preliminary results suggest that a diet designed to create urine undersaturated for struvite (RSS $<1$ ) is effective both in vivo and in vitro in dissolution of struvite bladder stones. These results suggest that in vitro studies might be sufficient to predict dissolution times in vivo.

\section{B - KLOSTERMAN ACVIM AWARD WINNER} A CASE-CONTROL STUDY OF NEPHROTIC SYNDROME IN DOGS: 78 CASES. ES Klosterman ${ }^{1}$, GE Moore ${ }^{1}$, JF de Brito Galvao $^{2}$, SP DiBartola ${ }^{2}$, RP Groman ${ }^{3}$, JC Whittemore ${ }^{4}$, SL Vaden $^{5}$, TL Harris 5 , JK Byron ${ }^{6}$, S Dowling ${ }^{6}$, DC Grant ${ }^{7}$, GF Grauer ${ }^{8}$, BM Pressler ${ }^{1} .{ }^{1}$ Purdue Univ, W. Lafayette, IN, ${ }^{2}$ OSU, Columbus, OH, ${ }^{3}$ UPenn, Philadelphia, PA, ${ }^{4}$ UTenn, Knoxville TN, ${ }^{5} \mathrm{NCSU}$, Raleigh, NC, ${ }^{6} \mathrm{U}$ of Ill, Urbana, IL, ${ }^{7} \mathrm{VMRCVM}$, Blacksburg, MD, ${ }^{8} \mathrm{KSU}$, Manhattan, KS.

Nephrotic syndrome (NS), an uncommon complication of glomerular disease, is defined as the concurrent presence of proteinuria, hypoalbuminemia, hyperlipidemia (i.e. hypercholesterolemia), and ascites or other third space fluid accumulation. Although NS is well-recognized in dogs, published information is limited to occasional mention of affected animals in larger case series of glomerular disease and sporadic case reports. The purpose of this study was to describe a larger population of dogs with NS, and determine whether or not the diagnosis of NS is associated with select signalment, clinicopathologic, or histologic findings in patients with glomerular disease.

Medical record databases were searched at 8 participating institutions using the term 'nephrotic syndrome.' Records were reviewed by participating nephrologists, with inclusion requiring the concurrent presence of all four criteria. Two non-NS dogs with glomerular disease were selected as controls for each NS dog, using the search terms 'protein-losing nephropathy,' 'glomerular disease,' and 'glomerulopathy'. Signalment, time until death, albumin, cholesterol, creatinine, BUN, sodium, UPC, and histopathologic diagnosis were recorded for each patient, and NS and control populations were compared using chi-squared or two-sample t-tests as appropriate.

78 dogs with NS and 156 control dogs were included in this interim analysis. Neither sex nor neuter status were associated with 
NS $(p=0.748)$. Mixed breed dogs and 11 pure breed varieties had $>5$ animals within the 234 total dogs; however no breeds were overrepresented in either group. Mean serum albumin in NS dogs was significantly lower than in control dogs $(1.7$ [95\% CI 1.6-1.8] vs. 2.7 [95\% CI $2.5-2.8] \mathrm{mg} / \mathrm{dL}, \mathrm{p}<0.001)$; mean cholesterol $(373[95 \% \mathrm{CI}$ $357-390]$ vs. 313 [95\% CI 289-338] mg/dL $)$ and UPC $(15.4[95 \% \mathrm{CI}$ $13.3-17.5]$ vs. 8.2 [95\% CI 7.1-9.2]) in NS dogs were significantly greater than in control dogs $(\mathrm{p} \leq 0.001)$. There were no significant differences in sodium, creatinine, or BUN between the two groups $(\mathrm{p}=0.311,0.854$, and 0.919 , respectively). Of the $38 \mathrm{NS}$ dogs where a histopathologic diagnosis was available, the most frequently identified diseases were membranous glomerulopathy $(\mathrm{n}=10)$, amyloidosis $(\mathrm{n}=8)$, and membranoproliferative glomerulonephritis $(\mathrm{n}=8)$; however, no subtype was over-represented in NS dogs as compared to control dogs $(\mathrm{p}=0.344)$. There was no difference in mean survival between groups (NS: $68 \mathrm{~d}$ [95\% CI 18-117 d] vs. controls: $74 \mathrm{~d}$ [95\% CI 35-113 d].

These preliminary results suggest that neither signalment nor histopathologic diagnosis affect the likelihood of dogs with glomerular disease being diagnosed with NS, and that NS is not a prognostic indicator for presence of azotemia or survival time in dogs. These findings are in contrast to people with NS, where specific diseases are more likely to result in NS, and NS may be a negative prognostic indicator. 